University of Louisville

ThinkIR: The University of Louisville's Institutional Repository

Electronic Theses and Dissertations

$12-2018$

\title{
"Why am I in school?": a mixed methods investigation into stopping out of college.
}

Kathryn Gardner Adamchik

University of Louisville

Follow this and additional works at: https://ir.library.louisville.edu/etd

Part of the Higher Education Commons

\section{Recommended Citation}

Adamchik, Kathryn Gardner, "'Why am I in school?": a mixed methods investigation into stopping out of college." (2018). Electronic Theses and Dissertations. Paper 3095.

https://doi.org/10.18297/etd/3095

This Doctoral Dissertation is brought to you for free and open access by ThinkIR: The University of Louisville's Institutional Repository. It has been accepted for inclusion in Electronic Theses and Dissertations by an authorized administrator of ThinkIR: The University of Louisville's Institutional Repository. This title appears here courtesy of the author, who has retained all other copyrights. For more information, please contact thinkir@louisville.edu. 
"WHY AM I IN SCHOOL?":

A MIXED METHODS INVESTIGATION INTO STOPPING OUT OF COLLEGE

\author{
By \\ Kathryn Gardner Adamchik \\ M.Ed., University of Louisville, 2008 \\ B.A., Earlham College, 2002

\begin{abstract}
A Dissertation
Submitted to the Faculty of the

College of arts and Sciences of the University of Louisville

in Partial Fulfillment of the Requirements

for the Degree of
\end{abstract}

Doctor of Philosophy

in Applied Sociology
Department of Sociology
University of Louisville
Louisville, KY

December 2018 
(C) Copyright 2018 by Kathryn Gardner Adamchik

All rights reserved. 

"WHY AM I IN SCHOOL?":

A MIXED METHODS INVESTIGATION INTO STOPPING OUT OF COLLEGE

\author{
By \\ Kathryn Gardner Adamchik \\ M.Ed., University of Louisville, 2008 \\ B.A., Earlham College, 2002 \\ A Dissertation Approved on
}

November 19, 2018

by the following Dissertation Committee:

Robert Carini, $\mathrm{PhD}$, Dissertation Committee Chair

Derrick Brooms, PhD, Committee Member

Karen Christopher, PhD, Committee Member

Melanie Gast, PhD, Committee Member

Amy Hirschy, PhD, Committee Member 


\section{DEDICATION}

This dissertation is dedicated to my family and my students. Firstly, I dedicate this to my parents, Ann and Ben Gardner, who have always encouraged my desire to question and seek understanding of what I see in the world and for not only always believing in me, but for helping me to believe in myself.

Secondly, I dedicate this to my life partner, William Adamchik, who supported me every step of the way while prioritizing the care and growth of our family and our relationship.

Thirdly, I dedicate this to my children, Ira and Ari, who inspire me every day to love with all my heart, work for justice, and appreciate life's moments.

Finally, I dedicate this to my students, all the students I have had the pleasure of working with over the years who let me into their worlds, shared their stories with me, and allowed me to support them on their paths. In particular, I dedicate this to my stopouts who inspired this research. 


\section{ACKNOWLEDGEMENTS}

I would like to thank my committee members for their support over the years and throughout this dissertation process. To my chair, Bob Carini, thank you for supporting my vision for this project, your meticulous editing, your belief in my quantitative abilities, and for sticking with me over the years! To Derrick and Karen, thank you for serving on my various committees, your qualitative and theoretical insights, and encouraging me throughout the program. To Melanie, thank you for eagerly jumping onboard as a committee member, offering your theoretical insights, sharing new resources with me, and the feedback you provided along the way. And to Amy, thank you for continuing to serve as a mentor for over 10 years, for encouraging me to pursue sociology, and for reminding me that my sociological perspective needs to be shared.

Thank you to my university community. Thank you to my supervisors and friends, Tomarra Adams, Danielle Dolan, and Joe Dablow, for supporting me, emotionally and pragmatically, as I attempted to balance all of my hats over the years. Thank you to my team, Daniel Darland, Emily Spoden, Eric Turner, Jessica Newton, Jessy Rosenberg, Marissa Williams, and Melissa Law-Penrose, who listened to my celebrations and tribulations along the way and who are not only colleagues, but friends. Thank you to Christy Metzger and Greg Vittitow for being my counselors at work whether it be about work, school, or life. Thank you to Dale Billingsley for your mentorship throughout the dissertation process. Thank you to my friends for standing by me throughout this experience including Megan Clifton, Michelle Henderson, and Josie Raymond.

Thank you to Melissa Davis for a lifelong, unconditional friendship that has helped me through numerous ups and downs including this process.

Thank you to Jill Bowdon for sharing your intelligence with me and for guiding me along the way.

Thank you to Courtney Hite for being my cheerleader and providing a place of refuge each summer for my family and me.

Thank you to Katie Partin for serving as my editor and enthusiastic encourager.

Thank you to my two PhD support groups! Thank you Robin Weiss and Brandon McReynolds for your unending support and friendship throughout this process. Thank you Heidi Williams and Jennifer Rudy for everything - for talking me down, for reminding me that I know what I'm doing, for making me laugh and listening to me cry, and for answering my many, many questions. 
To my family, thank you for all the support you have given me and sacrifices you have made throughout this process. Thank you to my parents, Ann and Ben Gardner, and inlaws, Dan and Julie Adamchik, for helping out with the boys, supporting Will with managing our lives, and for listening, supporting, and encouraging me along the way. Thank you to my sister, Maggie Elder, for accepting this inconvenience into our lives, being flexible with our planning, and for expressing your pride in my work. Thank you to Ira and Ari for sharing me with work and school.

To my William, thank you. Thank you for all the love and support. For the reassurance and companionship. For drying my tears. For making me laugh. For listening to my passionate tirades. For giving me time. For believing in me. For believing in us. For being a wonderful father. For our lifelong partnership. For making all of this possible. 


\begin{abstract}
“WHY AM I IN SCHOOL?”:

A MIXED METHODS INVESTIGATION INTO STOPPING OUT OF COLLEGE

Kathryn Gardner Adamchik

November 19, 2018

Higher education research often looks at student retention as a dichotomous

outcome, either students stay enrolled or not; however, students' enrollment pathways are more complicated than that as they frequently transfer, swirl between institutions, and stopout and return. This study was designed to explore students who stopout and return to the same institution within their six-year graduation window. More specifically, I sought to learn who stops out, why they stopout, what happens while out, why they come back, and what may be different upon their return. Four conceptual frameworks were applied to understand students' experiences with stopping out including Tinto's (1993) theory of college student departure, Arnett's (2004) theory of emerging adulthood, Baxter Magolda's (2001) theory of self-authorship, and Bourdieu's (1986) theory of social reproduction.
\end{abstract}

Participants of this study were students at a large, public research institution who initially enrolled in fall 2010 or 2011 . I employed a mixed methods investigation to explore the complexities of stopping out. I conducted 27 in-depth interviews and conducted a constant comparative method of analysis to explore students' motivations and decision-making regarding decisions of whether to and where to apply, initial 
enrollment, stopping out, and returning. Qualitative findings revealed that students enrolled in college out of obligation with little personal motivation and quickly struggled to engage academically as they faced the uncertainty with why they were in college. Few students identified utilizing support services, such as advising or meeting with faculty, during their initial enrollment. Students chose to leave the institution due to their uncertainty and lack of academic engagement. While they were not enrolled, students learned about themselves and found academic interests leading them to return to college for themselves instead of enrolling due to familial or societal expectations. Finally, upon returning, participants actively engaged with their academics and defined the value of their college education as more than simply a credential.

Institutional records were used to conduct quantitative secondary analyses on two full cohort populations. There were approximately 5000 students in the fall 2010 and fall 2011 cohorts combined, and the analyses covered their entire 6-year windows. Bivariate chi-square and ANOVA tests were utilized to understand the characteristics of the stopout population relative to the total population as well as the other enrollment pathways; binary logistic regression was used to identify factors that predicted stopping out; and multinomial logistic regression was used to investigate factors that predicted stopping out compared to other pathways (graduates, persisters, and nonpersisters). Results revealed that stopouts were a small (less than 4\%) portion of the student population and that academic performance as demonstrated by GPA and financial aid received were the most significant variables in predicting stopping out, as well as differentiating stopping out from other pathways. 
This study's findings revealed how students' developmental needs and challenges impacted their integration, including their utilization of resources and their enrollment, at the institution under study. Thus, the four conceptual frameworks integrated to explain the experiences of stopouts. As emerging adults, stopouts had not yet developed their self-authorship for their life's path and struggled with the instability of their present and future. In what was perceived as an unsupportive campus environment, their struggles were amplified by their lack of academic integration that resulted in an inability and/or unwillingness to work with faculty and staff to work through them. Taking time off of college allowed participants to develop their internal voice and return to college with a purpose and the confidence to integrate academically. Departing from previous retention research, this study uncovered the significant influence students' uncertainty played in their ability to integrate as the interviewees described leaving the institution to do the work of self-discovery. Several recommendations are made for institutions to apply a more developmental approach to uncertainty and integration by focusing on institutional culture, pedagogy, and student services. By acknowledging and implementing programs to address the developmental and integration needs of students, institutions may see their retention and graduation of both would-be stopouts and would-be dropouts improve. 


\section{TABLE OF CONTENTS}

DEDICATION

ACKNOWLEDGMENTS

ABSTRACT vi vi

LIST OF TABLES $\quad$ XV

LIST OF FIGURES I Xvii

CHAPTER I: INTRODUCTION 1

Rationale 2

$\begin{array}{lc}\text { Research Aims } & 6\end{array}$

$\begin{array}{lr}\text { Study Setting } & 8\end{array}$

Defining Stopouts 9

$\begin{array}{lr}\text { Dissertation Outline } & 10\end{array}$

CHAPTER II: CONCEPTUAL FRAMEWORKS AND LITERATURE 12

REVIEW

$\begin{array}{ll}\text { College Student Departure and Integration } & 13\end{array}$

$\begin{array}{ll}\text { Emerging Adulthood and Self-Authorship } & 15\end{array}$ 
Social Reproduction and Capital

Literature Review on College Choice, Integration, and Stopping Out

Conclusion

Qualitative Methods and Analyses 

Pathway Outcomes 
Summary of MLR Findings

$\begin{array}{ll}\text { Conclusion } & 142\end{array}$

CHAPTER VI: DISCUSSION AND CONCLUSION 145

$\begin{array}{ll}\text { Discussion } & 145\end{array}$

Comparison of Stopout Sample, Population, and Literature 149

Comparison of Stopout Population to Other Enrollment Pathways 152

Addressing Psychosocial Barriers and Development as well as 153

Isolation and Integration

Understanding Uncertainty and Obligation 153

Integrating Development into the Curriculum 156

Intentionally Designing Academic Advising 158

Improving Institutional Culture for Their Students $\quad 161$

Recommendations for Institutional Policy and Practice $\quad 164$

$\begin{array}{ll}\text { Contribution to the Literature } & 168\end{array}$

$\begin{array}{ll}\text { Future Research } & 172\end{array}$

$\begin{array}{ll}\text { Conclusion } & 175\end{array}$

$\begin{array}{ll}\text { REFERENCES } & 180\end{array}$

$\begin{array}{ll}\text { APPENDIX A } & 201\end{array}$

$\begin{array}{ll}\text { APPENDIX B } & 202\end{array}$ 


\section{LIST OF TABLES}

TABLE

PAGE

1. Description of Variables 38

2. Sex, Race, and First-Year Residential Status of In-Depth Interview Participants

3. Independent and Dependent Variables including Coding 108

4. Correlation Matrix for Covariates 110

5. Size of Stopout Population 111

6. Percentages Categorical Characteristics by Student Pathway 114

7. Means and Standard Deviations of Continuous Independent Variables 115 by Student Pathway

8. Percentages Categorical Characteristics by 4-Way Student Pathway 124

9. Means and Standard Deviations of Continuous Independent Variables 125 by 4-Way Student Pathway

10. Odds Ratios (and 95\% Confidence Intervals) for the Predictors on Stopping Out Any Time after the First Year

11. Relative Risk Ratios (and 95\% Confidence Intervals) for the Predictors on Graduating, Persisting, and Not Persisting versus Stopping Out Any Time after the First Year

12. Relative Risk Ratios (and 95\% Confidence Intervals) for the Predictors On Graduating, Persisting, and Not Persisting versus Stopping Out 
Any Time after the Second Year 


\section{LIST OF FIGURES}

FIGURES

PAGE

1. First Semester Students Stopout 112

2. Number of Semesters Students Stopout 112

3. Predicted Probabilities of Stopping Out After the First Year 128

4. Predicted Probabilities of Each Pathway by Sex 138

5. Predicted Probabilities of Each Pathway by Race 138

6. Predicted Probabilities of Each Pathway by STEM Major 139

7. Predicted Probabilities of Each Pathway by Cohort 139

8. Predicted Probabilities of Each Pathway by First Year Housing 140

9. Predicted Probabilities of Each Pathway by First Year GPA 140

10. Predicted Probabilities of Each Pathway by First Year Financial Aid 141

11. Predicted Probabilities of Each Pathway after the Second Year by Sex 207

12. Predicted Probabilities of Each Pathway after the Second Year by Cohort 208

13. Predicted Probabilities of Each Pathway after the Second Year by STEM Major 208

14. Predicted Probabilities of Each Pathway after the Second Year by 209

First Semester Housing

15. Predicted Probabilities of Each Pathway after the Second Year by 209 Second Year GPA 


\section{CHAPTER I: \\ INTRODUCTION}

In the $21^{\text {st }}$ century, many high school seniors expect to enroll in college full-time and graduate from that same institution four years later (Goyette, 2008; Rosenbaum, 2011). However, research suggests that these expectations do not uniformly translate to reality (Barefoot, 2004; Habley, Bloom, \& Robbins, 2012; Hossler, Dundar, \& Shapiro, 2013; Shapiro \& Dundar, 2016; Shapiro et al., 2014; Tinto, 2012). College students have diverse enrollment pathways, including transferring between institutions, part-time attendance, or stopping out and returning later. In this study, I examined "stopout" students who left a four-year university and returned to the same institution within six years of their initial enrollment. My goal was to understand the shared characteristics of students who stopout as well as their experiences and decision-making prior to, during, and after stopping out. When students return from stopping out, they likely do so with the goal of earning their degree and have the possibility of contributing positively to an institution's six-year graduation rate, a main accountability and success metric for fouryear colleges. Therefore, I set out to study the stopout subpopulation at one institution in order to explore who they are, why they stopped out, and what led to their return. I sought to gather and share the stories of their experiences as well as learn who these students were demographically and to uncover factors that predict stopping out. Through an examination of both institutionally-collected data and an analysis of stopout students' 
narratives, I hope to inform both researchers' understanding of this subpopulation as well as the design of institutional services geared toward student success. Since graduation is seen as both a student and an institutional goal, both students and institutions may benefit from the findings of this study.

\section{Rationale}

In the $21^{\text {st }}$ century, there have been dynamic changes to higher education in the United States including growth in college enrollments and college costs as well as diversification in the types of institutions, the race/ethnic backgrounds of students, as well as students' paths to degree. While higher education enrollment has taken a slight downturn since 2010, undergraduate enrollment overall has grown by $28 \%$ from 2000 to 2016, which is an increased rate from the previous two decades (Aud et al., 2011; McFarland et al., 2018). Since 2000, enrollment of Hispanic students made the most significant contribution to the enrollment growths by more than doubling, while Asian/Pacific Islander enrollment increased by 29\%, Black student enrollment increased by $56 \%$, and White student enrollment increased by $4 \%$ (McFarland et al., 2018). During the first decade of the $21^{\text {st }}$ century, all types of two- and four-year degree-granting institutions experienced growth (30\% increase at public institutions, $20 \%$ increase at private, nonprofit institutions, and over $300 \%$ increase at private, for-profit institutions); however, since 2010 they have seen enrollment declines with public institutions and private, nonprofit institutions seeing slight declines at $4 \%$ and $6 \%$ respectively whereas enrollment at private, for-profit institutions has declined 49\% (McFarland et al., 2018).

At the same time as enrollments have grown since the turn of the century, postsecondary education has become less affordable as college expenses continue to rise. The 
cost of college, including tuition, fees, room, and board at public 4-year institutions increased 33\% between 2004-2005 and 2014-2015 after adjustment for inflation (U.S. Department of Education, 2016b). As college costs were increasing, the country experienced the deep economic recession of 2007-2009, which occurred while the students under study in this research were in high school. During the recession, the unemployment rate doubled from $4.6 \%$ to $9.6 \%$ and home prices fell approximately $33 \%$ (Nothaft, Boesel, \& Khater, 2018; Rogers \& Winkler, 2013). With the increase in college expenses and the effects of the recession, more students relied on financial aid to assist them with paying for college. The percentage of first-time, full-time students receiving federal aid at 4-year public institutions has risen from $71 \%$ in $2000-2001$ to $83 \%$ in 2015 2016 with a slight increase in the percentage of students receiving loans (41\% in 20002001 to 47\% in 2015-2016) (McFarland et al., 2018; U.S. Department of Education, 2017).

While college student enrollment has grown during the $21^{\text {st }}$ century, the rate of college completion has not improved substantially (Hossler et al., 2013; Shapiro \& Dundar, 2016). Bachelor's degree completion data is collected within a six-year timeframe that begins with first-time, full-time undergraduate students who initially enroll in a fall semester. For the fall 2008 cohort, the six-year graduation rate of students for all institutional types was $59.6 \%$ compared to $55.4 \%$ for the fall 1996 cohort (U.S. Department of Education, 2016). Tinto (2012) estimated that more than two-thirds of four-year entrants will eventually complete their degree, though many will not in the sixyear timeframe tracked by state and national education departments. Additionally, an analysis of U.S. Census Bureau data revealed that one-fifth of the U.S. adult population 
has completed some college but has not earned a degree (Shapiro et al., 2014). In 1993, Tinto prophesized "the so-called standard path to college completion may soon be the exception rather than the rule" (p. 26) and that can be seen in studies of student pathways. Horn and Carroll (1998) found that almost 30\% of students enrolled at 2-year or 4-year public institutions take time off during just their first year, while O’Toole, Stratton, and Wetzel (2003) found that almost $30 \%$ of students take at least one term off within five years of their initial enrollment. In an examination of student pathways at four-year institutions, Goldrick-Rab (2006) found that $48 \%$ of students had interrupted enrollment with students from low and middle socioeconomic backgrounds being more likely to take breaks.

The social norm of college enrollment and of growing up during difficult economic times for many has been impacted by the college-for-all ideology with which the traditionally-aged college students in this study were raised. This ideology is popular in American society telling students that everyone should go to college as the means to a financially secure future (Rosenbaum, 2001). Research into student aspirations is consistent with this ideology as up to $89 \%$ of high school seniors plan to attend college (Goyette, 2008; Rosenbaum, 2011). Many economic measures, including employment and earnings data, are used as evidence to support the importance of college. For example, young adults aged 25 to 34 years old with at least a bachelor's degree had a full-time employment rate of $86 \%$ compared to $72 \%$ of those who earned a high school diploma or equivalent (McFarland et al, 2018). Additionally, the 2014 median income for those aged 25 to 34 with a bachelor's degree was $\$ 52,000$ in comparison to $\$ 30,000$ for those with a high school diploma or equivalent (Kena et al., 2016). 
The college-for-all ideology, the projected increases in college enrollment over the next decade, and the rising costs of college have resulted in institutional accountability being on the minds of legislatures, employers, families, and students (Hussar \& Bailey, 2018). In addition to the six-year graduation rate, the other main accountability metric used in determining institutional success is first- to second-year retention of first-time, full-time degree-seeking students with initial enrollment in the fall term. However, these metrics are limiting in their portrayal of student success due to the rise in non-traditional paths toward graduation which reflect the increase in postsecondary participation and diversity of students (Barefoot, 2004; Habley et al., 2012; Shapiro et al., 2014; Tinto, 2012). Non-traditional paths include transferring institutions, initial enrollment in a spring term, fluctuating between full-time and part-time, and taking a semester or more off while on a trajectory toward degree completion. The preoccupation with these established institutional accountability metrics to understand student success overlooks students as active shapers of their paths, disregards student intentions or commitments, excludes students' personal and intellectual development, and assumes that all institutions have essentially identical missions and traditional, unencumbered student populations.

The experiences of students who stopout and return to college are infrequently the focus of studies on higher education retention and graduation. Higher education research has historically focused on student success as dichotomous rather than nuanced: either students are retained or not, graduate or not; however, in recent years, the various pathways to degree completion are increasingly recognized as an important consideration (Campbell \& Mislevy, 2013). This shift to diverse pathways alters the focus of research 
more to students as the unit of analysis and more specifically to student persistence within higher education rather than institutions' retention of students. Stopping out and reenrolling is a non-traditional enrollment pattern, but given the increased prevalence of this pathway, it should be investigated more fully (DesJardins, 2003). Through recruitment and enrollment, institutions make an investment in students and should continue to engage those who stopout by keeping the lines of communication open in addition to developing procedures that ease the transition back (Shapiro \& Dundar, 2014; Tinto, 2012). This continued investment could lead to improved student success, including increased student completion rates. In order to make this investment, institutions must better understand these students and their experiences during their initial enrollment, while they are not enrolled, and after they return. Through this study, I sought to develop this understanding at one public university and the population of students who have stopped out and returned to the university from two recent cohorts.

\section{Research Aims}

My goal was to examine the experiences of students who have stopped out of a university and returned within their six-year graduation window. Students were included in this study if they had reenrolled after being out for at least one fall or spring semester. Students with more than one period of stopout were defined as stopouts. Specifically, I analyzed student experiences prior to and during stopout, as well as their experiences with re-integration and their continued enrollment. Students' academic, personal, paid workforce, and social experiences were considered as well as students' interactions with the institution and its agents including faculty and staff. By employing a mixed methods approach, I utilized in-depth interviews with 27 stopout students, quantitative methods to 
examine the characteristics of the stopout population, and compared them to students in other enrollment pathways. The quantitative analysis used institutionally-provided data for 2010 and 2011 cohorts in their entirety to investigate how background (e.g., firstgeneration status, race/ethnicity, sex, and ACT test scores), financial aid (e.g., PELL eligibility and aid received), college engagement (i.e., on-campus residence and academic major), and academic performance (e.g., cumulative grade point averages) measures differed for students who (a) graduated, (b) stopped out and graduated, (c) stopped out and persisted through their sixth year but did not graduate, (d) persisted through their sixth year but did not graduate, or (e) did not persist. The integration of the students' narratives with the quantitative analyses allowed for a more comprehensive understanding of stopouts than relying on only a single source of data and analytic method.

Specifically, my research questions included:

1. How large was the stopout population within each cohort and across the two cohorts?

2. What were the characteristics of cohort students who stopped out and returned in comparison to those (a) with continuous enrollment until graduation, (b) with continuous enrollment through the closure of the sixyear graduation window but who had not graduated, and (c) who did not persist?

3. What factors predicted stopout?

4. How did students decide when to leave and return?

5. How did stopouts spend their time while not enrolled? 
6. What were the educational goals of stopouts prior to leaving and upon returning? How did their goals change upon returning?

7. What were the attitudes of stopouts toward their education prior to leaving and upon returning? How did their attitudes change?

My analysis provided an in-depth look at students' experiences within a single institutional context. Due to the complicated nature of understanding student departure, DesJardins, Ahlburg, and McCall (1999) suggested that institution-specific enrollment challenges and methods may better inform institutional policy through rich, contextspecific findings. The findings of this study may assist institutions with developing their own investigations into their stopout population as well as provide insights into students' enrollment patterns within the current societal context as costs increase and enrollments decline. Finally, this study may contribute to sociological theory exploring students' experiences in higher education relating to educational ideology, integration, and social/cultural capital as well as investigating the influences of historical and social contexts on the meaning-making and decisions of college students.

\section{Study Setting}

The university under study will be termed City University (City U), and is a public university located in a city in the south. It is a Doctoral University and has more than 15,000 students enrolled (The Carnegie Classification, 2015). The university's firstto second-year retention rate for first-time, full-time baccalaureate degree-seeking students is more than $70 \%$ and its six-year graduation rate is above $50 \%$. 


\section{Defining Stopouts}

This study focused on students who stopout rather than on returners. Returners are generally defined as students aged 24 or over who left college and reenrolled later in life (Deutsch \& Schmertz, 2011); however, there is not a consistent definition of what makes a student a stopout instead of a returner. Stopouts are students who leave temporarily and then return to complete their degree (Desjardins et al., 1999; Hoyt \& Winn, 2004; Kim, Saatcioglu, \& Neufeld, 2012; Schulte, 2015; Stokes \& Zusman, 1992; Tinto, 1993; and Woosley, 2004). Students who stopout have also been identified as those who take time off with the intention to return (Oseguera \& Rhee, 2009; Terriquez \& Gurantz, 2015). Other researchers put a timeframe around stopouts, such as Scott and Kennedy (2005) who suggested that a stopout is a student who leaves but returns within four consecutive semesters, whereas Stratton, O’Toole, and Wetzal (2008) considered stopouts those who leave after their first year but return within one year. Similarly, Pascarella, Duby, Miller, and Rasher (1981) defined stopouts as students who took time off during their first year and returned in their second year. More broadly, Horn and Carrol (1999) delineated stopouts as those who take a break in their first year and reenrolled within four years. Additionally, Goldrick-Rab (2006) defined stopouts as students who experienced discontinuous enrollment for a minimum of one year. While not all studies investigating stopouts restrict their definition to stopping out of and returning to a single institution, several studies specify that stopouts return to their initial institution (Campbell \& Mislevy, 2013; DesJardins et al, 1999; Hoyt \& Winn, 2004; Pascarella et al., 1981; Scott \& Kennedy, 2005; Stokes \& Zusman, 1992; Woosley, 2004). Whereas, others also look at stopping out from a system-level perspective wherein students take a break and then 
enroll at another institution (Goldrick-Rab, 2006; Horn \& Carroll, 1999; Kim et al., 2012; Terriquez \& Gurantz, 2015).

In this study, I defined stopout as one who enrolls as a first-time, full-time baccalaureate degree-seeking student, took at least one fall or spring semester off, and reenrolled at the same institution within their 6-year graduation window. This relatively short timeframe for stopping out and returning at a single institution allowed me to investigate students' experiences and needs within shared societal and institutional contexts. Through this study, I sought to inform the theoretical understanding of this subpopulation's decision-making processes as well as hoped that secondary and postsecondary institutions, policy makers, and families, will be able to develop better mechanisms to support the success of all students.

\section{Dissertation Outline}

In addition to this introduction, this dissertation contains five other chapters which include literature review and conceptual framework, methodology, qualitative findings, quantitative findings, and discussion and conclusion. Chapter 2 introduces the four main conceptual frameworks, Tinto's (1993) student departure theory, Arnett's (2004) emerging adulthood theory, Baxter Magolda's (2001) theory of self-authorship, and Bourdieu's (1986) theory of social reproduction, followed by a review of the student retention and stopout literature. The third chapter describes the methods employed for the study as well as includes statements on limitations and positionality. Chapter 4 reviews the qualitative findings and themes of Psychosocial Barriers and Development and Isolation and Integration. Chapter 5 presents the quantitative findings of the bivariate and multivariate analyses. The final chapter (6) weaves the qualitative and quantitative 
findings together, relating them to the study's theoretical frameworks. Chapter 6 also puts findings in context with what others have found, makes policy recommendations, and discusses future research avenues. Finally, the dissertation concludes with references, appendices, and my curriculum vitae. 


\section{CHAPTER II: \\ CONCEPTUAL FRAMEWORKS AND LITERATURE REVIEW}

When investigating college enrollment pathways and student success, one must consider the roles and actions of the institution, its students, and the interactions between the two. As communities, institutions both create and limit opportunities to membership. As individuals, students juggle their evolving understanding of themselves and the world which, in turn, influences their exchanges with institutions. Both institutions and students possess cultural frameworks that include expectations and dispositions which inform their interactions. To explore the roles of the institution and the student in student persistence as well as the complexity of the interactions between the two, I utilized four theoretical frameworks: social integration, emerging adulthood, self-authorship, and social reproduction. First, the institution's role will be explored through Tinto's (1993) college student departure application of Durkheim's (1951) theory of social integration. Next, the student's perspective will be considered within Arnett's (2004) theory of emerging adulthood and Baxter Magolda's (2001) theory of self-authorship. Finally, the interaction of the institution and the student will be examined through an application of Bourdieu's (1986) theory of social reproduction.

The qualitative analyses conducted for this study uncovered two main themes from which the above theoretical frameworks were selected. The first theme, 
psychosocial barriers and development, emerged from how students initially struggled to understand personal meaning in their college education but were able to uncover it through their time away from school. The second theme, isolation and integration, explores the challenges students faced connecting to the academic community on campus during their initial enrollment, only to be more active participants upon their return. This chapter will introduce each of the theoretical frameworks, followed by a review of the literature that examines student college choice, persistence, retention, and stopping out.

\section{College Student Departure and Integration}

As a single university study, the institutional context and students' interactions with it are key components to understanding students' experiences. In seeking to understand college student departure, Tinto (1993) introduced his framework by considering how they become members of their new community, asserting that the transition into college must be taken into consideration when examining student success. Building on Van Gennep's (1960) anthropological rites of passage, Tinto posited that students must pass through three stages during the first year of college to form a membership within the community, helping lead to persistence. The three stages include separation from one's former community and roles, transition into the norms of the new community, and incorporation as an integrated member of the community. The incorporation stage is where Tinto turned to Durkheim's (1951) theory of social integration, proposing that the interaction between the institution and its students is key to individuals' integration into college life which leads to successful degree completion. This third stage is the main phase of interest to this study. 
Investigating the social forces behind suicide, Durkheim (1951) found that individuals committed egotistical suicide when they failed to become integrated members of their communities. Community membership includes both social (e.g., personal connections within the community) and intellectual (e.g., shared common values) integration. Durkheim argued that communities have the power to both influence individuals' lives and structure themselves to assist individuals with integration. Thus, both communities and individuals are actors in the process of integration. As applied to the higher education context, institutions influence students' decisions to persist or depart through their role in incorporating students into their community (Tinto, 1993).

Expanding the conversation about student retention beyond the individual students' characteristics and actions, Tinto's (1993) work elevated the role of the immediate institutional context as key to student persistence. When examining student departure, Tinto considered how an institution influences its students to stay or leave, arguing that increasing students' social and academic integration into the institutional environment is fundamental to limiting student attrition. He argued, "student departure is more a function of what goes on within the institution following entry than of what may have occurred beforehand" (p. 228). Students interact with institutional agents, traditions, procedures, and environments and it is through these interactions that both the individual student and their institutional context play a role in students' decisions of whether to persist or leave. Students enter university with their cultural perspectives and networksin addition to their own intentions and levels of commitment—-through which their interactions with the institution are filtered. Historically, the onus to successfully navigate various aspects of life, including college, has been placed on the individual; however, 
Tinto asserts that institutions actively create or limit access to integration and that if universities and colleges want to solve the puzzle of student departure they must examine their own actions. The experiences students have when interacting with their institution influence their adjustment and academic and social engagement, which then impacts student persistence. Institutions can modify their culture and practices in order to better meet students where they are and incorporate them into their new environment.

\section{Emerging Adulthood and Self-Authorship}

The college students in this study are traditionally aged (in their late teens and early twenties) due to the student population City U serves and the cohort specific design of the study. Arnett (2004) labels this period in life as emerging adulthood and argues that Americans' transition between adolescence and adulthood has been slowed over the past few decades. Loosely between the ages of 18 and 25, this period of one's life is when people experience uncertainty and instability as they explore what they want. Emerging adulthood is characterized by five main features: it is an age of identity exploration where one considers various possibilities for love and work; an age of instability as one revises their relationships, their plans, and their residences; a selffocused age where one has few obligations to others and is able to direct their attention to decisions about their own lives; an age of feeling in-between adolescence and adulthood; and an age of possibilities about the direction of one's life and one's identity (Arnett, 2004). Though not all Americans attend college, those who do are afforded an extended period of exploration during which they can consider various versions of self and career paths. An application of emerging adulthood to the college path helps to understand the 
somewhat meandering approach many students take as they investigate the possible directions their lives can take as adults (Arnett, 2004).

Adulthood is often characterized by three main criteria: accepting responsibility for one's self, making one's own decisions, and becoming financially independent (Arnett, 2004). The first two of these criteria are developmental components reflected in the concept of self-authorship which Kegan (1994) identified and Baxter Magolda (2008) articulated as "the capacity to internally define one's beliefs, identity, and relationships" (p. 269). As individuals move through the exploration of emerging adulthood, they work toward self-authorship where they are able to consider various options before making decisions about who they are and what they want.

While students may not enter college consciously expecting growth and transition, college is inherently designed as a place to explore and consider options for one's life and roles in the world (Arnett, 2004; Baxter Magolda, 2001, 2014). Most individuals leave adolescence and enter emerging adulthood following external formulas of authority through which they decide what to believe and what to do. Individuals seek approval from authority figures as they make the decision to attend college, what to major in, and who they are to become (Baxter Magolda, 2009). The college environment and exploration of emerging adulthood create occasions for individuals to experience tension between their external influences and their emerging internal voices (Baxter Magolda, 2001, 2014). This tension places students at a crossroads and can lead to questioning what one wants and a dissatisfaction with the current path. For example, college students often question - and frequently change - their academic major as they begin exploring other options (Arnett, 2004; Orndorff \& Herr, 1996). It is through this 
questioning that students begin to listen to and trust their internal voices as they author their own lives. Students no longer follow external points of view uncritically, but instead consider them and manage them while trusting their own voices (Baxter Magolda, 2001, 2004). The inclusion of emerging adulthood and self-authorship in the conceptual frameworks of this study acknowledges that students are not stagnant individuals but instead they are evolving throughout their enrollment and are active participants in their own persistence. Students' thinking and judgment are influenced by their backgrounds and the contexts they are in, including their academic experiences and relationships with institutional agents.

\section{Social Reproduction and Capital}

As actors, institutions play an active role in the reproduction of social inequalities by limiting access and impacting individuals' success within the institution. Social reproduction is the system through which class inequalities across generations are consistently reproduced within a hierarchical social class structure (Bourdieu \& Passeron, 1977). In addition to the generational nature of it, social reproduction also occurs within institutional contexts which ascribe value to specific cultural perspectives, behaviors, and dispositions (Yee, 2016). The institutional role in social reproduction is of interest to this study as it relates to student success within higher education.

Under Bourdieu's (1986) framework, societal relations are structured around differing levels of capital including economic, cultural, and social. Economic capital consists of one's finances and access to financial support. Economic capital is often correlated with the communities within which one lives, the schools one attends, and the cultural and social capital one possesses. Next, cultural capital is comprised of tastes, 
cultural goods, and experiences most often passed down within families and through cultural experiences within institutions including schools, leisure, media, and peers. The cultural capital of the dominant culture is rewarded through various institutions, including the educational system. Bourdieu argues that the educational system reproduces the social structure by holding all students to the cultural capital of the dominant culture; those who cannot operate successfully within the established standards will fail in their educational endeavors, limiting their occupational options and, in turn, continuing to perpetuate the social structure. Lastly, social capital is one's network of relationships through which one engages in order to gather social understanding and gain access to institutions and opportunities (Bourdieu, 1986; Coleman, 1988).

Coleman (1988) advises that, unlike other forms of capital, social capital is not something that is owned by individuals but rather is contingent upon the interactions between them. In addition to one's capital, one's habitus (socially learned and influenced attitudes and dispositions) informs an individual's strategies for navigating various social contexts (Bourdieu, 1984). For those college students who have the "right" finances, dispositions, and connections, one's path through higher education should be smooth as their habitus is often aligned with the institution's habitus; those who are lacking in any area of capital preferred by colleges are likely to face significant challenges along the way. Thus, the application of social reproduction theory to the conceptual frameworks illustrates how institutions are not neutral in their relationships with students, but instead have great influence on their students' paths to success. 


\section{Literature Review on College Choice, Integration, and Stopping Out}

Since the decisions to stopout and return do not occur in a vacuum, it is important to investigate students' reasons for college application and enrollment, their experiences during initial enrollment, that led to stopping out, and that occurred once reenrolled. Literature exploring these circumstances and the interactive nature of students and institutions will be discussed in an effort to examine the influence on students' enrollment paths. After reviewing the literature on college choice, persistence, and retention, I will more specifically explore the literature on stopping out.

\section{The Contexts of College Choice}

To better understand students' departure from higher education, we must consider their paths into higher education. According to Perna's (2006) college access and choice model, students' decisions to enroll in college must be examined within students' larger contexts. A student's high school and community serve as environmental influences that shape their awareness of their college options (McDonough, 1997; Rosenbaum, 2001; Simon, 1957). Each environment convenes the information that is available to individuals, in effect, framing the options to be considered. When making decisions, rational choice theory tells us that individuals optimize their choice in order to have the best outcome (Coleman \& Fararo, 1992). This would suggest that students choose to attend the college from which they believe they have the best opportunities and chance to succeed. However, bounded rationality indicates that individuals can only optimize their decisions within the options with which they are aware; thus, they are more likely to satisfice their choices based on the information that is constrained by their contexts (Coleman \& Fararo, 1992; McDonough, 1997; Rosenbaum, 2001; Simon, 1957). 
Both high schools and colleges influence the options of which students are aware. At the high school level, the school's habitus, including the organizational structure of the counseling program (e.g., the counselor to student ratio as well as the services offered), the socioeconomic class of its students, along with the institutional assumptions about the needs of the student population, influence the college options with which students are presented. Thus, the information shared, bounds, or limits, the students' college options (McDonough, 1997). At the college level, students' choices are influenced through an institution's selection of where to recruit. Since recruitment activities are an expensive investment for colleges, admissions offices target students most likely to enroll while also stretching to reach students who are academically competitive and able to pay full tuition (Armstrong \& Hamilton, 2013; Selingo, 2013). As such, admissions offices choose high schools whose habitus align with the university's habitus to be the beneficiaries of their recruitment activities (Armstrong \& Hamilton, 2013; Crow \& Dabars, 2015; Perna, 2006). McDonough argues, "the central role of habitus is in defining and limiting what is seen by an actor and how it is interpreted" (p. 109). Thus, high schools and colleges structure students' interpretations of their options through which students can exercise their agency.

Beyond an individual's high school and the institutions of higher education that engage them during their college search, larger social forces, economic conditions, and public policies also influence a student's decision-making about college. Over the last 150 years the United States federal and state governments have increased access to college by passing legislation to democratize higher education (Williams, 1991). Most recently, the state of New York developed The Excelsior Scholarship, a tuition-free 
college program for state residents to attend state-funded institutions (New York State Website, 2018). These acts improved opportunities to attend college and diversified higher education, encouraging more students of color, students with disabilities, lowincome students, and women to enroll. This democratization of higher education encouraged an American college-going ethos wherein college became both a necessity and a right (Clark, 1960). College students today are the beneficiaries of these changes as going to college is now an accepted, and expected, norm for most students.

This notion of equal opportunity and the American college-going ethos have evolved into a college-for-all ideology, leading the majority of high school students to plan to attend college, as an undergraduate degree is believed to be the precursor to employment stability and economic security (Ovink, 2017; Rosenbaum, 2001). This college-for-all norm can be found across the nation in political candidates' platforms, states' legislation, community initiatives, as well as throughout the messaging within elementary, middle, and high schools. This norm is situated within our society such that a college degree is now all but required to gain access to professional jobs where it had not been previously, further stratifying social structures by increasing the status of various professional fields (Collins, 1979). The market-based logic behind the emphasis on the credential stresses the instrumental value of a college education in the job market, potentially detracting from the intellectual and moral development of a college education (Rosenbaum, 2001). This logic also leads students and their families to approach higher education as something that is managed and acquired rather than experienced (Arum \& Roksa, 2011; Dewey, 1938). In addition to telling students that college is necessary, this ideology tells them it is the next logical step in one's life after high school. 
Many students, especially middle-class students, assume early in their lives that they will attend college instead of making a more informed decision about college attendance later in their K-12 educational career (Grodsky \& Riegle-Crum, 2010). As an internalized preference, students are unaware of the college-going habitus; it feels normal and natural serving as the lens through which students see they world (Bourdieu, 1974). This normalization of college-going behaviors has both limited the conversation around alternative paths to careers (such as vocational training) and limited high schools' assistance in making realistic plans for all students (Rosenbaum, 2001). High school counseling strives to maintain the college-for-all ideology through their college admission materials and messaging, but rarely do counselors have the time to help students explore their options, understand the expectations of college enrollment, or manage their search and application process (Farmer-Hinton, 2008; Gast, 2016; RiosAguilar \& Deil-Amen, 2012). In turn, more students are entering college because it is the only option presented; they know they are supposed to get a degree, but do not understand what it takes to be successful in earning one. This engrained external expectation results in students neither considering the value of a college education beyond the marketable nature of the credential, nor being interested in a broader college experience beyond the credits earned on the way to that credential. Thus, once enrolled, students often see the navigation of college as a checklist of courses to complete in order to obtain their degree instead of a time of holistic development (Arum \& Roksa, 2011).

\section{Integration within the Institution}

Once students are enrolled in college, what helps them stay and graduate? As discussed above, Tinto's (1993) work identifies keys to student persistence as both social 
and academic integration, but that as an academic community, academic integration is imperative and that social integration alone is insufficient. Academic integration is essential for all students' academic success, but often it is challenging for students whose individual habitus does not align well with the institutional habitus (Reay, Crozier, \& Clayton, 2009). As such, first-generation students benefit even more from this type of integration in order to stay focused and motivated on their schooling when facing financial and psychological stress (Adams, Meyers, \& Beidas, 2016; Clark, Middleton, Nguyen, \& Zwick, 2014; Próspero \& Vohra-Gupta, 2007). A key factor to students’ integration is the utilization of a network of support within their institution. This network of support is their social capital, or their relationships with institutional agents who work within the institution and who can assist students with accessing resources and opportunities (Stanton-Salazar, 1997). Agents acting on behalf of the institution must intentionally and proactively help students navigate their college, otherwise they encourage students' departure by reproducing inequality and limiting access to all that the school has to offer (Stanton-Salazar, 1997; Tinto, 1993).

In addition to the culture of the institution and the actions of its agents as key to students' integration, students' help-seeking behavior must also be considered when exploring students' engagement with their school. Help-seeking behavior is a mechanism through which students gain access to support and resources and it is directly tied to students' social capital and their trust of institutional agents (Bourdieu \& Passeron, 1977; Holland, 2015; Jack, 2016; Stanton-Salazar, 1997). Students' engagement with the academic activities outside-of-class (e.g. meeting with faculty and advisors, participating in study groups) have been found to significantly impact first-year retention (Ishitani, 
2016; Kuh, Kinzie, Buckley, Bridges, \& Hayek, 2007). Men, students of color and firstgeneration students have been found to be more reluctant to ask for help from peers, faculty, or staff as they often employ a self-reliant independence instead of cooperative interdependence when it comes to their academic success (Jack, 2016; Reay, et. al., 2009; Steinfeldt, Steinfeldt, England, \& Speight, 2009; Yee, 2016). Students’ social capital varies based on their social class, impacting the rules they follow when navigating their education and asking for help (Yee, 2016). Furthermore, the transactional nature of counseling relationships experienced in high school informs students' perspectives on the limited nature of those in helping roles, encouraging a lack of trust in institutional agents (Gast, 2016; Holland, 2015; Stanton-Salazar, 1997). Applying a social reproduction lens to our understanding of the challenges students face in connecting with institutional agents helps to better identify barriers to integration.

One particular area in which students seek and benefit from guidance is career and academic decision-making. Students tie their academic and professional identities together and expect to develop both through their college experience (Jensen \& Jettson, 2016). Students seek assistance through trusting relationships with institutional agents to explore possible selves and find clarity (Hinkelman \& Luzzo, 2007; Jensen \& Jettson, 2016). Frequently, the development of academic and career paths as well as identities can result in stress and other forms of psychological distress (Beiter, et al., 2015; Constantine \& Flores, 2006; Jensen \& Jettson, 2016; Liao \& Ji, 2015). Though not exclusively tied to academic and career uncertainty, psychological distress among college students-in particular anxiety and depression— - has been on the rise in recent decades, with over half of college students reporting experiencing overwhelming anxiety in the past 12 months 
(National College Health Assessment, 2016; Beiter, et al., 2015; Pisarik, Rowell, \& Thompson, 2017). Specifically, career uncertainty and low levels of self-clarity are related to anxiety (Beiter, et al., 2015; Constantine \& Flores, 2006; Pisarik, et al., 2017). Additionally, anxiety has been found to be related to procrastination, poor relationships, and low self-esteem (Beiter, et al., 2015; Haycock, McCarthy, \& Skay, 1998).

Institutional agents must work with students to identify the underlying challenges to their success, engagement, and clarity in order to refer students to the appropriate services (i.e. academic coaching, academic advising, career counseling, mental health counseling, etc.) needed to address those challenges (Baxter Magolda, 2001; Jensen \& Jettson, 2016; Liao \& Ji, 2015). Providing support to students through the exploration and instability of emerging adulthood will also assist students' recognition of the external influences in their thinking in order to help them clarify and trust their own desires (Baxter Magolda, 2014). This support should be proactive in order to help students build their social capital and engage in the services designed to assist them.

Similar to students' help-seeking behaviors, students' other actions, experiences, and enrollment patterns - all of which are mediated by their social, cultural, and economic capital—have been shown to affect their success. All three forms of capital impact how students enroll and engage in college. Enrolling immediately after high school, living on-campus, participating in campus involvement activities, enrolling fulltime, earning a higher first-year GPA, and enrolling continuously have all been found to relate positively to student persistence (Allen, Robbins, Casillas, \& Oh, 2008; Hossler et al., 2013; Ishitani, 2016; Mayhew et al., 2016; Pike, Hansen, \& Childress, 2014). As the costs associated with college continue to rise, challenging how far students' economic 
capital can go toward covering the expense, students' financial aid has been increasingly considered when looking at student enrollment. Scholarships, grants, and work-study/oncampus employment have been found to consistently relate to improved student persistence (Hossler et al., 2013; Ishitani, 2016; Mayhew et al., 2016). Finally, more students are working for pay for school which appears to impact students' retention in a curvilinear relationship with working up to 20 hours a week appearing to benefit student persistence, but once students work more than that they are more likely to drop to parttime status, withdraw, or dropout (Bozick, 2007; Mayhew et al., 2016).

Considering social integration specifically, there have been mixed results when looking at social engagement factors, with some studies finding that social connectedness and on-campus peer relationships are positively related to retention (Allen et al., 2008; Hausmann, Ye, Schofield, \& Woods, 2009) while other studies finding no significant relationship (Mayhew et al., 2016). Moreover, Ishitani (2016) found that social integration measures such as participating in intramurals and clubs have no significant effect on first-year retention, whereas Cragg (2009) found participating in student organizations to be positively related to both retention and graduation. In general, research into on-campus extracurricular involvement continues to return complex results, especially when other factors such as individuals' socioeconomic class or institutional commitment to student success are considered, but commonly show positive impacts on persistence (Flynn, 2014; Kuh et al., 2007; Mayhew et al., 2016; Pascarella \& Terenzini, 2005). Men of color, in particular, have been found to benefit from participating in programs designed to leverage and nurture their educational agency by bringing them together for mentoring, development, and leadership opportunities (Brooms, Clark, \& 
Smith, 2018). Participation in fraternities and sororities (which is often mediated by students' background characteristics) has also been found to positively impact persistence and graduation but not always GPA or college learning measures (Arum \& Roksa, 2011; Mayhew et al., 2016; Routon \& Walker, 2016; Walker, Martin, \& Hussey, 2014). Thus, student engagement on campus generally relates positively to persistence; however that engagement is mediated by students' social, cultural, and economic capital.

Students are more likely to be successful when their personal habitus toward their college education aligns well with the organizational habitus, including informal peer culture as well as formal institutional culture (Reay et. al., 2009). Student background characteristics that have been found to increase one's probability of persistence and graduation have changed little over time and include factors such as higher scores on college entrance exams, higher high school GPA, college-educated parents, and higher parental income (Astin \& Oseguera, 2012; Ishitani, 2016; Marsh, 2014; Mayhew et al., 2016; Pike et al., 2014; Wells, 2008). These factors are social and cultural capital operationalized and align well to the expectations of colleges' organizational habitus. Furthermore, whereas private, residential, and more selective institutions' dispositions and expectations are often aligned with their student populations who are often better academically prepared and from higher socioeconomic backgrounds, other institutions have more diverse student populations and do not share this alignment (Astin \& Oseguera, 2012; Oseguera, 2005; Marsh, 2014; Mayhew et al., 2016). Additionally, students who identify as women, White, or Asian have been found to have higher rates of persistence, which could be tied to these populations' socialization into the institutional 
norms leading to a consistency between individual and institutional habitus (Hossler et al., 2013; Ishitani, 2016; Pike et al., 2014).

Though institutions cannot quickly change students' habitus to align with the institutions' habitus upon entry, they can design a campus environment around their student populations' diverse needs to include intentional programs and services that bridge the gap between the dispositions of students and the culture of the institution. Often times, as working-class students adjust to the organizational habitus of their college — including internalizing new dispositions and gaining cultural capital—workingclass students find their habitus of origin is in conflict with their college's habitus (Lehmann, 2013, Reay et al., 2009). In experiencing and navigating these conflicts, working-class students increase their awareness of stratification and class-consciousness, but this awareness does not necessarily lead to success within an institution (Lehmann, 2013; Reay et al., 2009; Stuber, 2011). Since institutions cannot change the background of their students, it is not productive to continue to put the onus solely on students to adapt to institutions (Ostrove \& Long, 2007). Instead, institutions can adapt to the needs of students by adjusting their institutional climate, including their procedures and services as well as their formal efforts to engage students (Ostrove \& Long, 2007; Reay et al., 2009; Rosenbaum, Deil-Amen, \& Person, 2006; Tinto, 2012). For example, institutions can build access to social capital through experiential opportunities within the curriculum, e.g., service learning and internships, allowing students to develop networks and skills valued in the job market (Lehmann, 2013). Pre-enrollment and on-going programming can help students integrate into campus life through proactively engaging students throughout the academic year in opportunities that increase their social and 
cultural capital (Stuber, 2011). Increasing students' networks can have a ripple effect as they also develop their sense of belonging, resulting in greater participation in both the academic and social systems of the institution, which then results in improved persistence and graduation (Ostrove \& Long, 2007; Tinto, 1993, 2012).

Through specific, targeted efforts within a student-centered culture, institutions can achieve retention and graduation rates higher than the demographics of their student populations would predict (Kuh et al., 2005). Instead of a culture that assumes students will figure out how to be successful or determines that those who cannot figure it out are not cut out for college, a student-centered culture is one that recognizes and is responsive to students' needs both academically and personally. Thus, institutions are able to help students succeed by responding to their needs for appropriate socialization and access to resources. Institutional initiatives that respond to student needs and have been found to positively impact student retention include supplemental instruction for difficult courses, first-year seminars, early alert systems, learning communities, academic advising, mental health counseling, orientation, and summer bridge programs (Mayhew et al., 2016; Ziskin et al., 2016). Additionally, Marsh (2014) investigated the impact of institutional expenditures on student retention at nearly 500 institutions and found that academic support expenditures, including faculty development, course and curriculum design, and instructional technology, significantly impacted student retention. Therefore, institutions can increase student persistence by improving the learning environment for students, helping students navigate the challenges they face in college, and assisting students with their navigation of the institution. 


\section{Stopping Out}

Recent research into interrupted student enrollment patterns investigates who interrupts enrollment as well as situational circumstances that correlate to interrupting enrollment but does not investigate students' thinking behind taking a break nor students' assessment whether taking a break is beneficial to their development. When considering who is more likely to have interrupted patterns of enrollment, the literature reveals that men and Latinos are more likely take a break (Allen et al., 2008; Clery \& Topper, 2009; Ewert, 2012; Goldrick-Rab, 2006; Nora \& Crisp, 2009). Additionally, students are more likely to take time off if they are older, have children, work full-time, have health issues, are less academically prepared, or have financial concerns regarding their ability to pay for school (Goldrick-Rab, 2006; Hoyt \& Winn, 2004; Kim et al., 2012; Terriquez \& Gurantz, 2015; Woosley, 2004). Of those who do take time off, traditionally-aged college students, those who are not first generation, those who attend college in-state, and those of middle and higher income levels were more likely to return (Horn \& Carroll, 1998; Hoyt \& Winn 2004; Kim et al., 2012).

When considering within college circumstances that impact continued enrollment, Campbell and Mislevy (2013) found that men are at greater risk of stopping out when their attitude about the institution is less-than-positive while women are at greater risk of stopping out when they are unsure of their future direction even when they are high performers (Campbell \& Mislevy, 2013). Involvement in student organizations and extracurricular activities has been found to be positively related to whether students return to the same institution after taking a break from their enrollment (Kim et al., 2012; Woosley, 2004). Students' academic engagement influences the likelihood of returning to 
the same institution as students with higher GPAs, students who attend school full-time, as well as those who meet with faculty and advisors are more likely to return after a break (Horn \& Carroll, 1998; Kim et al., 2012). Of note, the majority of students who take time off of school whether they stopout or dropout are not in academic failure (Barefoot, 2004); however, academic performance appears to influence the timing of stopping out with the later the stopout occurring in a student's career, the less likely they are to be below good academic standing (Stokes \& Zusman, 1992; Woosley, 2004). While stopping out delays degree completion it does not necessarily change students' outcomes (Shapiro et al., 2014; Stokes \& Zusman, 1992).

\section{Conclusion}

Through the incorporation of social integration, emerging adulthood, selfauthorship, and social reproduction, I examined the complexity of stopping out. Students are developing individuals when they enroll in college and this affects their interactions with the institution as well as their decisions about enrollment. Additionally, students' economic, cultural, and social capital impacts how they interact with the institution's culture, agents, and processes. The programs, services, and resources schools create or do not create influences students' integration and persistence. Since students and institutions are both considered actors in my study, I consider the institutional context, the interactions between the school and the students, and the students' decision-making in my examination of students who stopped out and returned within their six year graduation window. 


\section{CHAPTER III: METHODOLOGY}

This study is an investigation into the experiences of students who stopout. Specifically, I conducted a mixed methods investigation first using qualitative methods to develop an understanding of student experiences (e.g., why students stopped out, what they did while out, why they returned, and how their perspective may have changed once reenrolled), followed by quantitative methods to analyze the relative size of each stopout population to its cohort, the timing of stopout, and the explanatory impact of various variables on stopping out. The site of the study is City $\mathrm{U}$, a public research institution with over 20,000 students. As a single institution study, my goal is to provide a more comprehensive understanding of students from the 2010 and 2011 cohorts who stopped out at City U.

Stopout motivations and experiences are complex. The use of mixed methods can both reveal these complexities (Seifert, Goodman, King, \& Baxter Magolda, 2010), as well as tap into "different dimensions, qualities, or aspects of a given phenomenon" (Hunter \& Brewer, 2003, pp. 581-582). Thus, the qualitative and quantitative findings may support each other or they may disclose inconsistencies further revealing the complexities of the issue (Slonim-Nevo \& Nevo, 2009; Teddlie \& Tashakkori, 2003). A benefit to a mixed methods approach is that it allows for a more complete understanding of stopping out through an analysis of both the breadth of data about a stopout population 
and a depth of understanding through a close examination of a smaller sample (Hunter \& Brewer, 2003). Quantitative investigations allow for the analysis of the size and characteristics of a population, the identification of the predictors of an outcome, and test for differences between outcomes. Qualitative investigations explore multifaceted processes that unfold over time and reveal the meanings individuals ascribe to their experiences. Additionally, the use of mixed methods helps assess the validity of conclusions through the convergence of data from one method with another method (Greene, Caracelli, \& Graham, 1989; Hunter \& Brewer, 2003; Reynolds, Gross, Millard, \& Pattengale, 2010; Seifert et al., 2010). Therefore, this study seeks to provide a comprehensive picture of the experiences of stopout students through both institutionallyprovided student data and individual student voices.

\section{Qualitative Methods and Analyses}

The qualitative findings included in this study are from in-depth interviews I conducted with students during the spring semester of 2016. Qualitative research design focuses on a particular issue and "the goal is to look at the ... 'meanings' individuals attribute to their given social situation" (Hesse-Biber, 2007, p. 117). In this case, the situation is that of stopping out and the situation of returning to the university within their six-year graduation window. The interviews were used to explore the decision-making processes and motivations as students chose to enroll, stop attending, return, and persist at City U. The enrollment office at City U provided a list of all students from the 2010 and 2011 cohorts who were enrolled during spring 2016 and who had stopped out for at least one semester. I invited students who had stopped out to participate in an in-person interview via email. After the initial email invitation, I sent two reminder emails to non- 
respondents approximately three weeks after the previous email and no emails were returned as undeliverable. In total, 206 students were invited and 27 participated in interviews between February and May 2016. All interviewees volunteered their time and there was no incentive beyond sharing their stories to participate. I completed the semistructured interviews containing open- and closed-ended questions at several public spaces on City U's campus (see Appendix A for the interview guide). The interviews lasted between 20 and 75 minutes with a median of 39 minutes. I conducted, audio recorded, and transcribed each interview. To assist with anonymity, I applied pseudonyms to all interviewed students in addition to the institution (City U).

During the interviews, students described their enrollment, initial experiences, time away, and experiences since returning. At the beginning of each interview, I introduced myself as a doctoral student to build student-to-student rapport. After reviewing and signing an Informed Consent form, participants completed a brief demographic questionnaire (see Appendix B) before the interviews began. The openended nature of the in-depth interviews allowed participants to reflect on their experiences and meaning-making for the interviewer and themselves. This format encouraged participants to act as storytellers, tracing their experiences through time as they "actively composed meaning by way of situated, assisted inquiry" (Holstein \& Gubrium, 1995, p. 29). I selected in-depth interviewing because it offers more detail on "lived experiences" than what would be gleaned from closed-ended survey questions (Hesse-Biber, 2007). This approach allowed both the interviewer and interviewee to be active participants, thereby encouraging interviewees to think deeper about their own meaning-making of experiences in order to provide authentic explanations in the context 
of the interview (Holstein \& Gubrium, 1995). In response to my inquiries, the interviewees willingly shared their stories, reflecting "the fact that people are not often listened to; that their views and experiences are not treated as being of any account" (Gillham, 2000, p. 8). As students reflected on their decision-making processes to stopout and eventually return to the university, they shared rich details about their experiences over time.

Along the way, I transcribed the interview recordings to critique the wording of questions and inform question probes during subsequent interviews. At the completion of the interviews, I coded the transcripts line-by-line to reveal emergent categories and subcategories. I conducted a constant comparative method of analysis through an inductive process of comparing data with data, with categories, and with the developing concepts (Charmaz, 2006; Glaser \& Strauss, 1967). A descriptive, thematic, exploratory analysis was undertaken as I sorted quotes into subcategories then linked the subcategories into larger categories. I found that the dominant themes of the data were prevailing early in the data collection and determined theoretical saturation was achieved after the last several interviews did not reveal new insights or patterns (Charmaz, 2006). To check the authenticity of the findings, I provide rich in-situ quotes, share experiences that were divergent within the sample, and checked for representativeness of the patterns throughout the sample (Miles \& Huberman, 1994). 


\section{Quantitative Data Source and Analyses}

\section{Data Source}

The enrollment office at City U provided a dataset which included no direct student identifiers. The data included the 2010 and 2011 cohorts in their entirety in order to provide a comparative picture of students who stopout with graduates, persisters, and non-persisters. The stopout population is composed of two groups: stopouts who graduated within six years (stopout graduates) and stopouts who were enrolled through their six year and had not graduated (stopout persisters). These two groups were compared with those who graduated within six years after being continuously enrolled (graduates), those who were continuously enrolled through their sixth year but had not graduated (persisters), and those who stopped enrolling and did not return (nonpersisters). The 2010 and 2011 cohorts contained 5000 students combined. (In order to mask the identity of the institution, the exact cohort numbers have been approximated.) The datasets began with the students' first semester of enrollment, either fall 2010 or fall 2011, and ended with the closure of each cohorts' six-year window, either summer 2016 or summer 2017 respectively. The statistical analyses included variables (see Table 1) that have been identified in the literature as important to retention and graduation as well as trends uncovered in the qualitative findings of this project. While age is cited frequently as an important variable to consider in studies of college students, each cohort examined here has fewer than 15 students aged 24 or older at the time of their initial enrollment; thus, age did not have sufficient variability to be analyzed here. (City U's student population included many students aged 24 or older; however, most were either returners or transfer students and, in turn, not within a six-year cohort.) 
The independent variables were categorized into the three groupings: Background, Pre-College Preparedness, and Early College (see Table 1). Prior to conducting the bivariate and multivariate analyses, the categorical variables were recoded into dummy variables. Race/ethnicity was recoded into White (1) and other (0) due to the small numbers of the racial categories other than White when distributed among the student pathways. Sex/gender was recoded into male (1) and female (0). (Binary biological sex was how the variable was measured in the data; thus, I chose to remain consistent with the data as I received it rather than use a categorical (non-binary) gender measurement.) Residence was recoded into local (1) for students from the surrounding area and not local (0) for students who were from within the state but not the surrounding area, students who were from out-of-state, and international students. (Students' residence was determined by their high school since the student record system did not maintain the original address students submitted on their application; instead, their address was updated in the system each time a student gave the university a new home address.) First-generation college student was recoded into first generation (1) and not first-generation (0). PELL grant recipient was recoded into PELL recipient (1) and not PELL recipient (0). (Students who did not file FAFSA are included as not PELL recipients along with students who did file a FAFSA and did not qualify for or did not accept a PELL grant.) First-semester housing was recoded into on-campus (1), which included university-owned and university-affiliated residence halls, and off-campus (0). Reflecting the qualitative findings from this study, initial, intended academic major was condensed into a dummy variable for STEM majors (1) and others (0). Since there is no universal definition of STEM degree programs, I utilized a commonly accepted definition 
to define STEM majors as those in biology, chemistry, computer information systems, engineering, mathematics, and physics (Gonzalez \& Kuenzi, 2012; Malcolm \& Feder, 2016). Students' entering cohort was recoded into 2010 (1) and 2011 (0). Additionally, two continuous variables were recoded. Total credits (test and dual credit) earned prior to enrollment was recoded into a dummy variable (1=earned hours prior to enrollment; $0=$ did not earn hours prior to enrollment) because over half of the population had zero hours earned prior to enrollment. Total financial aid received each year was recoded into quintiles rounded to the nearest one thousandth due to the dispersion of the values. The other continuous variables were not recoded and consisted of high school grade point average, maximum ACT composite score, and first semester grade point average. For missing independent variables, I used listwise deletion which resulted in losing 116 students.

\section{Table 1}

Description of Variables

\section{Dependent Variable Categories}

\section{Student Pathway}

Graduate

Persister

Stopout Graduate

Stopout Persister

Nonpersister
Students who were continuously enrolled until graduation within 6-years of initial enrollment

$$
\text { Students who were continuously enrolled through } 6^{\text {th }} \text { spring }
$$

Student who stopped out, returned, and persisted until graduation within 6-years of initial enrollment

Student who stopped out, returned, and persisted through $6^{\text {th }}$ spring

Student who stopped attending and had not returned by the $6^{\text {th }}$ spring 


\section{Independent Variable Categories}

\section{Background}

$\begin{array}{ll}\text { Race/Ethnicity } & 1 \text { White } \\ & 0 \text { Other (including students of color and two or more races) } \\ \text { Sex } & 1 \text { Male } \\ & 0 \text { Female } \\ \text { Residency } & 1 \text { Local } \\ & 0 \text { Not Local } \\ \text { First-Generation } & 1 \text { Yes (parent/s or grandparent/s did not attend college) } \\ & 0 \text { No (parent/s or grandparent/s attended college) } \\ \text { PELL Grant } & 1 \text { Yes } \\ \text { Recipient } & 0 \text { No }\end{array}$

\section{Pre-College Preparedness}

High School GPA Cumulative high school grade point average

ACT Composite Highest ACT Composite score earned $\begin{array}{ll}\text { Earned Credits } & 1 \text { Yes (earned test credits and dual credits prior to enrolling) } \\ \text { Prior to Enrolling } & 0 \text { No }\end{array}$

\section{Early College}

$\begin{array}{ll}\begin{array}{ll}\text { Initial Intended } \\ \text { Academic Major }\end{array} & \begin{array}{l}1 \text { STEM } \\ 0 \text { Other }\end{array} \\ \begin{array}{l}\text { First-Semester } \\ \text { Housing }\end{array} & \begin{array}{l}1 \text { On-Campus } \\ 0 \text { Off-Campus }\end{array} \\ 1^{\text {st }} \text { Year GPA } & \text { First Year Cumulative Grade Point Average } \\ \text { First Year } & 1 \$ 0-4000 \\ \text { Financial Aid } & 2 \$ 4001-8000 \\ \text { Quintiles } & 3 \$ 8001-13000 \\ & 4 \$ 13001-18000 \\ & 5 \$ 18001+ \\ & \text { Second Year Cumulative Grade Point Average } \\ 2^{\text {nd }} \text { Year GPA } & 1 \$ 0-2000 \\ \text { Second Year } & 2 \$ 2001-8000 \\ \text { Financial Aid } & 3 \$ 8001-12000 \\ \text { Quintiles } & 4 \$ 12001-18000 \\ & 5 \$ 18001+\end{array}$


The goals of my quantitative design were to understand the magnitude of the stopout population, when did students stopout and for what duration/s, what factors predicted stopout, as well as conduct a comparative analysis between students who stopped out and those who graduated, persisted, and did not persist in order to investigate whether stopouts can be distinguished from graduates, persisters, and non-persisters. Since stopout students can still contribute positively to an institution's six-year graduation rate if they graduate within six years of their initial enrollment, I initially analyzed stopout graduates and stopout persisters as two separate groups. Thus, I chose to include the two separate stopout groups resulting in five pathways (graduates, stopout graduates, stopout persisters, persisters, and non-persisters) to comprise the dependent variable categories for the bivariate analyses. (Students with multiple stopouts were included in their respective stopout group).

\section{Quantitative Analyses}

As the focus of the study, stopout graduates and stopout persisters are the reference categories of interest, but all five pathways were included in the bivariate models in order to do a comparative analysis of student pathways, and in particular, a comparison between the stopout pathways and the others. A descriptive analysis of background variables was conducted to compare the students in each pathway. This comparison helped to better distinguish each outcome as it revealed similarities and differences between groups for each pathway of student enrollment.

Before running the bivariate models, I began my analyses with a correlation matrix to understand how the variables relate to each other. Next, I ran the chi-square test of independence on the categorical independent variables to understand the differences of 
student pathways between each other and to the total. Since the dependent variable included more than two categories, Cramer's V was utilized to understand the strength of the relationship between variables. Finally, a chi-square test was run to determine if the observed differences between each student pathway and the total student population on each categorical independent variable was statistically significant and whether to retain or reject the null that the probabilities were the same.

For the continuous predictor variables, I computed central tendency and variability statistics for the combined cohorts' population and for each student pathway as well as conducted an ANOVA with a Games-Howell post-hoc test for each continuous independent variable on each of the student pathways. Games-Howell was chosen as the post-hoc test because the sample sizes are of sufficient size, it allows for group sizes that are unequal, and it is a conservative test when variances differ across the dependent variable categories (Shingala \& Rajyaguru, 2015). This analysis looked at whether there was a statistically significant difference for each continuous independent variable on the categorical student pathway variables while also reporting which pathways were significantly different from one another on each continuous independent variable. This test looked at each variable individually and did not control for the other variables. Additionally, effect sizes were calculated to understand the practical significance of the differences of independent continuous variables on students' pathways. Effect size focuses on whether the difference is meaningful in the real world and not just statistically different (Kirk, 1996). The effect size describes the magnitude of the difference between groups. Glass's delta was used as the estimate because it does not pool standard deviations between groups since it does not assume homogeneity of variance. 
I ran binary logistic regression (BLR) to investigate which variables predicted stopping out versus all other outcomes combined. Next, I conducted multinomial logistic regression (MLR) to examine predictors that were statistically significant when predicting each outcome in comparison to stopouts. Similar to Stratton et al. (2008), MLR is an appropriate test for my investigation as I seek to determine how the factors associated with students who stopout are statistically different than the factors associated with other enrollment outcomes. MLR reduces bias across multiple dependent variable categories through the simultaneous inclusion of all outcome pathways; whereas binary logistic regression requires dissimilar pathways to be collapsed so that only two remain, leading to more bias in a less efficient model (Long, 1997). MLR allows for the analysis of how the distinct pathways relate to one another and provides a comprehensive picture of the various student outcomes; such an analytic strategy is consistent with recent calls in the literature for more nuanced understandings of diverse student pathways.

\section{Hypotheses:}

\section{Background Characteristics:}

$\mathrm{H}_{1}$ : Males will be more likely to stopout than females.

$\mathrm{H}_{2}$ : Local students will be more likely to stopout than students not from the immediate area.

$\mathrm{H}_{3}$ : White students will be less likely to stopout than students from other racial backgrounds.

$\mathrm{H}_{4}$ : Those who are first-generation students will be more likely to stopout than students who are not first-generation. 
$\mathrm{H}_{5}$ : Students who receive the PELL grant will be more likely to stopout than students who do not receive the PELL grant.

\section{Academic Preparation:}

$\mathrm{H}_{6}$ : Students who have lower high school GPAs will more likely to stopout.

$\mathrm{H}_{7}$ : Students who have lower ACT Composite scores will be more likely to stopout.

$\mathrm{H}_{8}$ : Students who earn college credits prior to enrolling will be less likely to stopout.

\section{In-College Experiences:}

H9: Students who live off-campus their first year will be more likely to stopout than students who live on-campus.

$\mathrm{H}_{10}$ : Students in STEM majors will be more likely to stopout than students who begin in other fields.

$\mathrm{H}_{11}$ : Students with higher university GPAs will be less likely to stopout.

$\mathrm{H}_{12}$ : Students who receive more financial aid will be more likely to stopout.

My hypotheses are situated in theory, the persistence literature, and my qualitative findings. The first five hypotheses consider the role of student background characteristics on the likelihood of stopout. $\mathrm{H}_{1}$ : Males will be more likely to stopout than females. The literature has found that men are more likely to stopout than women (Allen et al., 2008; Clery \& Topper, 2009; Ewert, 2012; Goldrick-Rab, 2006). Additionally, Sax (2008) found that college affects men and women in different ways, and in turn, they approach 
college differently as more women are enrolling in college and are more engaged while in college than men.

$\mathrm{H}_{2}$ : Local students will be more likely to stopout than students not from the immediate area. Hoyt and Winn (2004) as well as Kim et al. (2012) found that in-state residents were more likely to stopout than transfer out or dropout. Additionally, Johnson and Muse (2012) found that out-of-state students have significantly lower return rates after interrupting their enrollment than in-state residents.

$\mathrm{H}_{3}$ : White students will be less likely to stopout than students from other racial backgrounds. There are mixed results in the literature when it comes to determining which racial categories are more likely to stopout. Some studies have found that students of color are more likely to stopout than white students (Johnson \& Muse, 2012; Pascarella et al., 1981), while others have found that white students are more likely to stopout (Campbell \& Mislevy, 2013), and others have found no racial differences in the likelihood of stopping out (Goldrick-Rab, 2006; Terriquez \& Gurantz, 2015).

$\mathrm{H}_{4}$ : Those who are first-generation students will be more likely to stopout than students who are not first-generation. Horn and Carroll (1998) found that first-generation students are less likely to return after interrupted enrollment and Stratton et al. (2007) found that students whose parents completed college are less likely to interrupt their enrollment.

$\mathrm{H}_{5}$ : Students who receive the PELL grant will be more likely to stopout than students who do not receive the PELL grant. Interrupted enrollment has been found to be more common among students with fewer financial resources (Goldrick-Rab, 2006; Kim et al., 2012). 
The next three hypotheses $\left(\mathrm{H}_{6}\right.$ : Students who have lower high school GPAs will more likely to stopout; $\mathrm{H}_{7}$ : Students who have lower ACT Composite scores will be more likely to stopout; and $\mathrm{H}_{8}$ : Students who earn college credits prior to enrolling will be less likely to stopout) consider the impact of students' academic preparation on their likelihood of stopping out. The persistence literature consistently suggests that the more prepared students are entering college the more likely they will be successful (Astin \& Oseguera, 2012; Habley et al., 2012; Kuh et al., 2007; Pascarella \& Terenzini, 2005; Rosenbaum et al., 2006). Goldrick-Rab (2006) found that students were more likely to interrupt their enrollment the weaker their academic preparation. Therefore, I included variables measuring preparation to investigate the effects of each on stopping out and introduced them as a block in the multinomial logistic regression to represent students' level of preparedness.

The final set of hypotheses examines the impact of in-college experiences on the likelihood of stopping out. $\mathrm{H}_{9}$ : Students who live off-campus their first year will be more likely to stopout than students who live on-campus. Higher education persistence research continues to demonstrate that living on-campus increases persistence (Ishitani, 2016; Pascarella \& Terenzini, 2005).

$\mathrm{H}_{10}$ : Students in STEM majors will be more likely to stopout than students who begin in other fields. Studies have found that students were less likely to stay in STEM majors (Ma \& Cragg, 2013; Sulak, Massey, \& Thomson, 2017).

$\mathrm{H}_{11}$ : Students with higher university GPAs will be less likely to stopout. Barefoot (2004) found that the majority of students who took time off were not in academic 
failure; likewise, Stokes and Zusman (1992) found that students who stopped out later in their careers were more likely to be in good standing.

$\mathrm{H}_{12}$ : Students who receive more financial aid will be more likely to stopout. As stated above, interrupted enrollment has been found to be more common among students with fewer financial resources suggesting a need for more financial aid (Goldrick-Rab, 2006; Kim et al., 2012). Additionally, Nora, Barlow, \& Crisp (2006) found that having a higher proportion of loans increased students' likelihood that they would not return after taking time off.

To test each hypothesis, I ran binary logistic regression with all the covariates on the stopout outcome versus all other pathways grouped together to facilitate interpretation. Afterwards, I used MLR to compare the relative importance of each independent variable on each student pathway. The MLR provided a more nuanced understanding of how the predictors performed for each of the other student pathways in comparison to stopouts. After the MLR was ran, I computed predicted probabilities for the variables found to have a statistically significant impact between students who stopout and at least one other pathway in order to offer more nuanced interpretation.

\section{Limitations}

This study is a snapshot of two cohorts from one institution. The context specific nature of it provides rich perspective about the participants' contextual experiences, but limits its generalizability across institutions and student populations. Restricting the sample to students within cohorts limited the age range of the students in the overall stopout population due to the composition of City U's cohort populations. The traditional ages of the interview sample may also reflect them having more availability to participate 
in this study due to possibly more flexible schedules and fewer work and family commitments than older students. Additionally, the participants may have been more involved or integrated into the university and thus, more willing to share their stories to help another student at the institution. The interviewed students willingly shared stories of their experiences, but there is always the risk of social desirability influencing participants' answers. Since interview participants situate their responses within the social interaction and particular context within which the interview is taking place (Briggs, 1986), reporting bias may have transpired as the participants likely interpreted the meaning of their experiences through the consideration of being interviewed by a doctoral student. As with any sample of a larger population, sample selection bias may be at play in the current study leading to a limited interpretation of the social process of stopping out (Winship \& Mare, 1992). However, strong, consistent themes were found throughout the interviews and were used to develop the narrative of their experiences as thematic saturation was determined through the analyses of the interview transcripts after the 27 interviews. While the sample consisted of over $10 \%$ of the cohorts' enrolled students who had stopped out and returned, it may not be generalizable to all stopouts since not all invited stopouts participated in an interview. Thus, the students interviewed may not be representative of all stopouts within the institution. Additionally, the interviews were cross-sectional in that they took place at point in time during one semester of enrollment for the participants; thus, it is not known if students were successful in accomplishing the plans they presented in their interviews.

The quantitative data were provided by the institution from the student record system. This system had limitations that impacted the variable construction (such as 
developing the residence variable discussed above) as well as the type of variables available. For instance, there were very few variables available that related to students' campus engagement or experience other than living on-campus or off-campus.

Additionally, total financial aid received prevented a disaggregated investigation into the impact of various types (awards versus loans) of aid. Due to the analyses of five enrollment pathways, the numbers of students whose racial background was other than White became very small across pathways and therefore race was collapsed into a dummy variable of White and other. (White was chosen as the reference group because the institutional data included a category of two or more races that did not distinguish which two racial categories were included. While the two or more races could include White as one of them, I chose White as the reference group due to the size across enrollment pathways since the other race categories might have a higher underrepresentation proportionally due to the two or more races category.) Due to the low numbers in some enrollment pathways, my ability to look at the divergence of experiences for students from various racial backgrounds as well as the intersectionality of students' identities was limited. Closing the analysis window at 6 years is also a limitation resulting in a censoring error since if the timeframe was extended some nonpersisters would become stopouts, some stopout persisters would become stopout graduates, and some persisters would become graduates. Finally, as a single institution study, my findings may be limited to its context, but are potentially generalizable because they analyze the enrollment pathways of two full cohort populations. 


\section{Researcher Positionality}

As a college educated, White woman pursuing a doctoral degree whose career has been dedicated to access to and success in higher education, my perspectives influence my research interests and interpretations (Hesse-Biber, 2007). As the interpreter of my findings, I am part of my study and my perspective influences my interpretation (Charmaz, 2006). My perspective is informed by my background, my life experiences, and my professional experiences. Growing up the daughter of a father who was a firstgeneration college graduate and became a lawyer and a mother who was a college graduate from a long tradition of higher education including a grandfather who earned a $\mathrm{PhD}$ in physics, college was a given for me. I knew I was going to go to college from a young age. I do not recall feeling pressure from family or society to attend college as the path to a career; instead, I saw college as a natural part of my education.

My father's family struggled financially his whole life and he was determined to provide everything in his power to help his own daughters. Through his narrative, I learned that his education gave him the opportunity to live a more financially stable life that included cultural experiences in the arts and travel. Early on, I saw issues of equality and equity in my own educational experiences as I switched schools with varying levels of racial and socioeconomic integration. When I applied to colleges, I sought schools that offered majors in Black Studies and Education in order to study racial stratification in our society as well as schools and education specifically.

The transition into college was difficult for me socially and academically, but I was able to call home to talk through the challenges I faced and even built a mentoring relationship with the school's registrar at the encouragement of my father to help me 
succeed. During college, I worked for a college access and preparation program where I mentored middle and high school students who would be the first in their family to attend college. My formal education, work experience, and my father's story fueled a steadfast commitment to education as the great equalizer. I graduated in four years and knew I wanted to work in education, assisting students with increasing their own aspirations, improving their preparation, and gaining access to higher education.

My whole career has been geared toward access to and success in college. For five years, I worked with rural and urban schools and communities to improve their students' access to higher education through teacher professional development, tutoring, mentoring, and assistance with the college search and application process. As I saw firstgeneration students head off to college, I realized they would have to find their own supports at college, supports of which I was not certain were there. So, I switched my focus and began to work within higher education to improve the success of enrolled students. Since then, I have worked individually with students while also advocating to the institution to improve students' experiences.

My interests in stopouts began shortly after I became an academic advisor more than a decade ago. As I worked with students returning to college, I heard their stories of what led them to take time off, what they did while they were out, and what had changed in order for them to return. I heard stories of lacking purpose in college, stories of anxiety and depression, and stories of the need to care for a loved one. I noticed many of these students did not take many semesters off, yet were approaching their education very differently. I began to think about what institutions could do to help them stay enrolled or transition back smoother; this became the motivation for my dissertation topic. 
During my research interviews, I would find myself connecting to students' stories of personal struggle while also wanting to offer strategies to overcome institutional barriers. Sometimes their challenges would remind me of my own and sometimes their challenges would be ones that I could help with in my professional role. Throughout, I would have to remind myself of the importance of maintaining neutrality and letting the interviewee share their perspective without influencing it with my advice. At the same time, I sought to connect to students as a student myself and have brought in my own perspectives as a resource when interpreting the data in order to acknowledge my role in the research and overcome the challenges of objectification (Sprague, 2005). 


\section{CHAPTER IV: \\ QUALITATIVE FINDINGS}

\section{Analytic Sample}

In spring 2016, I interviewed 27 students for whom the median number of semesters stopped out was four. The number of semesters students took off ranged from 1 to $10 ; 5(18.5 \%)$ participants took only one semester off; $12(44.4 \%)$ took between two and four semesters off; and $10(37 \%)$ took between five and ten semesters off. The majority of these students identified as seniors and juniors, with 12 seniors (90 or more credit hours earned), 10 juniors (60 - 89 credit hours earned), 4 sophomores $(30-59$ credit hours earned), and 1 first-year (29 or fewer credit hours earned). The ages of participants ranged from 22 to 25 with a median of 23 . Most of the students worked for pay with only three not working at the time of their interview. Eleven (40.7\%) students worked up to 20 hours a week while $13(48.1 \%)$ indicated they worked more than 20 hours a week. Six (22.2\%) participants identified as first-generation as they will be the first in their immediate family to earn a bachelor's degree. Eighteen $(66.6 \%)$ of the participants changed their academic major after returning to the university. Table 2 displays demographic information, including sex, race/ethnicity, first-generation status, on-campus residency, and local residency status, for the respondent sample and cohort stopout population. 
Table 2

Sex, Race, and First-Year Residential Status of In-Depth Interview Participants

\begin{tabular}{|c|c|c|}
\hline & $\begin{array}{l}\text { Participant Sample } \\
n=27\end{array}$ & $\begin{array}{l}\text { Combined Cohorts' } \\
\text { Stopout Population } \\
\text { at Close of } 6^{\text {th }} \text { Year } \\
N=196\end{array}$ \\
\hline \multicolumn{3}{|l|}{ Sex } \\
\hline Male & $55.6 \%(15)$ & $60.2 \%(118)$ \\
\hline Female & $44.4 \%(12)$ & $39.8 \%(78)$ \\
\hline White & $66.7 \%(18)$ & $77.0 \%(151)$ \\
\hline Other & $33.3 \%(9)$ & $23.0 \%(45)$ \\
\hline First Semester On-Campus Residence & $40.7 \%(11)$ & $40.8 \%(80)$ \\
\hline First Generation & $22.2 \%(6)$ & $20.9 \%(41)$ \\
\hline Local Resident & $85.2 \%(23)$ & $55.1 \%(108)$ \\
\hline
\end{tabular}

My interview sample was similar to the overall stopout population with the most divergent factor being local residents who were overrepresented. The next largest difference was with the racial breakdown of the groups as White students were underrepresented and students of color were overrepresented in the interview sample.

\section{Introduction}

Two overarching themes emerged from the interview transcript analysis. The first theme, Psychosocial Barriers and Development, encompasses students' personal struggles during initial enrollment, specifically tied to questioning their enrollment, as well as their path toward self-authorship during their time away and upon returning. The second theme, Isolation and Integration, involves participants' initial challenges to integrate into the university's academic community followed by their improved connections and help-seeking behaviors once they reenrolled. While the students' experiences have been categorized within these two main themes, they do not fit neatly into them as each theme influences the other; thus, they are interwoven throughout the 
qualitative findings. Participants' psychosocial barriers and development were impacted by their isolation and integration at City $\mathrm{U}$ just as their isolation and integration was impacted by their psychosocial barriers and development.

The first section, Entering College: Limited Agency, demonstrates the influence of the college-for-all ideology as most participants said they enrolled in college because of parental and/or societal expectations and the majority described City $\mathrm{U}$ as their default choice for college due to its location in their community.

The second section, Enrolled but Not Integrated, shows how once enrolled in college, students struggled to integrate into the academic community as they described an overall feeling of not knowing why they were in college and lacked connections to faculty and staff. Almost half articulated choosing majors in science and engineering because of societal pressures and experienced academic engagement challenges in those fields contributing to academic uncertainty. Students experienced limited interactions with faculty and staff that resulted in feeling like the university did not care about them. While the majority of students described their initial enrollment as not successful and lacking academic engagement, only six identified as having been academically suspended from the university.

The third section, Deciding to Leave: Addressing Personal and Family Issues, explores students' reasons for stopping out, including how their difficulty charting an academic path often led to or was complicated by depression and anxiety. Of the 27 participants, only 4 identified financial challenges as contributing to stopping out. Another two participants transferred to a community college to complete general 
education requirements stating they could not justify the cost of tuition for courses they deemed of little value.

The fourth section, Taking Time Off: Opportunities for Discovery and Growth, describes how students spent their time not enrolled including working hourly wage jobs, traveling, and volunteering. These experiences allowed them to mature and determine for themselves how a college degree fit into their life's path. Many of the students shared stories of finding subjects of personal curiosity and investigating them on their own while others pursued various wellness activities including counseling and working out. Through this time, students developed a sense of improved confidence and focus, better health, and/or intellectual interests and purpose that led them to return to City $\mathrm{U}$.

The fifth section, Returning to College: Personal Choice and New Focus, explores how upon reenrolling and selecting majors of personal interest, students approached their role as a student differently and were excited to learn and engage in their studies. Students shared how they considered their relationships with others including their children, their siblings, or their romantic partners in making the decision to reenroll. Additionally, several students shared that their financial situation or approach to financing college had changed.

The sixth section, Succeeding in College: Personal Growth and Degree Completion, examines how students define success and finds that they have few regrets about taking time off from college. Upon returning, students articulated intrinsic forms of success and suggested that their time away allowed them to approach their college education differently. 
The final section, University's Role in Integration, examines how after returning, the participants not only engaged differently with the university community but also expected more from the university. Students described engaging with their faculty and academic peers because they were excited about their curriculum and academic community. Participants reflected on the positive impact institutional agents had on them prior to and after stopping out and argued that the university should take a more proactive role with their students from the beginning instead of assuming students will either figure it out or do not desire their support.

\section{Entering College: Limited Agency}

Participants decided to attend college because that was the expectation, especially from their parents. Instead of exercising agency in their decision to enroll in college, participants responded to their family's expectations that told them college was the next step after high school. Whether it was a means of social mobility or the maintenance of the family's status position, parents stressed that pursuing a college education immediately after high school was the only option. The majority of participants shared how they did not engage in a college search but instead chose City $\mathrm{U}$ because it was the local option. Thus, students lacked a commitment to the institution, which likely impacted their willingness to leave (Tinto, 1993). Students' family's expectations, their high school organizational habitus, and the higher education landscape informed both their decision to go to college as well as their selection of City U specifically (Perna, 2006). These influences informed them that college was the means to a well-paying job and thus, a necessity, so they selected the public university located in their community. Students' options were bounded by the limited information they had from their families 
and communities since they did not pursue an active college search nor benefit from college coaching (McDonough, 1997). Students' stories exhibit how they decided to attend college based on the external formulas constructed from their families, schools, and society (Baxter Magolda, 2009).

\section{The Obligation and Necessity of College Attendance}

The majority of participants $(89 \%)$ said they attended college because of either parental and/or societal expectations. When speaking about their parental expectations, about half disclosed the family obligation they felt to attend college immediately following high school as it had always been part of their life's narrative that they received from their parents. For these students, college enrollment was the next step in their life and they followed the path laid out for them. Students described their initial enrollment in college as a decision made by their families, often their father. Michael shared the expectation "my dad wanted me to go to school so I just did it out of obligation. There was no want to (attend college)." This experience with parent pressure was corroborated by Abe who entered as an engineering major and stated "it was ... beat into my head growing up. ... going to college when I got out of high school. That was just expected of me more or less. ... I was doing (it) ... to kind of please my dad." Johnny agreed, "it's just the expectation, it's just what's accepted, this is what you need to do (after high school)."

Several students suggested that their family's educational background played into their parents' narrative of how their life should progress. Tim's parents wanted something different for him, "my parents had been ... really big about going to college and finishing college. They both went to college and never finished so they really wanted me to go 
through." Three students who identified as first- or second- generation immigrants also emphasized the influence of their families' narratives for their lives including the pressure they felt to attend college in order to have a secure financial future. Jasmine, a second-generation immigrant whose parents hoped she would pursue a medical or law degree, shared: “my parents were like ‘... put all that work into school, then you come out you have a job that's great. You don't have to struggle the way we did.",

The expectation of college attendance was often coupled with an understanding that college was the gateway to a better career and life. In this college-for-all society, students are led to believe that a college degree is necessary for financial security without considering alternative paths to careers (Rosenbaum, 2001). This necessity makes a college education an obligation. Tyler went to college for "mostly just personal success. ... (a college degree) can help more so than not having one, so I honestly feel it's more like a paradigm obligation as opposed to a personal want." Sally shared Tyler's perspective "I had heard that you just can't get anywhere without a degree and ... I wanted more opportunities .... I realized maybe college isn't for everybody but it seemed like partially obligation and partially ambition." These participants felt that college enrollment was the only possibility for them.

\section{City University as a Default}

Most participants were ambivalent as to why they chose to attend City U. McDonough (1997) argues that students select their college from the information they gather through their social and organizational networks including their families, friends, and schools. Instead of describing a college search process, over half of respondents described City U as the default option since it was local. Matthew stated, "It was local ... 
so this is my first choice of university ... the only place that I applied." Melissa

considered other schools but said "It was in (town) so I was close to home... City U was kind of like a default option." Ally also saw City U as her only option since no one in her family knew much about higher education and "It was the closest and it offered a bachelor's program yeah, ... in all honesty, I wasn’t very picky.”

For several students, financial incentives played a role in selecting City U. Instead of conducting an active college search, three students selected City $U$ because they received tuition remission since their parents were employed there. Paul originally attended City U "because it was close ... and I got free tuition.” Julie suggested it was "the smartest plan for me to not go into a lot of debt." Likewise, Reggie suggested the financial benefit of the tuition remission was a "very convenient (way) to attend school for free in today's economy." This form of economic capital granted access to a tuitionfree college education and allowed them to protect their current and future economic capital.

Similar to tuition remission, receiving institutional scholarships also impacted participants' decisions to attend City U for both local (6) and out-of-town (2) students. Local scholarship recipients emphasized both the scholarship and the location to the school as impacting their decision to enroll. Tim was unsure what he wanted to do after high school but chose to attend City $U$ because of the expectations of his parents, it was in town, and of the scholarship he received, "I had no idea what I wanted to do ... but I did well enough in high school that I got a full scholarship for City U ... I didn't (apply to other schools)". Kayla was also local and applied to other institutions but decided on City U after she was offered a full tuition scholarship "I mean I was like 'well, they 
paying, it's just up the street'." Anthony received the same scholarship and had a similar decision-making process as Kayla stating "yeah, the home school, yeah, grew up here and ... got a scholarship." Similar to the embedded benefits of tuition remission, scholarships gave access to important economic capital to cover the expense of college while helping to protect current and future economic capital.

Unlike the majority of local students who chose City U because of its location, non-local participants identified the consideration of other factors in their college selection process in addition to receiving scholarships. Ronnie, an out-of-student, shared "they gave me a nice amount of money to come to school and seemed like a right fit for me and I like the sports. ... so, I just, I decided to come here." Peter, an in-state student from several hours away, decided on City U because "I had friends that I knew were going here and it was close to home, so I could visit.”

\section{Enrolled but Not Integrated}

Once enrolled, the majority of participants found that they lacked a sense of direction and purpose as to why they were enrolled and what they wanted out of college. This lack of goal commitment combined with the academic challenges they faced, made it easy for students to stopout (Tinto, 1993). Students' stories demonstrate a lack of integration into the academic system of college as they described questioning their major, a lack of connection to institutional agents, and struggling with their coursework (Tinto, 1993). Knowing the value of a college education, and not just as a credential, is a component of cultural capital that these students struggled to understand. Additionally, few participants indicated talking to their parents or to anyone at the university about taking time off; instead, they approached their options dichotomously as either they stay 
enrolled or not. This suggests a lack of social capital since they did not have a network to turn to for support to consider their options (Rosenbaum, 2001). During their initial enrollments, few students identified exploring majors or even reconsidering majors even though they were struggling with the ones that had chosen upon entry.

\section{Experiencing Academic Uncertainty}

Participants described feeling disconnected from their initial majors and the people in their majors. Almost half of the participants initially chose a science or engineering major due to pressure from their families and/or the societal belief that a STEM major was the best path to a job and a secure financial future. This indifferent approach to major selection and coupled with the rigor of the classes quickly presented challenges to participants' academic engagement that led them to question their paths and enrollment. Jack entered the engineering school his first year and suggested that he did not have the interest or motivation at the level it demanded since "first year ... was [long pause] ... a lot of work, ... it just felt very forced because like I said, I didn't really, I mean I wanted to be here, because I knew I was supposed to be here but I was just here.” Like Jack, Mary entered the university with a rigorous STEM major because she believed it was the best choice to a secure financial future, despite not being interested in the major:

I had no idea what I wanted to do. I knew then my major was (physical sciences) ... (laughs) I went for the first couple days and I was like "ok, this is not what I want to do.” ...but in today's world, you know, it's like pressure ... once you graduate high school, you go to college like that's 
just how it was, so I was there just to be there with no idea what I was doing.

Jasmine entered as a (life sciences) major with a pre-health profession emphasis due to pressures from her parents. In turn, she lacked the sufficient motivation to focus on her academics, "I definitely struggled, my first, my first semester, and definitely was not driven. Um, I wasn't sure what I was doing." Students entered City U with an ambivalence toward college and the work that was needed to be successful. The ability and wherewithal to navigate the academic demands of college are operationalized forms of cultural capital in that academic success is about both technical skills and social status or competence (Lareau \& Weininger, 2003). Thus, students were missing both the motivation and cultural capital to successfully integrate with the academic side of college.

\section{The Escape of Social Life}

Struggling to find academic direction and motivation did not always inhibit students from engaging socially on campus. Eight students that they used social life as an escape from academic struggles, indicating that they had a form of social integration on campus. Similarly, to Jasmine, Melissa entered the university with a STEM major due to parental pressure to become a doctor. When deciding to stopout, she planned to:

Come back but 'obviously this isn't the right major, but I don't know what the right major is' ... so I decided to take time off to just kind of figure out what it is that I was passionate about. ... My first year, I really struggled with my classes and I was drawing (sic) more into like having fun. 
Ricky's experiences were similar to Melissa's in that he enjoyed the social aspects of college while finding his first-year engineering courses challenging:

My first year at City U was great. I, I loved it. ... I joined a fraternity on campus ... none of them were engineers, so I kind of had a separate um social life than I did an academic life. ... I found um, the school challenging $\ldots$ but I enjoyed my social life and found school hard.

For these students, their social life distracted them from their academic struggles, but was not enough to keep them from stopping out. These stories provide support for Tinto's (1993) argument that some level of integration into both the academic and social systems of college is required for students to persist since social integration alone was not enough to keep these students enrolled. For many students, this uncertainty of direction was identified as the impetus for stopping out. The inability to consider other options or turn to an institutional network of support are examples of not having access to the necessary cultural and social capital to successfully navigate the university; instead, bounded rationality limits their choices in how to respond to their difficulties leading them to stopping out (Berger, 2000; Jack, 2016; Yee, 2016).

\section{Isolation from Faculty and Advisors}

In addition to finding it difficult to connect with their chosen academic paths, students also demonstrated a lack of academic integration through their limited interactions with faculty. Nine students described their perceptions that faculty lacked interest in them as individuals, which produced a view that the university cared little 
about their success. Jack took classes at a community college while away from City U and expressed how different his experiences were while enrolled there:

(At) City U it does not feel like they care about the students; ... it's kind of got this feeling like "oh well, you have to come here and you have to pay and we'll give you this degree." Whereas at (the community college) it's much more a culture of pushing the students forward. ... It is so much more focused on the success of students whatever their path may be.

Although Ricky did not transfer to a community college, he shared Jack's perceptions. After struggling in his engineering courses, he was moved into lower level courses and found that "once you step down a level you are on the fringe anyway and so, if you don't pick up the material at that point they just stop... caring about you." Julie expressed similar frustration with her instructors her first year, "I didn't have a lot of teachers that ... were interested ... in helping." These quotes demonstrate the social reproduction taking place within the institution as participants felt a distinct distance between themselves and their instructors and did not have a social network to turn to in order to navigate it.

Likewise, when describing their interactions with advisors, three participants described conversations not based on a relationship but instead, based only on the transaction of academic requirements. This lack of connection resulted in them not trusting their advisors. For instance, Michael found little value in advising because he did not have a trusting relationship with an advisor, "I don't trust people to tell me what to do or advise me. Because they don't know me." These interactions with faculty and advisors informed participants' experiences and suggested to them that the university was not 
interested in helping them. The lack of connection, and in turn social capital, meant that students did not see institutional agents as members of their network for which to turn to for assistance.

\section{Lack of Success: Academic Suspension}

In contrast to the majority of the respondents who reported stopping out based on their own decisions and personal circumstances, six respondents indicated that they took time off due to academic suspension. Lea, a second-generation American who entered college due to the expectations of her parents, was suspended after her third semester as a (life sciences) major:

So, I ended up taking time off because my grades were suffering. ... I went head first into something that I wasn't prepared for and ... I guess I let peer pressure kind of get to me ... my grades suffered mostly in my science classes.

After struggling with study skills and time management, Johnny was suspended following his second year because "I didn't put enough effort into it. ... I wasn't disciplined enough academically. Um, so it really put a damper on things about like 'oh, what am I doing with my life?"'

Similar to the students who were not suspended, those who were not allowed to enroll for one to two semesters due to suspension did not look to the institution to provide them support as they figured things out, suggesting a lack of connection to the institution. Participants lacked academic integration and did not have access to the social capital necessary to strategize with institutional agents prior to or during their suspension 
(Rosenbaum, 2001; Stanton-Salazar, 1997; Tinto, 1993). When describing what led to their departure, the majority of students focused on their experiences within college including their uncertainty, concerns over the costs of college, and academic challenges, following Tinto's (1993) assertion that one's integrative experiences within college are the primary influence on persistence. Thus, students' lack of integration within the institution made it easy to discontinue enrollment.

\section{Deciding to Leave: Addressing Personal and Family Issues}

While students entered college due to the expectations of external authority, they departed college as an exercise of their own agency. During their initial enrollment, participants' struggled to understand the purpose of college to them personally, which led to discomfort and the questioning of why they were even in school. This discomfort intensified as students were at a crossroads and realizing that they did not have to follow the external formulas laid out for their lives, but that they had not yet determined what they personally wanted for their paths (Baxter Magolda, 2009). Once they left the daily influence of the external voices of authority and began questioning their own purpose and identity, they found it to be uncomfortable and unsettling. One's exploration of purpose and identity can lead to anxieties "that are exacerbated without a solid foundation of commitment" (Sumner, Burrow, \& Hill, 2015, p. 52). During the self-exploration of emerging adulthood, debating the role of college in one's life is part of the process but the lack of commitment to college and uncertainty in one's path may result in departing from college (Arnett, 2004). Students were at a crossroads wherein they still felt the external pressures but where also able to hear their internal voice that suggested they explore other options outside of college (Baxter Magolda, 2014). 
At this crossroads, participants faced challenges that interfered with their commitment to college and they chose to take time off instead of seeking assistance from City U. For 13 students, they faced uncertainty and had to figure out what they wanted out of college for themselves. For others, they had to overcome mental health issues. And still others had to work through challenges within their family or in their personal lives. Tinto (1993) argued that institutions should orient themselves toward being active actors in students' lives, which includes offering support to students as they work through educational uncertainty, mental health issues, and other personal challenges in order to limit student departure. He went on to argue that "for most students the impact of external events upon institutional departure is secondary to those within the college" (p. 129) such that when students are connected to their college they will turn to the college to navigate challenges, but that it is when they are not connected that they decide to leave to address their personal, family, and financial struggles. Participants' decision to leave was bounded within the options they thought to be available due to the cultural and social capital they had, or did not have, available, to them (Berger, 2000). While City U offered counseling for mental health, academic exploration, and career decision-making, most participants were either unaware of these services or unwilling to engage in them at the university.

\section{Mental Health}

The challenges of the uncertainty and lack of personal commitment to college was often linked to students' mental health and almost half disclosed experiences with anxiety and/or depression during their initial enrollment. Some described it as merely linked to their lack of direction while others identified the lack of direction as the root of the 
anxiety and/or depression. Whether the anxiety and/or depression was linked to - or the cause of - them, participants acknowledged that they discontinued their enrollment because of them. Tim, who changed majors several times prior to stopping out, left school during his fourth semester and was "in a weird place kind of ... trying to figure a lot of things out ... not knowing what I really had wanted to do; the whole crisis of like thinking 'why am I in school? ... What do I even want out of school?'” During the term Tim withdrew, it was the first time he had struggled academically:

I was just in a bad spot with how, like how horribly I was doing in school. ... there was this one day that I ... woke up and I just couldn't bring myself to go to class. ... I just got on my computer and I just withdrew from everything. And I was just like "I'm done" and you know it all, it happened very quickly... and ... it was like a huge weight had lifted.... it's kind of hard to say ... but yeah, ... I was a bit depressed at the time.

Julie struggled with depression and felt intimidated by the university environment. She was uncertain about what she could do with a (social science) major and was not sure where to go for help, so she chose to leave:

I also was um, dealing with ... some depressive issues, ... and I just didn't know anything about City U really. I didn't know who to talk to at all. I didn't feel like anyone was really interested in answering my questions because I would try to talk to people, ... I just was always being rerouted to someone else, you know. So ... I just kind of dropped everything. 
While questioning his academic path and purpose in college, Ronnie experienced an existential crisis leading him to take an extended break for three semesters:

I needed time off just to think about what I wanted to do. I didn't know if college was right for me still. ... I figured it would be smarter to take time off than to keep going and not do so great at something I didn't know if I wanted to do and waste the money. ... I was battling a lot of anxiety and what my therapist (later) called ... depression and an existential breakdown. ... The anxiety got pretty bad and I couldn't really go to class anymore. ... So. I figured it would be best for me to take a mental break from all the pressure of college.

In addition to dealing with anxiety and depression, three students shared that they struggled with other mental illness diagnoses including bi-polar disorder and dissociative identity disorder. All three illustrated the difficult process of finding the "right" medication and the constant work it takes to manage school and their mental health. For example, Ally was diagnosed soon after she stopped out, "so now thanks to medication, I'm a little bit more balanced and it improves my thought process ..., but it is still an experimentation, so whenever medication is semi-right it really helps as far as academics go.” In sharing their decision to take time off or leave the university, over half of participants disclosed that their mental health impacted their college enrollment and experience while others faced external challenges. 


\section{Family and Personal Issues}

In addition to mental health issues, family issues challenged students' ability to focus on school for seven participants. Abe talked about how issues in his family were "like a whole crazy, uh if you ever watch Game of Thrones ... where there's a whole bunch of like subplots that like tie into one." The "subplots" included his father's alcoholism and unemployment as well as his parents' eventual divorce, which diverted his attention from school; "I ended up (with) like depression ... I ended up having to um drop out ... cause ... I just kind of lost the motivation to go to school."

Candice, while academically focused and motivated, decided to take a semester off to deal with issues related to her parents' divorce, "I took time off for ... major family problems, ..., it was too stressful and between working and dealing with all these problems I knew all that I would be doing is spending money for Fs." In addition to her mental health issues, Ally struggled both with not knowing why she was in school and tensions at home due to her parents' volatile relationship:

I knew that I wanted to go to school; I just didn't know ... what I wanted to do, the type of degree program. ... um, I really honestly decided to make that decision (to take time off) after I just, I tanked in classes and I just wasn't interested and I had no drive. I ... had so much going on with my parents at home, my primary goal ... became just getting out of the house versus getting an education.

Participants faced other personal challenges, such as the loss of a loved one or being involved in an abusive relationship, that interfered with their enrollment and for 
which they sought supports outside the university. For instance, Anthony was struggling academically and facing his grandfather's terminal illness, "my grandfather, he was getting sick, he had cancer, you know that was pretty stressful... he ended up passing away." While struggling with low academic self-efficacy, Mary was in an abusive relationship that took a toll on her mentally, "It was ... an abusive relationship like emotionally. ... And I like didn't go to class a lot. Um, I withdrew from a lot of classes and I was really shy at the time and I had really low self-esteem.” Sara, who went to college because of her family's expectations, began to spiral downward academically and mentally after she was sexually assaulted:

That like changed like the whole way I looked at school ... that was spring semester and I remember my uncle died like a month later and I was like failing all my classes and I couldn't tell my parents ..., so, I was like "well, I just got to act like everything is ok."

Sue was the only participant to identify a physical health issue as one of reasons behind her decision to stopout: 'I was really frustrated, because I felt like I've been in school for five years and I'm not getting anywhere. ... And some of it was my health too, ... and just my (illness) was flaring up really bad."

\section{Finances}

Though students were not asked specifically about finances, six interviewees distinguished finances as one of the reasons they took time off from City U. Only two students stated that finances prevented them from persisting while four others decided that the expense of college was not worth the return-on-investment. For instance, as an 
out-of-state student, Jim struggled to cover college expenses stating "I couldn’t pay for anything. So, um, I would try to get any loans or whatnot and loans was something that ... I didn't want to do because I didn't want to have to pay loans after school was done." In addition to Ronnie's and Candice's worries about not doing well and wasting money due to personal issues discussed above, Abe and Jack expressed that taking general education courses at City U was not worth the financial expense. Abe reflected, "I was doing a bunch of gen ed classes like 'why am I doing these at City U when I could be doing them at (the community college) and saving a lot of money?"' Jack shared Abe's concern over the cost of City $\mathrm{U}$ and decided to finish his general education courses at the community college due to the university's approach to general education:

The apathy of gen ed type classes ... it's just the atmosphere that nobody cares, the teachers don't care, the students don't care, so why should I care. ... Before I waste any money, I really need to figure out what I actually want to do,.. because $\mathrm{City} \mathrm{U}$ is so expensive.

For these six participants, access to and the value of economic capital influenced their decisions. For a couple of students, it was the lack of access to economic capital while for others it was a desire to protect the economic capital they had that contributed to their decision to take time off.

\section{Stopping Out: Opportunities for Discovery and Growth}

As traditional-aged college students, the participants were experiencing emerging adulthood, which is characterized by the exploration of self, love, and work as well as the ambiguity between adolescence and adulthood (Arnett, 2004). The way participants 
described their time leading up to their stopout with a lack of agency in that they were not actors in their decision to enroll in college and for many, in their choice of major. They were in college because they thought they were supposed to be and, while these things were happening to them they were not sure how to address them. This created instability, one of the key features of emerging adolescence that demands that they revise their plans (Arnett, 2004). Instead of taking in the information as they found courses they disliked or identified academic areas in which they struggled and revising their plan within the university, they pulled away from college, exploring the world outside of higher education. Through this external exploration, participants made their own decisions, increased their self-awareness, and found their way back to City U. While not enrolled, participants began the process of turning to and trusting their internal voices as they made decisions about their life's path (Baxter Magolda, 2009). Students learned about themselves through hourly jobs, service and travel, personal wellness, and uncovering areas of interest. The self-exploration and experimentation with various possible selves allowed them to define what a college education would mean to them as well as helped them develop a sense of self-efficacy that they could be successful.

\section{Hourly Work for Pay}

The majority of participants spent their time away employed in hourly wage jobs, which allowed them to learn about the world of work as well as about themselves. Through paid work, participants were able to consider what they wanted to do while also exploring skills they had to offer (Arnett, 2004). Due to the low pay and monotony of the work, these experiences helped them realize that they did not want to continue this type of work for the rest of their lives. Instead, students decided they needed a college degree 
to change their path. For example, Matthew took time off because he had lost interest in school and developed uncertainty about his path, "I did a lot ... of hourly wage jobs and honestly, ... that really gave me a lot of motivation to come back and just work my butt off to get it done." Sue worked at a grocery store while out, which gave her the opportunity to take a break and consider her path:

I mean I had to come back; I don't want to work at (large chain grocery store) for the rest of my life. ... I was just like "take a breather, and realize ... that yes, this is what I want to do; yes, this is why I want to stay in this degree. I just kind of need a little vacation and refocus."

Like Sue, Alex wanted more for himself than what he was experiencing in his job. While working $3^{\text {rd }}$ shift at a logistics company, he realized "there was just nothing going on in my life that was really making me passionate to continue being a blue-collar guy... I don't hate it but I wanted something more. I wanted something, mentally, intellectually stimulating." Similarly, Tim felt stalled in his life while working in the food industry. After taking a year and a half off, he started thinking about returning; "I realized I wasn't doing anything being out of school. Wasn't really moving toward anything. ... I didn't have any goals ..., so I started thinking about ... going back (to City U)." Likewise, Abe realized that working two fast food jobs was not what he wanted long term:

I mean ... the struggle that I went through ..., kind of made me look forward a little harder and think more deeply, like big picture, like what is my life gonna look like.... The experience with like trying to make a life without a college degree, ... just working two part-time jobs, it's just not, it's not fun, it's not something I really want to do (laughs). 
Unlike most participants, Paul found his hourly job to be a good job in terms of pay but he had to work over 40 hours a week in a physically demanding job which "helped push me ... toward wanting to go back to school cause it was a good job but I don't want to do physical labor for the rest of my life."

In addition to figuring out what they did not want to do, four reflected on their realization that they had transferable skills, specifically interpersonal skills that were of value in the world. Michael found a sense of confidence in his interpersonal skills while he worked three hourly jobs simultaneously, "because I actually got to meet people and ... interact with them, even though it was on a superficial basis ... and a lot of people actually turned out to like me." While working in the cosmetology industry, Jasmine enjoyed talking with her clients and realized the benefits of "having that one-on-one interaction with an individual, ... definitely built up a lot of skills I didn't know I had. ... I, um, learned a lot about myself." Even though she enjoyed her positions working frontline with patients in medical offices, Ally realized she wanted to be able to have more variety in her work, which "gave me more motivation to actually go back to school and do better. ... I really love the patients but the job itself gets very monotonous and ... I kind of found myself just wanting more." Through work, many participants reexamined their paths and what they had to offer. They were able to build skills and learn about themselves, which helped them see that a college degree could help them achieve their potential.

\section{Service and Travel: Personal Exploration and Development}

While not enrolled, four participants engaged in other experiential opportunities, including volunteering and traveling, that allowed them time to think about who they 
were and what they wanted to become. These types of opportunities expand identity exploration further by taking one outside of their comfort zone to learn about themselves, others, and the world (Arnett, 2004). For instance, toward the end of his first semester not enrolled, Ronnie decided to join a national volunteer program where he tutored math in a high school several hundred miles away from City U In addition to helping him determine that he did not want to become a teacher, he expressed "that year changed my entire life because I learned so much about so many different people and so many different ways of life." Similar to Ronnie, Peter moved across the country for a service opportunity, serving a lengthy mission with his church. During this time, Peter developed skills and learned about himself allowing him to commit to school on a deeper level when he returned:

I learned how to study a lot better. ... Um, I got to learn a lot about myself and as a person and as a student ... and so suddenly I understood the value of knowing a lot about a subject and ... the satisfaction of being good at something. ... That kind of motivated me to, to be a better student when I got back to school. ... Um, I came back with a very different mindset ... when I got back I felt like an adult.

While Ronnie and Peter moved across the country for specific opportunities, Reggie and Melissa traveled for other reasons. Reggie traveled and worked while putting his creative skills to use:

Developing like two clothing companies at the time, shooting like lookbooks and ... directing music videos, editing, ... and just like traveling, 
shooting photos, partying, you know but like capturing ... everything. ...

Uh, I loved working, I liked expanding ... my, I guess, abilities.

Similarly, Melissa learned about herself through a year of traveling as she experienced the world with a boyfriend:

I just kind of lived like pretty different than I ever experienced. ... He did graffiti ... it also exposed me to a (another) side of ... the world ..., we would go to like very impoverished areas in the city, $\ldots$ and I saw drug addiction. ... I think like that whole year, I just grew up so much.

Similar to hourly work, service and travel allowed participants to learn about themselves, think about the world, consider their paths in life, and decide that they wanted to return to their education. A college education and a career became some of the possibilities that participants began to see through their exploration as emerging adults. These were no longer seen as obligations but were seen as opportunities characterized with hopeful anticipation (Arnett, 2004).

\section{Personal Wellness: Physical Fitness and Mental Health}

In addition to the possibilities explored through work, participants discovered different versions of themselves through physical fitness and mental health counseling. By focusing on themselves, students were able to consider who they wanted to be and what they wanted in life. These reflections are key components as they move toward adulthood wherein they began to listen to their internal voices as they self-authored their lives (Baxter Magolda, 2014). Half of participants stated that focusing on their personal wellness (physical and/or mental) while they were not enrolled helped them find their 
way back to school. By taking care of their physical health, seven participants were able to develop confidence and direction in their lives while developing skills they found to be transferrable to being a successful college student.

After traveling, Melissa decided to focus on her health, which led to her new health-focused major:

I started eating really healthy and I started focusing on myself and I started ... bettering my physical self and my mental self. ... I fell in love with health ... like the preventative side of health and how I could get people to kind of be like better versions of themselves ... and so I found my passion during that year off, completely.

Jasmine had a similar experience with wellness that led to a health-focused major. Jasmine started focusing on her health at the urging of her mother:

She got me into more yoga. ... And I was like "this is pretty cool" ... this is a pretty awesome workout. ... And like if I'm good at this maybe I'm good at other stuff. ... I was feeling better about myself and I was finding a, I don't want to say a purpose, but something ... that made me feel good.

In addition to confidence and purpose, participants developed discipline and persistence through their workout routines that they were able to apply when they returned to school. Prior to his volunteer work, Ronnie worked at an athletic store and began dieting and working out through which he developed discipline and structure that helped him improve how he felt about himself: 
When I first got home I was a mess, but then I started fishing, started rock climbing ... I was ... dieting and getting in great shape.... that kind of got me in a much more organized way of life and it made me start to um, feel good about everything again and I was working out so I just felt good in general so then my whole life eventually outside of school turned into working out, cooking, dieting, fishing, and rock climbing, and work ... (and led to) my healthier mental being.

Some participants, including Ronnie, combined working out with counseling during their time not enrolled, while others focused solely on counseling. Through counseling, six students were able to manage their negative thought patterns, address things they had been avoiding, develop personal goals, and develop strategies to more effectively deal with stress. After being sexually assaulted, Sara struggled in school and decided to focus on her personal wellness after an academic suspension:

I was like, "I got to do something," so I went (to) ... counseling, I worked out, I worked a lot ... I like opened up to my parents about what had happened to me and I was just at a better place. ... I kind of like focused on myself and ... internal issues and just like with self-esteem and selfworth stuff like that.

Through exploring their struggles in counseling, two students had therapists who suggested they be tested for attention deficit disorder (ADD) during their time not enrolled. Julie explained: 
I was also diagnosed with ADD, ... so that may have really contributed to what was going on. Um, I don't take medication for that now, um, but I still go to a therapist and I just, well, I just take less course hours, just because ... I know I need to give myself space, you know, I know how I work, I know that I'm easily overwhelmed.

Prior to their diagnoses, both students felt like they did not belong in college. Once diagnosed and through counseling, they were able to understand their challenges in school and that they had to adjust their approach to school in order to succeed.

\section{Intellectual Awakening: Finding Interests and Purpose}

As discussed above, over half of the participants described a lack of academic direction and connection to the university during their period of initial enrollment. Upon reenrolling, 18 participants changed their major. For almost half of the participants, their experiences while not enrolled led them to an intellectual awakening as one of the components to developing a better sense of self. Identifying and clarifying one's area/s of interest are central factors to the exploration of self and possibilities done during emerging adulthood as one forms and revises their life plans (Arnett, 2004). For some participants, this clarification included having confidence in their long-held areas of interest and for others it meant uncovering a new area of interest. Either way, they uncovered new possibilities that a college education could provide them personally.

Through their emphasis on their personal wellness while not enrolled, prior quotes identify how Melissa and Jasmine found their intellectual passions and decided to pursue health-focused majors once they returned. Similarly, Tyler decided a health-focused 
major would be a better fit than his original major in engineering after he began competing in body-building competitions. He has "always been fascinated by the human body ... and now at this point I am like ... I don't even care about money any more I just want to be happy doing what I am doing."

While working his hourly job at a gas station, Michael began reading classical philosophy and literature, which led him to become a (humanities) major upon returning:

I was reading Plato, and the back of it had the entire Greek alphabet in it, so I just memorized it. ... I got really interested in grammar and how things are put together. I like puzzles and ... I like to break things down and analyze them ... that's really what's helped me get motivated ... once I started to learn about ... how language is put together.

Similarly, Paul's intellect was stimulated while not enrolled. During his time off, Paul began doing research to understand his new area of interest, which led him to return with a (life sciences) major:

I became a born-again Christian, then the (Ken Hamm/Bill Nye) debate happened and I was like, “ok, I mean, I know Ken Hamm’s wrong and Bill Nye's right, but I don't really know why" because I couldn't actually defend that on my own. So, I started researching things like evolution. ... I just saw a perspective that I didn't know existed and it resonated with me far more than anything I've ever heard. ... I was finally like investigating science stuff for the first time ever and I realized it was just like (mind blowing hand motion with a blasting sound), "this is so cool, I love this 
all.” ... I just realized, “ok, I think I have a reason to return now, I want to learn this."

Tim, who returned to school to pursue an engineering major, also mentioned the impact the work of popular scientists had on him:

Being out of school, I read a little bit more and I started to pick up some, um, just science related books ... I picked up some Carl Sagan books ... he talks about the universe in almost a romantic way, and ... (he) kind of helped instill a wonder for the universe kind of thing in me.

Likewise, Julie reflected how reading things of interest and doing her own research led her to a (social sciences) major:

I also was really getting into um, like personality stuff, ... just how different people learn, how different people interpret information, how different people react to things. ... I read everything about it and I couldn't stop. But I guess when I realized that like there was something that I was like really passionate about, um, that also made me really want to go back to school because I just wanted it to be more than a hobby.

These participants discovered new areas of interest while out, but three other participants switched to majors they had initially not chosen because of a fear of not finding a financially stable career. For Reggie, his family did not want him to pursue a (humanities) major, but after returning he listened to his internal voice determined "well, if I'm going to get a degree this is what I'm going to get cause I took two years off." 
After watching her parents struggle with money, Ally initially chose a (life sciences major) as something "sensible" in order to have financial security instead of following her dreams. However, through her time away, Ally decided to pursue her love of (the humanities) through which "I feel a lot more comfortable and I know that this is what I'm going to do. I mean I cannot imagine myself doing anything else at this point." Similar to Reggie and Ally, Mary returned to the university committed to becoming a teacher, which she did not initially select due to societal pressure to pursue a major with higher financial earnings potential:

I'm a lot older now than I was and I was like "ok, I want to do something that I love." And um, I've always like had a passion for history, ... ever since I've been back, I've made like straight As and it's because, it's not because um, necessarily that I'm smarter now..., but it's because I actually want to be here. ...I'll be the first one to raise my hand to answer a question or to go to the professor if I have any questions.

Upon selecting a major of interest, whether a new subject for them or committing to a long-held interest, participants engaged differently with their studies and their role as a student. They sought to become active participants in their academic lives leading them to integrate into the intellectual community at City U (Tinto, 1993). In addition to being engaged in her classes, Ally found better social integration on campus when she returned as she explained "I will say that once you do find the major that you really want to get into, you find a lot of people that you can relate to a lot more. ... It makes me feel more at home." Participants' stories emphasized the importance of listening to their internal 
voices when selecting their academic path. Doing so aided in leading them to academic integration and better social integration.

\section{Returning to College: Personal Choice and New Focus}

Through imagining and experimenting with various versions of

themselves while not enrolled, participants considered their possible lives, revised their life plans, and decided for themselves to reenroll in college (Arnett, 2004;

Baxter Magolda, 2009). The growth they experienced during their time away allowed them to listen to their internal voices. These internal voices had shifted the meaning behind their college enrollment as they became self-authors of their own paths (Baxter Magolda, 2009). Their new perspective allowed them to look at college differently, as something they were doing for themselves and not just to meet other people's expectations.

\section{Personal Value in a College Education}

Seven students described how they decided a college education was important for their personal plans. For example, Abe suggested that experiencing life and work while stopped out allowed him to make a "more informed decision of ... college is really something I want to do." Through her personal relationships and counseling, Sara took the time to explore what college meant to her instead of thinking about what it meant to her college-educated family:

I had to work on ... "why do I even want to be in school? Like why is it that I want to graduate? Is it because of my parents and my extended 
family? Or is it because of me?" so once I ... unraveled that, I was like "well, then I'm going to go back."

Matthew carried the pressures from his father during his initial enrollment at City U, but upon returning he felt a personal sense of motivation and responsibility, sharing, "I still want to make my parents proud of me, but at this point the motivation is coming more from within." By taking time off from school, students grew as individuals and developed a sense of ownership of their goals. They became actors in their paths as they developed skills to apply when they returned to college as well as developed a purpose that drove a more mature approach to their education. Participants discussed at length how their discipline, focus, and work ethic had changed since reenrolling; they now had their own goals and the drive to achieve them.

\section{Remaking the Self: Growth and Maturity}

The majority (22) of participants suggested they were different after taking time off including having grown up, developing confidence, and taking care of their own business instead of partying or ignoring responsibilities. As emerging adults, participants described how their time away from City $\mathrm{U}$ was a self-focused time wherein they were able to develop the self-sufficiency necessary to make their own decisions and standalone along their paths (Arnett, 2004). This self-sufficiency includes skills, financial responsibility, and mature relationships. Almost half of the participants refined their social circles as they focused on their future. Refining relationships is an aspect of selfauthorship as one works toward developing an internal foundation that guides one's path and how one spends their time (Baxter Magolda, 2008). For example, Abe returned to school more focused on academics and goals than on his social life: 
I just really kind of buckled down and it kind of helped to be older, a little more mature, and think a little more deeply about the future. ... I didn't want to party every weekend. ... It just wasn't fun anymore and I kind of wanted a more serious outlook on life. ...more attention to goals and how to attain goals rather than just like what am I doing today, what am I doing this weekend.

Similarly, Julie's new outlook on life was shaped by her time out, allowing her to prioritize her time and redefine her relationships:

I had that moment where I was like "I need to get serious" and that really applied to like not spending time with people who weren't also serious or who didn't respect that I was trying to be serious or like who were just like bad influences or ... negative energy. I didn't need people who were gonna be in my way.

Jasmine also realized that she would rather be serious about her life instead of focusing so much time on partying. She reflected "I just kind of took a step back and was like, 'ok, I think I'm done' and ... it just kind of clicked in my head, 'it's time to get serious now, you've had enough time of having fun.'" Likewise, Ronnie changed his approach to his social life upon returning and prioritized his education choosing to "limit my distractions now. ... I'm older. I think I'm a little wiser. ... I'm just smarter with my decisions and just not the raging buck that I used to be back when I was a freshman.” The participants above changed their approach to school, returning with new focus, personal motivation, and the ability to make better choices as more self-sufficient individuals. For many 
participants, their growth and new approach to their education was also influenced by their personal networks.

\section{Mature Relationships}

In making their decision to return to school, nearly half of the participants shared the encouragement they received from romantic partners, family members, and mentors, as well as the influence of being a role model to their children or younger siblings. Though these relationships influenced their decision-making, the participants emphasized making their own decisions to reenroll instead of it being made for them as it was during their initial enrollment. Upon returning, while their own desires were at the foreground of their decisions, they thought differently about others' influences on their decisions as they were developing interdependent relationships (Baxter Magolda, 2008; Kegan, 1994). Participants used these close personal relationships, along with professional relationships with therapists, to identify their own intrinsic value in school, recognize that they could be successful, and reinforce their motivation to return.

Serving as a role model to their own child or a younger sibling was described by five participants as part of their motivation to return to school. Upon entering college, Tyler was focused on finding a job where he could make the most money in order to provide the best life for his son whom he had in high school. After taking two semesters off, Tyler returned with a different focus pursuing a major of interest after "something just clicked one day, you know, I was just like 'alright, I'm not happy with this anymore and I want to be a happy person for my son."' Both Mary and Kayla found that having a child after stopping out helped to motivate them to return in order to better support themselves and their children. In addition to the inspiration from their children, both 
Mary and Kayla stated how others helped them return to their college education. Mary found support from her mother and boyfriend, "They were both super supportive. ... So, that kind of helped me be like 'ok, then I'm going to do this because I need to, it will be hard for a few years, but it will be worth it." Kayla's older sister was both an inspiration and a guide when it came to her returning to college. She described her as "my advisor ... she's honest. ... she's the one that I talk to when I'm making big life decisions. ... and she'd always say “if I knew you couldn’t do it, I never would have encouraged you."

After taking a semester off due to academic suspension, Lea found motivation in a new major that kept her interest as well as in her relationship with her younger sister:

I think what really put things in perspective for me was that there's somebody else that's there to look up to me and if I'm doing something like this then it's setting a bad example for her, ... like I want her to go and succeed ... and like I'm being a bad role model ... and I think that kind of helped me set my priorities.

Likewise, Jasmine also left the university on academic suspension and talked about how her relationship with her younger sister was a motivating factor for her to return; "I don't want her to make the same mistakes I did and ... I, I felt like just a bad, a bad role model for my sister."

Six other participants identified how close relationships helped them think through their decisions and helped them plan to return to City U. In addition to his girlfriend's influence, Anthony emphasized the inspiration of his closest friends' graduation on his want to return; "Seeing your friends move on and seeing yourself like, 
you know, 'I'm not, I'm not there,' it really opened up something in me to want to get back." Tim found inspiration in the example set by his fiancé:

(She) was a really big influence on me going back in. ...she's a go-getter you know.... She's just rubbed off on me in so many good ways I think. ... she didn't really even push me at all to get back in school, just being around her ... she's just like such a crazy hard worker.

Unlike how participants described the impact of other's expectations when they initially enrolled in college, these participants utilized their relationships to assist them in making their decisions about school instead of those relationships making their decisions for them. Through their relationships, participants were able to reflect on who they wanted to be both for themselves and others in their lives.

\section{Financial Support and Responsibility}

While few participants mentioned that financial issues contributed to their decision to stop out, nine identified that changes in their financial situation helped make it possible to return to City U. Becoming financially independent is one of the top three criteria for adulthood and participants were able to move through some of the in-between feelings of emerging adulthood through their more mature attitude with the financing of their education (Arnett, 2004). Matthew and Jim strove to relieve their parents of the financial burden by finding a way to pay for school on their own. Matthew reenrolled when a friend told him that a logistics company was hiring and would pay his tuition, "I ... told my father that I was done being a bum and taking his money, so if I could find a way to go back to college on my own, no matter what it took, I was going to do it." Jim 
also found tuition support through his employer, which he used to release his mother of the financial burden of his education. He found that during his time out, he learned to think about money differently sharing “you don't realize um, like the importance of the money that you're using until it is actually yours."

While Jasmine decided to continue to work for her family business, she decided that her education was her responsibility and made a five-year plan within which "I would move home, I would ... start school back up, ... pay for my own school, so I know, like 'if you don't do well, it's your money, it's literally your loss." While Mary's parents provided financial support when she initially enrolled at City $U$ they did not offer it to her when she returned; however, Mary's financial situation had changed 'because I had a kid, I was finally able to file for FAFSA and be like an independent, ... so that's a big thing, because obviously, if I didn't have him, I'd have no way of really paying for it." For these participants, they were able to be self-sufficient when it came to covering the cost of college.

While working and exploring possible paths, a couple of other participants inspired financial benefactors who supported their return to school. Michael was very close to his grandmother and lived with her while not enrolled in school. His grandmother's childhood friend offered to fund his education, “my grandmother's neighbor..., he doesn't have any kids, so he offered to pay me, to fund me." Similarly, Ally's in-laws were extremely supportive of her returning to school as was her husband's grandfather who offered "if you get your grade point average a certain level, I'll even pay for school for you." The participants who shared how their changed financial situation 
influenced their return saw themselves accountable to either themselves or their benefactors instead of taking the financing of college for granted.

\section{Succeeding in College: Personal Growth and Degree Completion}

After returning to City U, participants were able to define success in college for themselves rather than for others as they listened to their internal voices instead of uncritically following external formulas (Baxter Magolda, 2008). As opposed to only focusing on earning their degree, participants now defined success in college through their personal growth. Participants shared how they had changed over the years and expressed appreciation for their growth. The intellectual, social, and self-regulating experiences during emerging adulthood help individuals gain maturity and direction (Arnett, 2004). Participants recognized that not only were they earning an important credential but they were developing skills and a network that would help them succeed after college.

\section{Intrinsic and Extrinsic Success in College}

When asked about what success in college looks like, participants often put more emphasis on intrinsic forms of success, though they described both intrinsic and extrinsic forms. Participants identified becoming more well-rounded and growing as a person, gaining knowledge, and the feeling of accomplishment as their intrinsic successes, while earning good grades, making others proud, and receiving the credential were extrinsic successes. Similar to Lehmann's (2013) finding of successful students shifting their focus "from a relatively utilitarian, career-focused to a more learning-focused attitude toward university" (p. 6), participants shifted away from seeing college as a means to an end and 
the fulfillment of their families' expectations of them. They now found personal meaning in their college education and focused on more intrinsic benefits. Abe defined being more well-rounded as "learning about yourself, learning about ... things that interest you, but doing it well, making good grades, making connections that are going to carry you through life." Similar to Abe, nearly half of the participants discussed both intrinsic and extrinsic forms of success including Candice who agreed that learning and grades go together for her; however, she placed more emphasis on retaining what she learned about the multiple languages she was studying; "definitely grades obviously, ... but particularly, actually retaining what I'm learning ... if ... I can actually remember all the grammar structures I'm working with then that is success to me." Julie also strove for good grades, but found that success is more about the intellectual and personal growth she experienced as a college student:

For me, success means graduating with a 3 something (GPA) and going to get a master's degree or at least having made the connections with people that if I want to, there are people who could, you know, help me out with that. ... I feel like college has helped me become more of an adult and like I've learned a lot ... like critical thinking ... that is ... irreplaceable and completely necessary to be a good citizen and a good person.

Jim stated, "Success, I feel, is the whole experience here while I'm here, me growing as an individual, um, which I can say I've been successful at this university already, but for me, the final straw is finishing my degree." For Jasmine, the credential of a bachelor's degree will confirm her success but she also hoped to graduate with intrinsic success 
markers such as "what's really important (to) me (is) to come out, I guess, more wellrounded and more prepared for what I want to do afterwards."

Peter, who switched to engineering after returning from his church mission, found that "the most rewarding thing is actually learning things...the more I went to class the more I was actually learning and learning is fun apparently, for me anyways ... cause I had picked a major that ... catered to my interests." Michael, a (humanities) major, believed that "success is if you got something out of it. ... It's not about chasing money. ... What I feel is successful is that I have something up here (points to head) that people can't take away."

Ricky switched from engineering to business, which he described as "mentally it was brutal, ... I had to legitimately admit that I had failed.” He has since found that success is "getting over your failures...truly understanding your coursework...being passionate about what I'm doing in school and knowing that I can apply it to ... the professional world outside." Similarly, Melissa found that success is in how much she has overcome as well as the connections she made:

I think success definitely means networking and building connections with your professors and faculty in your department. ... I think success really means putting your foot out there and really getting involved ..., after I found something I was really passionate about... it's empowered me.... so, it just makes me realize that I can do anything because I did take that year (off). 
Where the students above described various definitions of success, 10 students focused on the personal accomplishment of graduation. Anthony, shared that graduation would be "the end of a journey, ... to get to that point ... would just be amazing, like to know that everything, all the hard work that I put in and all the disappointment ... all meant something in the end."

After struggling with depression and anxiety, Ronnie shared that college graduation "would mean a lot, um, it would mean that I, well I did it and I stuck through it and I got it done. ... it would mean everything." Ally concurred that college graduation would mean:

Everything. Um, it would mean breaking a long line in my family of not having any college education which I really pride myself in. Um, I think that it would change my life a little bit ... (and) I think that I frankly will just like myself more when I have a bachelor's. It will ... be a personal achievement.

The aforementioned students saw graduation as a personal success while six other students saw college graduation as a demonstration of success to others. Tim will be the first in his family to graduate from college:

Graduating (laughs) um, ... to me that's success. ... I realized that um, at least on my dad's side of the family um, you know, him and none of his siblings or his parents ever got a college degree so, you know, I didn't realize how huge of a deal that was until recently. 
Being adopted by her college-educated foster parents, Sara emphasized the importance to everyone in her life of her eventual graduation:

It would be like an amazing experience, ...it's just one of those things like I made it out, like I did it, cause ... like everything I have just like gone through. And I just look at myself, ... the opportunity to sit in the classroom is like people, people where we're from they don't have that, that's not something that we do.... I'm not doing it for myself, I'm doing it for everybody else cause ... if I don't finish then I'm just, I'm just being another statistic.

Where the students above saw college graduation as a source of pride for their family and communities, three participants concurred that college graduation would validate their success to others:

Walking across the stage. ... Hand me my paper ... buy a big old picture frame cause I know how big that diploma is, I'm like "why is that diploma so big?" but I know why, cause I'll flaunt it too, I'll walk around with that on my back. (Kayla)

I'm ready to kind of, for all of my friends that haven't graduated or for my family that didn't go to school, I'm going to be like "hey look, I have a degree, you don't." I'm proud of myself. (Sue)

College graduation? Oh god, uh, I guess it'd be a milestone, it's definitely something that I can use to tell people to fuck off when they tell me that I won't amount to much. ... It definitely means that I made it through all 
that hardship to get to a destination that I thought was valuable and that I wanted. ... I had a teacher tell me in elementary school that I wasn't going to pass high school because ... I have ADD or because I wasn't focused enough. ... they said I wouldn't even make it to college and I'm already here, so it's definitely one of those things where it's definitely a personal victory for me." (Alex)

While graduating is the ultimate marker of success for many students, each found their own meaning within their graduation. The accomplishment that participants expected to feel upon graduation was filled with personal meaning as it would represent the work they put into their education, their own growth and development, and their ability to overcome obstacles.

\section{No Regrets: Satisfaction in Taking Time Off}

When talking about their time away, all participants stressed the benefits of their time away and almost half specifically suggested that they had no regrets about taking time off. As discussed above, their time away allowed them to grow, take care of themselves, try out other possibilities, and helped them forge their own educational path. Through their exploration of self, love, and possibilities, participants were able to clarify their own desires authoring their own life and committing to their paths (Arnett, 2004; Baxter Magolda, 2004). Participants recognized the growth and learning that occurred while they were away and often suggested that others should take time away to experience it as well. For instance, Ally and Abe stated that they would recommend that other students work for hourly pay in order to experience life without a degree. Ally shared "I honestly recommend that anybody take a little bit of time off before they go 
straight into college just to get into the work force and see what you are going to be dealing with." Abe agreed that working was "one of those ... trying it out and kind of like having to put your hand on the stove to learn that it's hot. Like go out and experience what you would have to live like."

Taking time off allowed Tim to think through his future, discover what he wanted, and think about college differently:

At this point, I feel like I just have zero regrets at all about doing it, um despite having lost my scholarship and all that, I'm just in so much of a better place now, and I think ... if I wouldn't have (taken time off), ... you know that semester I probably would have failed a lot of classes and ... probably would have continued to just kind of drudge through semesters like that until I would have really just drug myself down and just gave up on it.

Peter concurred that taking time off allowed him to learn about himself and become independent:

I think the idea of taking time off to go and pursue something that's important and allows you to be independent for a while is very beneficial ... definitely that was the perfect time in my life to go out and learn a lot about me and I came back, when I came back, college was a lot more important to me afterwards.

Of note, students who were academically suspended echoed the impact that the time away had on them and did not regret taking time off. In reflecting on her time away 
due to her second suspension, Sara concluded "I think I kind of needed, I think this past year was very beneficial." Jasmine initially petitioned to return after a one semester suspension, but was denied, "I think they made the right decision for me, telling me to sit out. I think they see that a lot with kids that aren't ready for college. Or ready to come back." Lea suggested the time off "was kind of like rejuvenating, um, it gave me time to think about the choices that I had made. ... so, I think just taking that time off ... really helped me."

Seeing that it had been five or six years since initially enrolling in college, nearly half of the students expressed that they were ready to graduate. Even with the eagerness to graduate, students did not regret taking the time off as Julie shared, "I'm so psyched to graduate. ... not because I'm like 'god I'm ready to be out of here,' which is in a weird way ... what taking my time off did give me, I didn't get burnt out." Like Julie, participants acknowledged the benefits in taking time off as they returned to college with the commitment and motivation that was missing during their initial enrollment.

\section{University's Role in Integration}

Upon reflecting on the role of the institution, students described an interdependent relationship recognizing the institution as an actor in their lives. Participants recognized the isolation they felt during their initial enrollment and suggested the institution should have seen it as well and intervened. Tinto (1993) described isolation as "the absence of sufficient interactions whereby integration may be achieved" and that it is avoidable if institutions take action to engage students (p. 50). Students interact with institutions differently based on their backgrounds and social capital; if institutions want to engage all students, they must employ proactive techniques with the goal of building trusting 
relationships that empower students to ask for help (Holland, 2015; Jack, 2016; Yee, 2016). In addition to striving to develop supportive relationships with students, institutions should engage in intentional learning partnerships where students' internal voices are brought into the conversation both inside and outside the classroom to assist students through their development (Baxter Magolda, 2008). Intentional, proactive relationships with students will help to foster both integration within the university community as well as individuals' psychosocial development throughout their educational paths. The reflections of participants suggested that they desired and valued institutional agents taking an interest in them personally in order to assist them along their paths.

\section{Reach Out to Students}

When asked what City U could do to assist students like them, about half of the respondents expressed a desire for the university to reach out and offer support to students. Some of these students specifically identified facing challenges while transitioning from high school to college and the need for university support during their first year. Paul, who stopped attending classes after the first week, suggested that firstyear students need extra consideration:

I would definitely say they need to be very, very attentive with incoming freshmen, ... there needs to be constant like or at least a good deal of communication between advisors and students ... so they know without a doubt there is somebody there they can turn to for assistance. ... everyone that enters college pretty much still has a high school mindset and it's a very, very immature mindset. 
Melissa also suggested that the university could reach out to freshmen to help them make positive connections on campus:

I think maybe just reaching out to students in those really big (life sciences courses) ... and their freshmen really need like roots, so to speak, and roots that are tied into campus life and campus like academics..., cause if you don't find that, you can go out and find roots in other places that will get you away from school.

In addition to focusing on the first year, eight students expressed that the university should see certain behaviors as red flags, such as transferring within the university, grades dropping, or not enrolling in the next term, and that someone should reach out to students. Abe transferred within the university before stopping out and suggested that his move from one school to another would have been a good time to monitor him: "maybe find people who, ... people who transfer within the university like I did ... and just keep, I guess, keep an eye on them grades wise and ... see if they're dropping classes or stuff like that." Like Abe, Ricky transferred out of engineering and agreed that would have been a good time to reach out to him: "so if there are any, any areas to get some love, it would be in that process to kind of transition you from going from (one) direction to another." Ronnie, also transferred within the university and struggled for a couple of semesters to find his place academically. He emphasized the power of reaching out to students and asking if they are ok:

There should be a way for them to see red flags on students that ... uh, stop showing up to class, uh, their grades plummet. ... The university should reach out to them and see if they're doing alright. That would mean 
a lot more than me just not being able to go to class anymore and feeling like the university just doesn't care. ... I just feel like there should be a way to recognize that some students aren't following their typical behaviors and they should check in with them. ... It would have just meant a lot if somebody would have came (sic) and asked me if I was ok without me having to go somewhere because it is hard to admit that you have issues.

Mary suggested that the large size of the institution likely makes it hard to reach out to students who need extra support, but proposed that reaching out could go a long way:

If something happens maybe we need to have advisors that are a little bit more involved; like maybe they see these issues ... and maybe they contact us because maybe we're too scared to go to them. ... you know, pull those people aside to really try to figure out a plan ... because otherwise you just kind of get lost because there are so many people here and you just feel so overwhelmed.

Jasmine's experience corroborated that of others as she found it hard to ask for help when she was struggling academically and wished that advisors had offered more guidance. She explained "my advisors weren't really persistent. I'm sure they had like a few other hundred kids to help but it was my responsibility to seek out that help ... and, you know, I was a little more embarrassed each time." Sara suggested that reaching out to students who were not enrolled could help students feel supported by the university: 
I felt like, if I wanted to come back, I had to do it on my own. City U didn't reach out to me, they weren't like "hey, what's going on?" I mean they tell you to make sure you fill out your course evaluation ..., they push things, but they didn't push a student that's gone..., no one was like, "hey, what's up? ... hey, is everything ok?"

These participants expressed a desire for the university to take a more active role in their lives by reaching out and offering support instead of making assumptions about students' experiences and decisions.

\section{Build Supportive Relationships}

As highlighted above, participants often expected that the role of advisors on campus was to provide support to students through their transitions or when facing academic difficulty. Nearly half of the participants shared stories about the influential impact of interactions and relationships with advisors and instructors prior to stopping out. Julie recalled the effect an instructor had when he reached out to her at the end of her first year:

I did have one teacher who was super awesome. Like I didn't turn in a paper at the end of the semester because I was just like "I can't do this" and he called me, ... and he was like "hey, I don't know what's going on, but I know something's going on, you don't need to tell me, I just know that you are a good student and if your paper's not in, there's a problem, so I'm going to give you an extension." 
While struggling emotionally prior to stopping out, Ronnie confided in a writing instructor and that conversation helped him begin to reach out for help:

He was the first person I talked to and it felt good to. I said "I don't know if I want to keep going to college" just after class; I had to tell someone. He was just a really nice guy, and uh, ... we just talked and then, I think shortly after that was when I called my parents and said "there's something wrong."

After talking with his writing instructor and parents, Ronnie reached out to an advisor and kept in regular contact with her while out for three semesters easing his transition back to the university. He reflected how without her "I would be very lost and it's good, because I always have somewhere, someone to go to if I ever need to talk about anything and it's not like I have to be afraid of my advisor. ...And it's nice being able to drop by whenever I need to just for five minutes."

Through close relationships with some faculty, Anthony identified the influence they had on him while he was out; "I feel that City U keeping in touch, like some of the faculty did here, really helped, cause it showed me that ... I wasn't in it alone and that, you know, there was people that cared about my success." Samantha had a close relationship with her advisor and described her as "my support group. She's the one who's been keeping me strong ... I go to her for advice. I also talk with her about personal stuff."

Moreover, upon reenrolling and picking a major that fit them better, six participants described stronger relationships with instructors. For instance, upon returning 
and committing to a major in education, Mary found that a history professor's classes “absolutely made me fall in love with history. ... he's just super awesome, he really makes me feel like he cares about not just me but everyone in the class, ... I never feel like too shy to go to him.” Similarly, Candice described how she can go to her major faculty with questions she has and that they were writing recommendation letters for her since she has "several deep connections with several professors. I can go to them, any questions I have, any concerns." Ally concurred, "the faculty is incredibly supportive ... they will actually send out emails with opportunities to do stuff with your (work)," which led to her having a piece of her work being displayed on campus. Participants'stories demonstrate the positive impacts relationships with institutional agents can have on student integration to campus as well as students' psychosocial development.

\section{Conclusion}

Students' stories demonstrated experiences with exploration and instability as they began to listen to their internal voices, which included finding the value of a college education for themselves. The majority of participants in this study entered college without a clear direction and without their own sense of purpose. In recent decades, a 'college for all' ideology has spread across the United States. In addition to creating wider access to higher education, this ideology has created a belief that this is the preferred option for future financial security. The students in this study demonstrate one

of its ramifications; they entered college because they thought they were supposed to as the next step after high school, resulting in a lack of personal commitment to or plan for success in college. They, as individuals, did not choose to attend college, but instead attended out of obligation to external expectations. 
Universities operate on the assumption that students want to be there and that students actively made a decision about their college choice. Regrettably, the large majority of students in this study shared that City U was a default choice because it was a four-year, public institution with a convenient location. The participants shared that they struggled once they enrolled in their first-year courses. Some only discussed struggling with the course materials and workload while most discussed challenges with motivation, interest, and in return, academics. For many, these challenges triggered anxiety and depression as they realized they were not sure why they were in college or what they wanted out of it. As they began to question their abilities and no longer wanted to go through the motions of being in college, they found themselves at a crossroads whereby they experienced tension between the external influences that led them to enroll in college and their growing internal voice that sought to find meaning in their life (Baxter Magolda, 2014).

Interestingly, all of the students, no matter the reason they stopped out, reflected that their time away was a period of growth and improvement, which allowed them to return and approach college differently. Most students chose to leave to take time to figure things out and get support. While not enrolled, participants worked for pay, traveled, or volunteered, through which they developed a sense of identity and strengthened their internal voice. Many spoke of finding a new intellectual passion or committing to long held interests that were not necessarily what their families wanted them to study. Through extra-school experiences and maturation, they gained insight into what they had to offer the world of work and how a college education fit into that plan. Furthermore, participants discussed refining their social circles, e.g. choosing people that 
were future-focused and supportive of their journey over casual friendships. Upon returning to City $\mathrm{U}$, over half of the participants changed majors and most discussed how much more focused and driven they were. Having recognized their personal growth while not enrolled, the participants now saw that their time in college was a time of continued development instead of just a hurdle to jump through on the path to their life.

Participants' improved engagement with their education facilitated academic integration and psychosocial development they needed to see themselves as successful. 


\section{CHAPTER V: \\ QUANTITATIVE FINDINGS}

This chapter addresses three of the research questions introduced in Chapter I:

1. How large was the stopout population within each cohort and across the two cohorts?

2. What were the characteristics of cohort students who stopped out and returned in comparison to those (a) with continuous enrollment until graduation, (b) with continuous enrollment through the closure of the six-year graduation window but who had not graduated, and (c) who did not persist?

3. What factors predicted stopout?

Various tests were utilized to answer the research questions and investigate students who stopout in comparison to students in other pathways. Descriptive statistics were used to understand the magnitude of the stopout populations, the timing of the first semester stopped out, and how many semesters students stopped out. Chi-square tests and ANOVA (analysis of variance) were used to explore the characteristics of the students in the various pathways. Next, binary logistic regression was used to investigate which factors predict stopping out. Finally, to further explore how stopouts differ from students in the other pathways, I utilized MLR to understand how the factors that predict stopping out vary from the factors predicting the other pathways. 
Table 3

Dependent and Independent Variables including Coding

\begin{tabular}{|c|c|}
\hline \multicolumn{2}{|c|}{ Dependent Variables } \\
\hline Pathway & $1=$ Graduate \\
\hline \multirow[t]{4}{*}{ (5-category) } & $2=$ Stopout Graduate \\
\hline & $3=$ Stopout Persister \\
\hline & $4=$ Persister \\
\hline & $5=$ Nonpersister \\
\hline Pathway (2) & $1=$ Graduate \\
\hline \multirow[t]{3}{*}{ (4-category) } & $2=$ Stopout \\
\hline & 3 = Persister \\
\hline & $4=$ Nonpersister \\
\hline Stopout & No $=0$, Yes $=1$ \\
\hline \multicolumn{2}{|c|}{ Independent Variables } \\
\hline \multicolumn{2}{|r|}{ Background } \\
\hline Local & No $=0$, Yes $=1$ \\
\hline First Generation & No $=0$, Yes $=1$ \\
\hline Male & No $=0$, Yes $=1$ \\
\hline White & No $=0$, Yes $=1$ \\
\hline 1st Year PELL Recipient & $\mathrm{No}=0, \mathrm{Yes}=1$ \\
\hline \multicolumn{2}{|c|}{ Pre-College Preparedness } \\
\hline ACT Score & $0-36$ \\
\hline Credit Hours Earned Prior to Enrolling & No $=0$, Yes $=1$ \\
\hline \multirow[t]{2}{*}{ High School GPA } & $0.0-5.0$ \\
\hline & Early College \\
\hline Cohort & $2011=0,2010=1$ \\
\hline 1st Semester STEM Major & No $=0$, Yes $=1$ \\
\hline 1st Semester On-Campus Housing & No $=0$, Yes $=1$ \\
\hline 1st Year GPA & $0.0-4.0$ \\
\hline 1st Year Financial Aid & Quintiles \\
\hline 2nd Year GPA & $0.0-4.0$ \\
\hline 2nd Year Financial Aid & Quintiles \\
\hline
\end{tabular}

Table 3 displays each variable and its coding. There were also three different dependent variables that were used for specific analyses. There were two dependent pathway variables due to the initial tests conducted to determine whether stopout graduates and stopout persisters performed differently on the predictor variables. Once it 
was determined that they were not significantly different, the two groups were combined into one stopout group resulting in the Pathway (2) variable. As discussed in chapter 3, the variables included in the tests come from the literature and the qualitative findings. As shown in Table 3, there were three sets of independent variables: Background, PreCollege Preparedness, and Early College.

Table 4 shows the bivariate correlations between the covariates. Most bivariate relationships were significant at either the .05 or .01 level indicating statistically significant relationships between the variables. None of the included covariates returned strong correlations with other covariates. First generation status, high school GPA, and financial aid quintiles were the only three covariates that returned significant correlations with all other covariates. While the results indicated most bivariate relationships were weak or trivial, some returned moderate strength relationships including first year financial aid quintiles and first semester on-campus housing $(r=.34)$, first year financial aid quintiles and PELL grant recipient $(r=.36)$, first year GPA and ACT score $(r=.30)$, credit hours earned prior to enrolling and ACT score $(r=.31)$ and first semester STEM major and ACT score $(\mathrm{r}=.33)$. 
Table 4

Correlation Matrix for Covariates $\left(N=5000^{\mathrm{a}}\right)$

\begin{tabular}{|c|c|c|c|c|c|c|c|c|c|c|c|c|c|c|}
\hline & & 1 & 2 & 3 & 4 & 5 & 6 & 7 & 8 & 9 & 10 & 11 & 12 & 13 \\
\hline 1 & Local & & & & & & & & & & & & & \\
\hline 2 & First Generation & $-0.04 * *$ & & & & & & & & & & & & \\
\hline 3 & Male & 0.02 & $-0.04 * *$ & & & & & & & & & & & \\
\hline 4 & White & 0.01 & $-0.06^{* *}$ & $0.05^{* *}$ & & & & & & & & & & \\
\hline 5 & $\begin{array}{l}\text { 1st Year PELL } \\
\text { Recipient }\end{array}$ & 0.00 & $0.22 * *$ & $-0.04 * *$ & $-0.24 * *$ & & & & & & & & & \\
\hline 6 & ACT Score & $-0.04 *$ & $-0.12 * *$ & $0.11 * *$ & $0.24 * *$ & $-0.18 * *$ & & & & & & & & \\
\hline 7 & $\begin{array}{l}\text { Credit Hours Earned } \\
\text { Prior to Enrolling }\end{array}$ & -0.02 & $-0.07 * *$ & -0.02 & $0.03 *$ & $-0.06^{* *}$ & $0.31 * *$ & & & & & & & \\
\hline 8 & High School GPA & $-0.15^{* *}$ & $-0.03 * *$ & $-0.05^{* *}$ & $0.06 * *$ & $-0.06 * *$ & $0.28 * *$ & $0.20 * *$ & & & & & & \\
\hline 9 & 2010 Cohort & -0.03 & $0.04 * *$ & 0.01 & -0.02 & 0.01 & $-0.04 *$ & $-0.07 * *$ & $-0.03 *$ & & & & & \\
\hline 10 & $\begin{array}{l}\text { 1st Semester STEM } \\
\text { Major }\end{array}$ & $-0.04 *$ & $-0.05^{* *}$ & $0.21 * *$ & 0.02 & $-0.04 * *$ & $0.33 * *$ & $0.11^{* *}$ & $0.12 * *$ & -0.03 & & & & \\
\hline 11 & $\begin{array}{l}\text { 1st Semester On- } \\
\text { Campus Housing }\end{array}$ & $-0.24 * *$ & $-0.06 * *$ & $-0.05^{* *}$ & $-0.08 * *$ & $-0.04 * *$ & $0.13 * *$ & $0.09 * *$ & $0.08 * *$ & 0.01 & $0.03^{*}$ & & & \\
\hline 12 & 1st Year GPA & $-0.04 * *$ & $-0.08 * *$ & $-0.13^{* *}$ & $0.06 * *$ & $0.14 * *$ & $0.30 * *$ & $0.21 * *$ & $0.23 * *$ & 0.00 & $0.03^{*}$ & $0.15^{* *}$ & & \\
\hline 13 & $\begin{array}{l}\text { 1st Year Financial } \\
\text { Aid Quintiles }\end{array}$ & $-0.15^{* *}$ & $0.09 * *$ & $-0.06^{* *}$ & $-0.26 * *$ & $0.37 * *$ & $0.18 * *$ & $0.12 * *$ & $0.11^{* *}$ & $-0.02 *$ & $0.12^{*}$ & $0.34 * *$ & $0.25^{* *}$ & \\
\hline
\end{tabular}

${ }^{a}$ Not all combined cohort members filed a FAFSA, so their population number differs: $4981 ;{ }^{*} p<.05,{ }^{* *} p<.01,{ }^{* * *} p<.001$ 


\section{Size of Stopout Population}

There were 5,000 students (see Table 5) in the 2010 and 2011 cohorts combined and $196(3.9 \%)$ were stopouts (71 were stopout graduates and 125 were stopout persisters). (The total population of stopouts (196) differed from the sample of stopouts invited to be interviewed (206). This is because there were 206 students who had stopped out, returned, and were enrolled during the semester I conducted interviews, but the stopout population is based on the students who stopped out and either graduated by or persisted through their sixth year. Thus, the difference comes from students who must have stopped attending again and had not returned and graduated by or persisted through the time of their six-year window closing.)

Table 5

Size of Stopout Population

\begin{tabular}{lcc}
\hline & \multicolumn{2}{c}{ Total } \\
& \multicolumn{2}{c}{$N=5000$} \\
\hline Not Stopout & 4,804 & $96.1 \%$ \\
& & \\
StopOut Graduate & 71 & $1.4 \%$ \\
StopOut Persister & 125 & $2.5 \%$ \\
Total StopOut & 196 & $3.9 \%$ \\
\hline
\end{tabular}

Of the students who stopped out, the third semester was the first semester not enrolled for over a third $(36 \%)$ (see Figure 1). The second semester was the first semester reported for stopout and students continued to stopout for the first time through the eleventh semester; however, almost three quarters of students took their first semester off during their 
second or third year. While the number of semesters not enrolled ranged from one to nine, over a third of students $(36 \%)$ stopped out for only one semester and over three quarters of students stopped out for two years or less (see Figure 2).
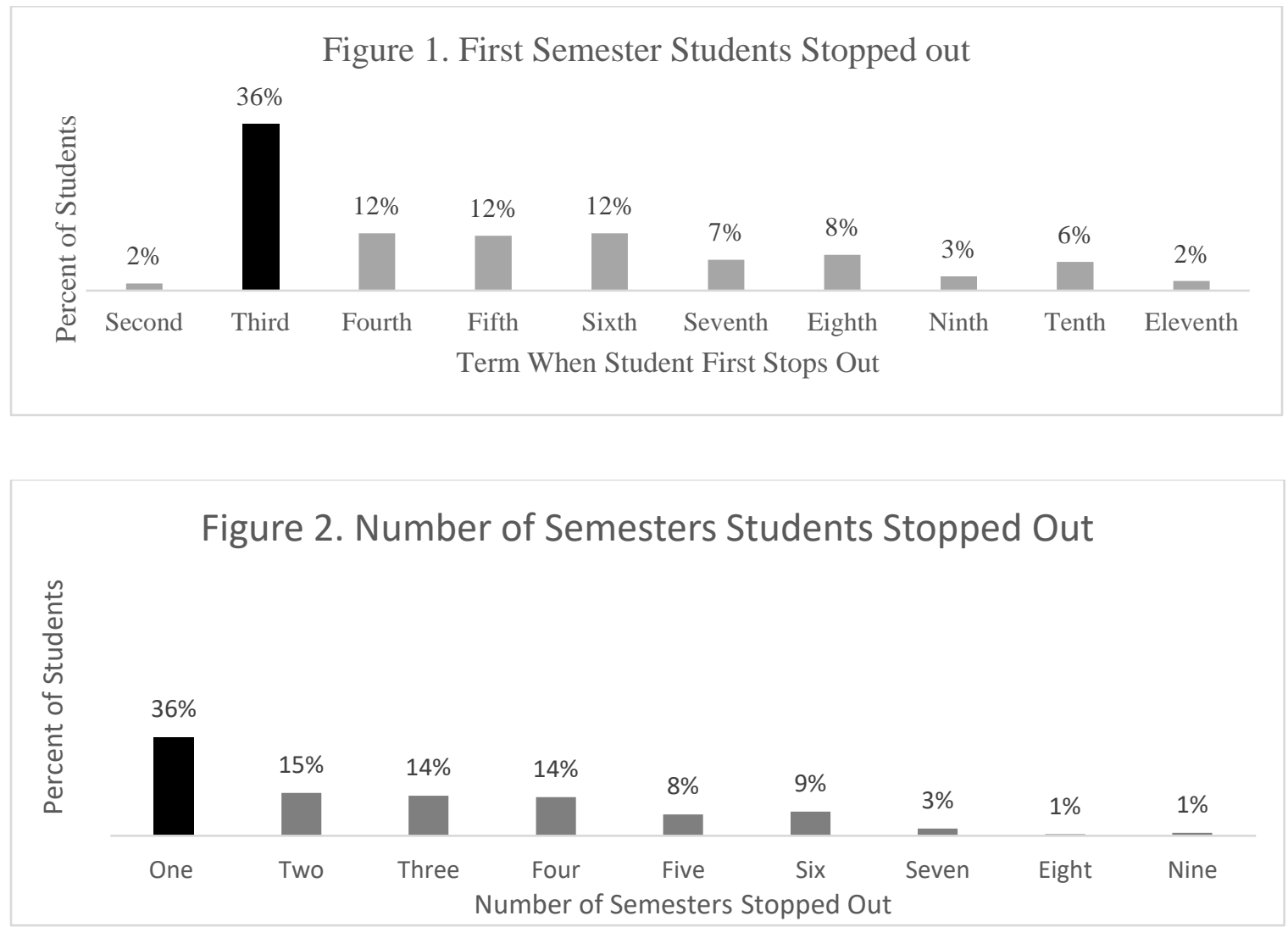

\section{Comparison of Characteristics by Student Pathway}

In order to investigate student demographic backgrounds and early college experiences of the students in each pathway, I conducted a bivariate analysis of the full population (5000) from the combined cohorts. Of the variables analyzed, only first year financial aid received had missing values. The variable was missing for 110 students who did not file a federal application for financial aid (FAFSA) for their first year of enrollment, which was just over $2 \%$ of the population analyzed. (Students who filed a FAFSA, but did not receive any financial have a zero for this variable.) Due to the small 
number of students who had a missing value and the fact that this was not a multivariate analysis, I left all students in and made a note of the financial aid received missing values in Table 6. Table 6 shows the categorical variables by student pathway and Table 7 displays the continuous variables by student pathway.

\section{Graduates}

White students, on-campus residents, and STEM majors were overrepresented among Graduates when compared to the total population, while local residents, first generation students, PELL recipients, and males were underrepresented (chi-square test with a $p<.001)$. 
Table 6

Percentages of Categorical Characteristics by Student Pathway $\left(N=5000^{\mathrm{a}}\right)$

\begin{tabular}{|c|c|c|c|c|c|c|}
\hline & & Graduate & $\begin{array}{c}\text { Stopout } \\
\text { Graduate }\end{array}$ & $\begin{array}{l}\text { Stopout } \\
\text { Persister }\end{array}$ & Persister & Nonpersister \\
\hline \multicolumn{7}{|l|}{ Background Variables } \\
\hline Local & Yes & $\mathrm{W}^{\mathrm{b}}$ & $53.3 \%$ & $54.4 \%$ & $59.7 \%$ & $50.4 \%$ \\
\hline First Generation*, V=.09 & Yes & $\mathrm{W}$ & $21.1 \%$ & $20.8 \%$ & $16.4 \%$ & $23.0 \%$ \\
\hline Male*, V=.10 & Yes & $\mathrm{W}$ & $53.5 \%$ & $64.0 \%$ & $70.9 \%$ & $51.0 \%$ \\
\hline White & Yes & $\mathrm{W}$ & $77.5 \%$ & $76.8 \%$ & $77.6 \%$ & $78.4 \%$ \\
\hline PELL Recipient (First Year)*, V=.13 & Yes & $\mathrm{W}$ & $28.2 \%$ & $33.6 \%$ & $38.1 \%$ & $41.0 \%$ \\
\hline \multicolumn{7}{|l|}{ Pre-College Preparedness Variable } \\
\hline Earned Credits Prior to Enrollment*, V=.20 & Yes & $\mathrm{W}$ & $42.3 \%$ & $34.4 \%$ & $44.8 \%$ & $37.0 \%$ \\
\hline \multicolumn{7}{|l|}{ Early College Variables } \\
\hline 1st Semester STEM Major*, V=.08 & Yes & $\mathrm{W}$ & $28.2 \%$ & $30.4 \%$ & $44.0 \%$ & $27.4 \%$ \\
\hline 1st Semester On-Campus Housing*, V=.16 & Yes & $\mathrm{W}$ & $46.5 \%$ & $37.6 \%$ & $50.0 \%$ & $51.6 \%$ \\
\hline \multirow[t]{2}{*}{ Cohort***, V=.07 } & 2010 & $\mathrm{~W}$ & $50.7 \%$ & $70.4 \%$ & $56.0 \%$ & $49.2 \%$ \\
\hline & 2011 & $\mathrm{~W}$ & $49.3 \%$ & $29.6 \%$ & $44.0 \%$ & $50.8 \%$ \\
\hline \multirow{5}{*}{ 1st Year Financial Aid Quintiles***, V=.10 } & 1 & $\mathrm{~W}$ & $29.6 \%$ & $34.4 \%$ & $23.9 \%$ & $24.8 \%$ \\
\hline & 2 & $\mathrm{~W}$ & $26.8 \%$ & $27.0 \%$ & $23.1 \%$ & $22.2 \%$ \\
\hline & 3 & $\mathrm{~W}$ & $21.1 \%$ & $14.8 \%$ & $19.4 \%$ & $20.3 \%$ \\
\hline & 4 & $\mathrm{~W}$ & $9.9 \%$ & $13.1 \%$ & $20.9 \%$ & $18.9 \%$ \\
\hline & 5 & $\mathrm{~W}$ & $12.7 \%$ & $10.7 \%$ & $12.7 \%$ & $13.8 \%$ \\
\hline
\end{tabular}

*p $<.05, * * \mathrm{p}<.01,{ }^{* * *} \mathrm{p}<.001$ The chi-square test is across all five student pathways simultaneousl $y$

Cramer's V is provided for variables that yielded significant results at alpha levels of 05 or lower.

${ }^{a}$ Not all combined cohort members filed a FAFSA, so the population for $1^{\text {st }}$ Year Financial Aid Quintiles differs; Total - 4891.

bWithheld to mask City U's identity. 
Table 7

Means and Standard Deviations of Continuous Independent Variables by Student Pathway $(N=5000)$

\begin{tabular}{|c|c|c|c|c|c|}
\hline & Graduate & $\begin{array}{c}\text { Stopout } \\
\text { Graduate }\end{array}$ & $\begin{array}{l}\text { Stopout } \\
\text { Persister }\end{array}$ & Persister & Nonpersister \\
\hline & Mean $(\sigma)$ & Mean $(\sigma)$ & Mean $(\sigma)$ & Mean $(\sigma)$ & $\operatorname{Mean}(\sigma)$ \\
\hline \multicolumn{6}{|l|}{$\begin{array}{c}\text { Pre-College } \\
\text { Preparedness }\end{array}$} \\
\hline HS GPA*** & $\mathrm{W}^{\mathrm{a}}$ & $3.42(0.47)$ & $3.35(0.43)$ & $3.46(0.45)$ & $3.38(0.49)$ \\
\hline ACT Score $* * *$ & W & $24.11(3.70)$ & $23.28(3.70)$ & $24.16(3.59)$ & $23.44(3.42)$ \\
\hline First Year GPA**** & $\mathrm{W}$ & $2.49(0.96)$ & $2.14(1.20)$ & $2.71(0.73)$ & $2.05(1.13)$ \\
\hline
\end{tabular}

$* \mathrm{p}<.05, * * \mathrm{p}<.01, * * * \mathrm{p}<.001$ The ANOVA test is across all five pathways simultaneously.

${ }^{a}$ Withheld to mask City U's identity. 


\section{Stopout Graduates}

There were 71 students in the cohorts who took at least one semester off, returned to City U, and graduated within 6 years of their first semester. Of the Stopout Graduates, $56.3 \%$ were local residents, $21.1 \%$ were first generation students, $53.5 \%$ were male, $77.5 \%$ were White, $42.3 \%$ earned college credits prior to enrolling, $28.2 \%$ received a PELL grant in their first year, 28.2\% entered as STEM majors in their first semester, and 46.5\% lived on-campus their first semester. Local residents and males were overrepresented among Stopout Graduates relative to the total population, while PELL recipients, STEM majors, on-campus residents, and White students were underrepresented (chi-square test with a $p<.001$ ). The percentage of first generation Stopout Graduates was not found to be significantly different from the total student population. For Stopout Graduates, the mean high school GPA was $3.42(S D=0.47)$, the mean ACT score was $24.11(S D=3.70)$, and the mean first year GPA was $2.49(S D=$ 0.96). The percentage of stopout graduates in each of the first year financial aid quintiles fluctuated but more stopout graduates were found in the lowest two quintiles (Quintile 1: 29.6\%, Quintile 2: 26.8\%, Quintile 3: 21.1\%, Quintile 4: 9.9\%, and Quintile 5: 12.7\%).

\section{Stopout Persisters}

There were 125 students who took at least one semester off, returned to City U, and were enrolled in their $12^{\text {th }}$ semester but did not graduate during their six-year window. Of the Stopout Persisters, $54.4 \%$ were local residents, $20.8 \%$ were first generation, $64.0 \%$ were male, $76.8 \%$ were White, $34.4 \%$ earned college credits prior to enrolling, 33.6\% received a PELL grant in their first year, 30.4\% entered as STEM 
majors their first semester, and 37.6\% lived on-campus their first semester. Local residents, first generation, and males were overrepresented among Stopout Persisters compared to the total population, while PELL recipients, STEM majors, on-campus residents, and White students were underrepresented (chi-square test with $p<.001$ ). For Stopout Persisters, the mean high school GPA was $3.35(S D=0.43)$, the mean ACT score was $23.28(S D=3.69)$, and the mean first year GPA was $2.14(S D=1.20)$. The percentage of stopout persisters in each of the first year financial aid quintiles decreased as the financial aid quintile increased (Quintile 1: 34.4\%, Quintile 2: 27.0\%, Quintile 3: 14.8\%, Quintile 4: 13.1\%, and Quintile 5: 10.7\%).

\section{Persisters}

Within the Persisters, $59.7 \%$ were local residents, $16.4 \%$ were first generation, $70.9 \%$ were male, $77.6 \%$ were White, $44.8 \%$ earned college credits prior to enrolling, 38.1\% received a PELL grant their first semester, $44.0 \%$ entered as STEM majors, and $50.0 \%$ lived on-campus their first year. Local residents, males, PELL recipients, and STEM majors were overrepresented among Persisters when compared to the total population, while first generations students, on-campus residents, and White students were underrepresented (chi-square test with $p<.001$ ). For Persisters, the mean high school GPA was $3.46(S D=0.45)$, the mean ACT score was $24.16(S D=3.59)$, and the mean first year GPA was $2.71(S D=0.73)$. The percentage of persisters in each of the first year financial aid quintiles was as follows: Quintile 1: 23.9\%, Quintile 2: $23.1 \%$, Quintile 3: 19.4\%, Quintile 4: 20.9\%, and Quintile 5: $12.7 \%$. 


\section{Nonpersisters}

Lastly, of the Nonpersisters, $50.4 \%$ were local residents, $23.0 \%$ were first generation, $51.0 \%$ were male, $78.4 \%$ were White, $37 \%$ earned college credits prior to enrolling, $41.0 \%$ received a PELL grant their first semester, $27.4 \%$ entered as STEM majors, and 51.6\% lived on-campus their first semester. Local residents, first generation students, and PELL recipients were overrepresented among Nonpersisters when compared with the total population, while STEM majors, females, on-campus residents, and White students were underrepresented (chi-square test with $p<.001$ ). For Nonpersisters, the mean high school GPA was $3.38(S D=0.49)$, the mean ACT score was $23.44(S D=3.42)$, and the mean first year GPA was $2.05(S D=1.13)$. The percentage of nonpersisters in each of the first year financial aid quintiles decreased as the financial aid quintile increased (Quintile 1: 24.8\%, Quintile 2: 22.2\%, Quintile 3: 20.3\%, Quintile 4: 18.9\%, and Quintile 5: 13.8\%).

\section{Bivariate Analyses of Characteristics by Student Pathway}

An initial comparison of the five student pathways (Graduate, Stopout Graduate, Stopout Persister, Persister, and Nonpersister) was conducted. Table 6 shows the percentage breakdown within four of the five student pathways for the background and early college categorical variables. As indicated by the asterisks, the pathways were found to be significantly $(p<.05)$ different on first generation status, male, first year PELL grant recipient, earned credits prior to enrolling, first semester STEM major, and first semester on-campus housing, cohort, and first year financial aid quintile. Table 7 displays the means and standard deviations of the continuous variables for four of the five 
student pathways. All three continuous variables were found to be statistically significant across the pathways.

Chi-Square and ANOVA tests were run to further explore background, academic preparation, and early college characteristics of the five student pathway groups. Since the pathway variable contains more than two categories, I used Cramer's V for the chisquare test of independence to evaluate the associations between pathways and each of the categorical independent variables. As shown in Table 6, the majority of the chi-square tests were significant $(\mathrm{p}<.05)$ for the categorical independent variables except for White and local; however, their Cramer's V effect sizes were generally quite modest. The Cramer's V statistic is out of a maximum of 1 and all the significant results returned small effect sizes with earned credits prior to enrollment having the highest Cramer's $\mathrm{V}$ statistic at $V=.20$, followed by first semester housing, $V=.16, V=.13$ for first year PELL grant recipient, and $\mathrm{V}=.10$ for male. While the effect sizes for first generation status $(\mathrm{V}=.09)$, first semester STEM major $(\mathrm{V}=.08)$, and cohort $(\mathrm{V}=.07)$ were found to be significant, the Cramer's V results were under 0.10 - a common heuristic for the threshold for a trivial effect size - and thus, were negligible (Fan, 2001; Kotrlik, Williams, \& Jabor, 2011). A chi-square was run for each predictor on each student pathway to determine if there was a statistically significant difference between the representativeness of each independent variable within each pathway compared to the total population. Accordingly, I was testing whether the null hypothesis that the probabilities were the same for each pathway compared to the total population could be retained. With the exception of first generation student status among stopout graduates, every other chi-square test returned statistically significant results rejecting the null (not 
shown in tabular form). Thus, stopout graduates have the same probability of being first generation as the total population.

To compare the student pathways on the continuous independent variables I ran ANOVA tests (see Table 7). All covariates returned significant results $(p<.05)$ from the Test of Homogeneity of Variance indicating that they failed the assumption of equal variance across student pathways. To investigate how each pathway differed from the total population on each continuous variable, I ran independent samples t-tests (not shown in tabular format). Glass's delta effect sizes are reported for each of the significant comparisons. Graduates returned significant results for each of the continuous variables. On average, graduates had higher high school GPAs than the total population $(\Delta=.14, p$ $<.01)$. On average, graduates had higher ACT scores than the total population $(\Delta=.25, p$ $<.001)$. Lastly, graduates had higher first year GPAs than the total population $(\Delta=.51, p$ $<.001)$. Neither stopout graduates nor stopout persisters returned significant results for any of the continuous variables in comparison to the total population. Thus, stopout graduates were not significantly different than the total population on high school GPA, ACT score, or first year GPA. Persisters only returned statistically significant results on first year GPA. On average, persisters had higher first year GPAs than the total population $(\Delta=.03, p<.001)$. Nonpersisters returned significant results for each of the continuous variables. On average, nonpersisters had lower high school GPAs than the total population $(\Delta=-.37, p<.01)$. On average, nonpersisters had lower ACT scores than the total population $(\Delta=-.28, p<.001)$. Lastly, nonpersisters had lower first year GPAs than the total population $(\Delta=-.61, p<.001)$. 
To further examine the statistical relationship between the pathways for each of the covariates, I ran Games-Howell post hoc tests. I selected the Games-Howell because equal variances are not assumed and because Games-Howell works well when group sizes are unequal (Shingala \& Rajyaguru, 2015), which was the case with the pathways. Since students who stopped out were my population of interest, I compared Stopout Graduates and Stopout Persisters with the other student pathways, including each other, to understand if and how they differed on the continuous variables.

\section{Stopout Graduates}

A Games-Howell post hoc test revealed that Stopout Graduates were significantly different than other student pathways, specifically Graduates and Nonpersisters. (Effect sizes, calculated in STATA 15.1, are included here, but not in tabular format.) Stopout Graduates were found to be significantly different from other student pathways for maximum ACT composite score $(F(4,4995)=91.39, p<.001)$, first year GPA $(F(4,4995)=542.32, p<.001)$. Stopout Graduates have lower maximum ACT composite scores $(\Delta=.43, p<.05)$ than Graduates with a moderate effect size. Stopout Graduates earned a first year GPA $(\Delta=-.77, p<.001)$ that was lower than Graduates with a high effect size. Additionally, Stopout Graduates $(\Delta=.46, p<.01)$ earned first year GPAs that were significantly higher than Nonpersisters $(2.05 \pm 1.13$ points $)$ with a moderate effect size.

\section{Stopout Persisters}

A Games-Howell post hoc test also revealed that Stopout Persisters were significantly different than other student pathways including Graduates, Persisters, and 
Nonpersisters. (Effect sizes, calculated in STATA 15.1, are included here but are not in tabular format.) Stopout Persisters were found to have a lower High School GPA (3.35 \pm .43 points, $F(4,4995)=37.22, \Delta=.42, p<.001)$ than Graduates with a moderate effect size. Stopout Persisters had lower ACT Composite scores $(23.28 \pm 3.7$ points, $F(4,4995)$ $=91.39, \Delta=.54, p<.001)$ when compared to Graduates and a moderate effect size. Stopout Persisters were found to have lower first year GPAs $(2.14 \pm 1.20$ points, $F(4,4995)=542.32, \Delta=-.91, p<.001)$ than Graduates with a high effect size. Stopout Persisters $(2.13 \pm 1.20$ points, $F(4,4995)=543.60, \Delta=-.47, p<.001)$ were also found to have lower first year GPAs than Persisters $(2.71 \pm .73$ points $)$ with a moderate effect size.

Interestingly, the Games-Howell post hoc test did not reveal any statistically significant differences between Stopout Graduates and Stopout Persisters. In addition to the bivariate analysis discussed above, results from an exploratory multinomial logistic regression comparing Stopout Graduates and Stopout Persisters were non-significant on all covariates. Since these two pathways perform similarly on these analyses, they were collapsed into one group for the binary and multinomial logistic regression. The descriptive statistics of the combined group is described below.

\section{Stopouts Combined}

There were 196 students who took at least one semester off, returned to City U, and either graduated within their six-year window or were enrolled in their $12^{\text {th }}$ semester but did not graduate during their six-year window. Of the Stopouts, $55.1 \%$ were local residents, $20.9 \%$ were first generation, $60.2 \%$ were male, $77.5 \%$ were White, $37.2 \%$ earned college credits prior to enrolling, 31.6\% received the PELL grant in their first year, 29.6\% entered as STEM majors their first semester, and 40.8\% lived on-campus 
their first semester (see Table 8). Local residents, first generation, and males were overrepresented among Stopouts compared to the total population, while PELL recipients, STEM majors, on-campus residents, and White students were underrepresented (chi-square test with $\mathrm{p}<.001$ ). As shown in Table 9, Stopouts' mean high school GPA was $3.38(S D=0.44)$, mean ACT score was $23.58(S D=3.71)$, and mean first year GPA was $2.26(S D=1.13)$. The percentage of stopouts in each of the first year financial aid quintiles decreased as the financial aid quintile increased (Quintile 1: 32.8\%, Quintile 2: 26.9\%, Quintile 3: 17.1\%, Quintile 4: 11.9\%, and Quintile 5: 11.4\%). 
Table 8

Percentages of Categorical Characteristics by 4-Way Student Pathway $\left(N=5000^{a}\right)$

\begin{tabular}{|c|c|c|c|c|c|}
\hline & & Graduate & Stopout & Persister & Nonpersister \\
\hline \multicolumn{6}{|l|}{ Background Variables } \\
\hline Local & Yes & $\mathrm{W}^{\mathrm{b}}$ & $55.1 \%$ & $59.7 \%$ & $50.4 \%$ \\
\hline First Generation $* * *, V=.09$ & Yes & $\mathrm{W}$ & $20.9 \%$ & $16.4 \%$ & $23.0 \%$ \\
\hline Male ${ }^{* * *}, \mathrm{~V}=.10$ & Yes & $\mathrm{W}$ & $60.2 \%$ & $70.9 \%$ & $51.0 \%$ \\
\hline White & Yes & $\mathrm{W}$ & $77.5 \%$ & $77.6 \%$ & $78.4 \%$ \\
\hline PELL Recipient***, V=.13 & Yes & $\mathrm{W}$ & $31.6 \%$ & $38.1 \%$ & $41.0 \%$ \\
\hline \multicolumn{6}{|l|}{ Pre-College Preparedness Variable } \\
\hline $\begin{array}{l}\text { Earned Credits Prior to Enrollment } * * *, \\
V=.20\end{array}$ & Yes & $\mathrm{W}$ & $37.2 \%$ & $44.8 \%$ & $37.0 \%$ \\
\hline \multicolumn{6}{|l|}{ Early College Variables } \\
\hline 1st Semester STEM Major****, V=.08 & Yes & $\mathrm{W}$ & $29.6 \%$ & $44.0 \%$ & $27.4 \%$ \\
\hline $\begin{array}{l}\text { 1st Semester On-Campus Housing } * * *, \\
V=.16\end{array}$ & Yes & $\mathrm{W}$ & $40.8 \%$ & $50.0 \%$ & $51.6 \%$ \\
\hline \multirow{2}{*}{ Cohort***, V=.06 } & 2010 & $\mathrm{~W}$ & $63.6 \%$ & $56.0 \%$ & $49.2 \%$ \\
\hline & 2011 & $\mathrm{~W}$ & $36.7 \%$ & $44.0 \%$ & $50.8 \%$ \\
\hline \multirow{5}{*}{ 1st Year Financial Aid Quintiles***, V=.11 } & 1 & $\mathrm{~W}$ & $32.6 \%$ & $23.9 \%$ & $24.8 \%$ \\
\hline & 2 & $\mathrm{~W}$ & $26.9 \%$ & $23.1 \%$ & $22.2 \%$ \\
\hline & 3 & $\mathrm{~W}$ & $17.1 \%$ & $19.4 \%$ & $20.3 \%$ \\
\hline & 4 & $\mathrm{~W}$ & $11.9 \%$ & $20.9 \%$ & $18.9 \%$ \\
\hline & 5 & $\mathrm{~W}$ & $11.4 \%$ & $12.7 \%$ & $13.8 \%$ \\
\hline
\end{tabular}

$\mathrm{p}<.05, * * \mathrm{p}<$

Cramer's $\mathrm{V}$ is provided for variables that yielded significant results at alpha levels of .05 or lower.

${ }^{a}$ Not all combined cohort members filed a FAFSA, so their population number differs: Total - 4891.

'Withheld to mask City U's identity. 
Table 9

Means and Standard Deviations of Continuous Independent Variables by 4-Way Student Pathway $(N=5000)$

\begin{tabular}{lcccc}
\hline & $\begin{array}{c}\text { Graduate } \\
\text { Mean }(\sigma)\end{array}$ & $\begin{array}{c}\text { Stopout } \\
\text { Mean }(\sigma)\end{array}$ & $\begin{array}{c}\text { Persister } \\
\text { Mean }(\sigma)\end{array}$ & $\begin{array}{c}\text { Nonpersister } \\
\text { Mean }(\sigma)\end{array}$ \\
\hline $\begin{array}{c}\text { Pre-College } \\
\text { Preparedness }\end{array}$ & & & & \\
HS GPA*** & $\mathrm{W}^{\mathrm{a}}$ & $3.38(0.44)$ & $3.46(0.45)$ & $3.38(0.49)$ \\
ACT Score*** & $\mathrm{W}$ & $23.58(3.71)$ & $24.16(3.59)$ & $23.44(3.42)$
\end{tabular}

\section{Early College}

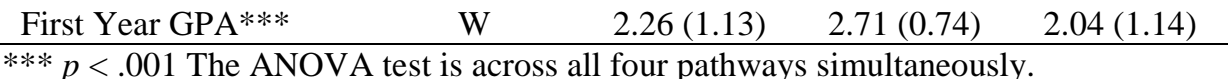
${ }^{a}$ Withheld to mask City U's identity.

\section{Factors that Predicted Stopout}

I ran a binary logistic regression to investigate which factors predicted stopout. Since only three students stopped out after their first semester, I ran the binary logistic regression to predict stopping out at any point after the second semester which allowed me to incorporate financial aid since it is an annual variable. I chose to run the analysis after the second semester since the third semester was the first semester not enrolled for $36 \%$ of the students who stopped out and only three students stopped out prior to that point (during the second semester). With binary logistic regression, STATA 15.1 automatically used listwise deletion resulting in 4,907 observations included in the analysis; however, even with this decrease, the model maintained over $97 \%$ of the population. Five covariates (male, first semester on-campus housing, first year GPA, 
financial aid received, and cohort) were found to be significant predictors of stopping out at $p<.05$.

Table 10

Odds Ratios (and 95\% Confidence Intervals) for the Predictors on Stopping Out Any Time after the First Year $(N=4891)$

\begin{tabular}{lccccc}
\hline & $\begin{array}{c}\text { Odds } \\
\text { Ratio }\end{array}$ & $\begin{array}{c}\text { Standard } \\
\text { Error }\end{array}$ & $\mathrm{z}$ & \multicolumn{2}{c}{ [95\% Confidence } \\
Interval]
\end{tabular}


The binary logistic regression provides the analysis that corresponds to the hypotheses discussed in chapter 3 . Of the hypotheses for the background characteristics, $\mathrm{H}_{1}$ was the only one supported in this study, as males were more likely to stopout than females. As shown in Table 10, males had a significantly $(p<.05)$ higher chance of stopping out as being a male increased the odds of stopping out by $45 \% . \mathrm{H}_{2}$ was not supported by the results as local residence was not found to be a significant predictor of stopping out. $\mathrm{H}_{3}$ was not supported as white students were not found to be more likely to stopout. $\mathrm{H}_{4}$ was not supported in this study as first generation status was not found to be a significant predictor of stopping out. $\mathrm{H}_{5}$ was not supported as PELL grant recipients were not found to be more likely to stopout.

When testing the academic preparation hypotheses $\left(\mathrm{H}_{6}, \mathrm{H}_{7}\right.$, and $\left.\mathrm{H}_{8}\right)$, none were supported by the results. Of the final set of hypotheses that predicted the impact of incollege experiences, two of the four were found to significantly impact stopping out. $\mathrm{H}_{9}$ was supported as students who live on-campus their first semester were less likely to stopout. As shown in Table 10, living on-campus their first semester reduced the odds of stopping out by $39 \%$. This finding is significant at the .01 level. $\mathrm{H}_{10}$ was not supported as majoring in a STEM field during the first semester did not predict stopping out. $\mathrm{H}_{11}$ was supported as higher first year GPA reduced the likelihood of stopping out as there was a $17 \%$ decrease in the odds of stopping out for every one unit increase in GPA (see Table 10). This is significant at the .05 level. $\mathrm{H}_{12}$ was not supported by the results and instead, the opposite was found as students who received more financial aid were less likely to stopout. As shown in Table 10, the odds of stopping out were $50 \%$ lower for students in the fourth quintile than students in the first quintile. Similarly, the odds of stopping out 
were $49 \%$ lower for students in the fifth quintile than students in the first quintile. These differences were significant at the .05 level. Of note, while not hypothesized, there is a cohort effect. For students in the 2010 cohort, the odds of stopping out was $74 \%$ greater than for students in the 2011 cohort (see Table 10). This difference is significance at the .001 level.

To complement the odds ratio interpretation, I translated the odds ratios into predicted probabilities on the significant $(p<.05)$ covariates as well as the overall predicted probability of stopping out. The predicted probabilities were calculated from the binary logistic regression results and hold all other variables constant at their means.

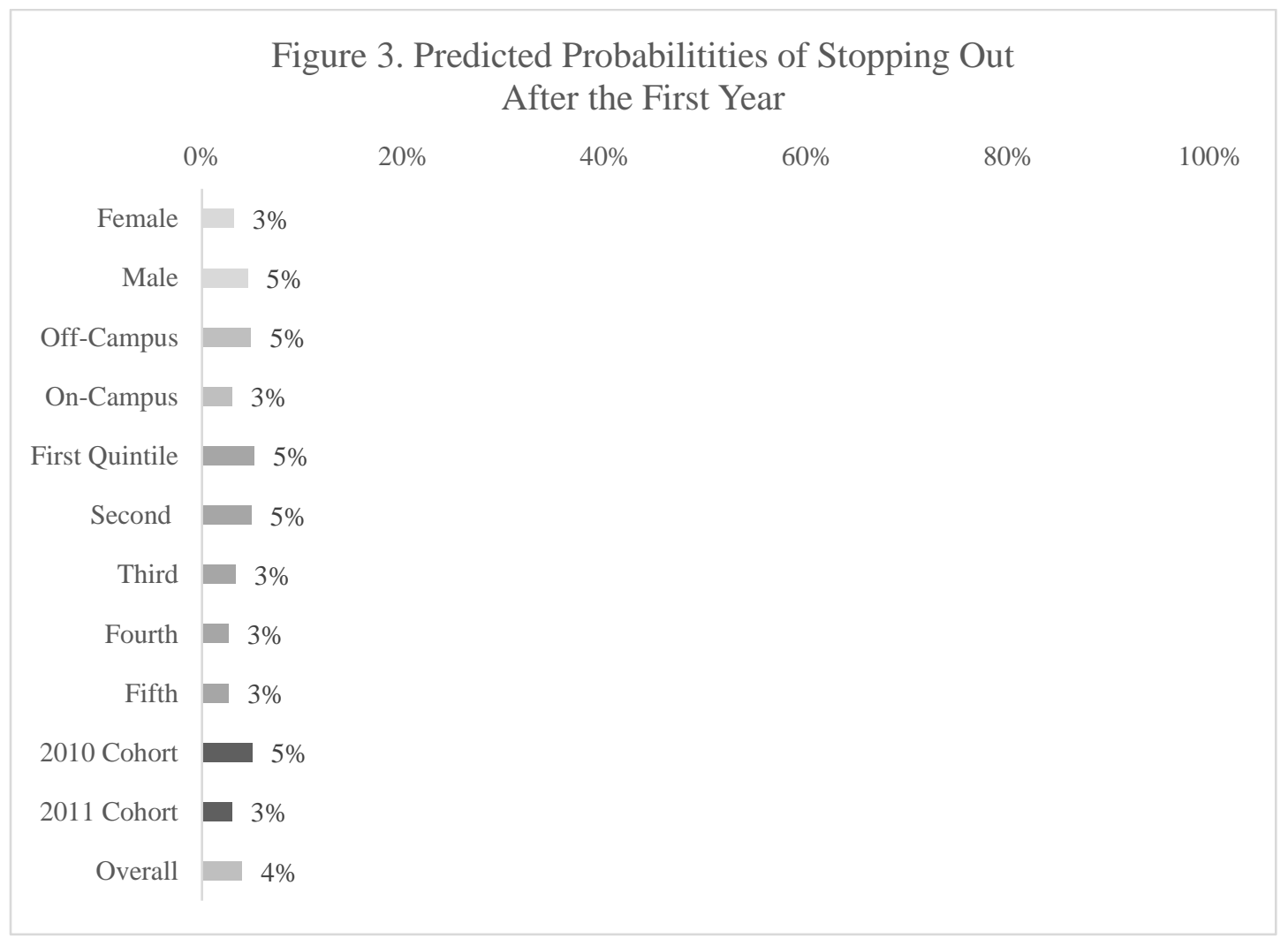

All statistically significant variables have only a modest effect on the probabilities of stopping out. In the combined cohort populations, students had a $4 \%$ chance of stopping 
out (see Figure 3). Males had a 5\% chance of stopping out whereas females have a 3\% chance of stopping out (see Figure 3). Students who lived off-campus their first semester had a $5 \%$ chance of stopping out compared to a $3 \%$ chance for students who lived oncampus their first semester. Students who were in the first and second quintiles had a 5\% chance of stopping out compared to students who were in the other three quintiles who had a $3 \%$ chance of stopping out. Students who were in the 2010 cohort had a $5 \%$ chance of stopping out whereas students who were in the 2011 cohort have a $3 \%$ chance of stopping out. Thus, students had a higher chance of stopping out if they were male, lived off-campus their first year, received a first year financial aid amount in the first or second quintile of total aid received, or were in the 2010. The binary logistic regression considered the factors that predicted stopping out versus not stopping out. My final analyses, multinomial logistic regression, examined how the factors that predicted stopping out compared to the factors that predicted other student pathways.

\section{Comparison of the Factors that Predicted Stopouts versus Other Outcomes}

Multinomial logistic regression (MLR) was employed to investigate which factors predicted each of the other three outcomes in comparison to stopouts at the end of year six. Since the student pathways were outcome variables that can occur at any point after enrollment and due to the fact that nearly three fourths of students stopped out in either their second or third year, I decided to run MLR tests for the pathways any time after the first and second years. Both of these tests run from that year through the sixth year since they were looking at stopping out any time after the examined year. The reference category for the each MLR was stopouts since they were the population of interest. The covariates were introduced in three separate models, each one introducing additional 
controls and holding all other variables at their means. MLR is a multivariate test in that it incorporates all predictors simultaneously returning relative risk ratios for each predictor that were net of other predictors in the model. MLR incorporates all outcome categories simultaneously; thus, the pseudo $\mathrm{R}^{2}$ per model is the same for each comparison. For the first year MLR, Model 1 included background characteristics and had a pseudo $\mathrm{R}^{2}$ of 0.018 . Model 2 included both background characteristics and precollege academic preparation variables and had a pseudo $\mathrm{R}^{2}$ of 0.066 . Model 3 included background characteristics, pre-college academic preparation variables, and first year college variables and had a pseudo $\mathrm{R}^{2}$ of 0.276 . The second year blocks were structured similarly and resulted in the same pseudo $\mathrm{R}^{2}$ for blocks one and two, but Model 3 resulted in a pseudo $\mathrm{R}^{2}$ of 0.264 as first year GPA was replaced with second year GPA and first year financial aid quintiles were replaced with second year financial aid quintiles. The improved pseudo $\mathrm{R}^{2}$ suggested improved model fit as each block was added for both years, which was confirmed with postestimation likelihood ratio tests that returned statistically significant improvement in model fit $(p<.001)$. Thus, for both years, the full models, with the highest pseudo $\mathrm{R}^{2}$, resulted in a statistically significant model fit and demonstrated that the college variables had the most impact on predicting enrollment pathways. To complement the MLR and relative risk ratios interpretation, I provide predicted probabilities for significant variables in Model 3 for both years.

\section{Year One}

After running listwise deletion, the number of observations included in the models for year one was 4,907 as compared with the full population of 5,000; however, even with this decrease, this model maintained over $97 \%$ of the population. 
As shown in Table 11, Model 1, for males relative to females, the relative risk ratio of graduating to stopping out would be expected to decrease by a factor of .55 ( $p<$ .001). In other words, males were less likely than females to graduate than stopout. Model 2 introduced academic preparedness controls along with the background variables, which all returned significant relative risk ratios. Similarly to Model 1, for males relative to females, the relative risk ratio of graduating to stopping out would be expected to decrease by a factor of $.51(p<.001)$ from Model 1 to Model 2. For every one unit increase in ACT score, the relative risk of graduating to stopping out by the end of year six would be expected to increase by a factor of $1.12(p<.001)$. Students who earned college credits prior to enrolling relative to those who did not have a relative risk of graduating to stopping out by the end of year six of 1.60; so students with earned college credits prior to enrolling were more likely to graduate than to stopout by the end of year six compared to students who do not bring in earned college credit $(p<.01)$. The final academic preparedness variable, high school GPA, also returned a statistically significant $(p<.05)$ relative risk ratio, indicating that for every one unit increase in high school GPA, the relative risk of graduating relative to stopping out by the end of year six increased by a factor of 1.47 .

The final model for graduating versus stopping out (Model 3) introduced college experience and performance to the background and preparedness variables. Males continued to return significant results as for males relative to females, the relative risk ratio of graduating to stopping out would be expected to decrease by a factor of .71 ( $p<$ .05). The academic preparedness variables no longer returned significant relative risk ratios, but some first year college variables did. For the 2010 cohort members relative to 
the 2011 cohort members, the relative risk ratio of graduating to stopping out would decrease by a factor of 0.56 . In other words, students in the 2010 cohort were less likely to graduate than stopout out by the end of year six $(p<.001)$. Living on-campus compared to off-campus, the relative risk of graduating to stopping out would be expected to increase by a factor of $1.7(p<.01)$. Thus, students who lived on-campus their first year were more likely than students who live off-campus their first year to graduate than stopout. If a student were to increase their GPA by one point, the relative risk for graduating compared to stopping out by the end of year six would be expected to increase more than fivefold $(p<.001)$. Students in the fourth and fifth first year financial aid quintile in comparison to students in the first quintile were more likely to graduate than stopout. For students in the fourth quintile in comparison to students in the first quintile of first year financial aid, the relative risk of graduating to stopping out by the end of year six would increase by a factor of $2.15(p<.01)$. For students in the fifth quintile in comparison to students in the first quintile of first year financial aid, the relative risk of graduating to stopping out by the end of year six would increase by a factor of $2.59(p<.01)$. Thus, receiving aid in the fourth or fifth quintile increased the chances of graduating relative to stopping out.

The second set of models, compared persisters versus stopouts. Model 1 in the second set consisted of demographic characteristics and returned only one significant predictor (male). As shown in Table 11, being male relative to female was associated with a 1.61-fold increase in persisting through all six years compared to stopping out $(p<$ $.05)$. Model 2 incorporated both background and preparedness variables introduced 
Table 11

Relative Risk Ratios (and 95\% Confidence Intervals) for the Predictors on Graduating, Persisting, and Not Persisting versus Stopping Out Any Time after the First Year $(N=4907)$

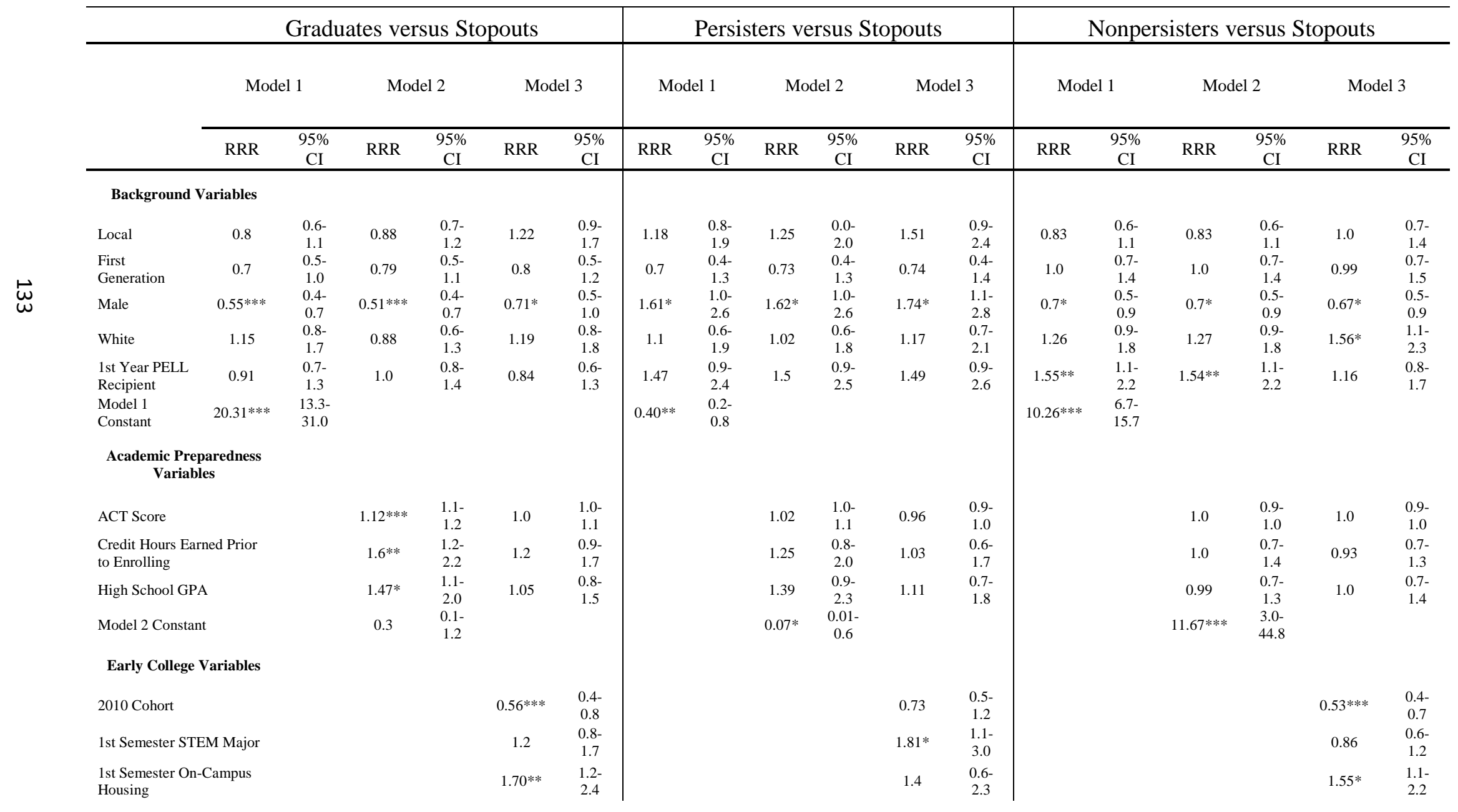




\begin{tabular}{|c|c|c|c|c|c|}
\hline 1st Year GPA & $\begin{array}{ll}5.43^{* * * *} & 4.5- \\
& 6.6\end{array}$ & $1.95^{* * *}$ & $\begin{array}{l}1.5- \\
2.6\end{array}$ & $0.68 * * *$ & $\begin{array}{c}0.6- \\
0.8\end{array}$ \\
\hline \multicolumn{6}{|l|}{ 1st Year Financial Aid } \\
\hline 2nd Quintile & $\begin{array}{l}0.7- \\
1.6\end{array}$ & 1.0 & $\begin{array}{l}0.5- \\
1.9\end{array}$ & 1.14 & $\begin{array}{l}0.8- \\
1.7\end{array}$ \\
\hline 3rd Quintile & $\begin{array}{l}1.0- \\
2.7\end{array}$ & 1.11 & $\begin{array}{c}0.5- \\
2.3\end{array}$ & $1.70^{*}$ & $\begin{array}{l}1.1- \\
2.8\end{array}$ \\
\hline 4th Quintile & $2.15 * *$ & 1.51 & $\begin{array}{l}0.7- \\
3.4\end{array}$ & $2.12^{*}$ & $\begin{array}{l}1.2- \\
3.8\end{array}$ \\
\hline 5th Quintile & $2.59 * *$ & 0.93 & $\begin{array}{l}0.4- \\
2.3\end{array}$ & 1.71 & $\begin{array}{l}0.9- \\
3.2\end{array}$ \\
\hline Model 3 Constant & $\begin{array}{lc}0.60^{* * *} \quad & 0.01- \\
0.3\end{array}$ & $0.90^{*}$ & $\begin{array}{c}0.01- \\
0.8\end{array}$ & $21.18 * * *$ & $\begin{array}{l}4.8- \\
93.9\end{array}$ \\
\hline
\end{tabular}


academic preparedness controls. In this model, males relative to females continued to have a significantly higher relative risk of persisting through all six years compared to stopping out at a factor of $1.62(p<.05)$. Unlike in the graduates versus stopouts comparison, none of the academic preparedness variables returned significant relative risk ratios for persisters versus stopouts.

The final model for persisters versus stopouts (Model 3) introduced college experience and performance variables to the background and preparedness variables. Males relative to females continued to have a significantly higher relative risk of persisting through all six years compared to stopping out at a factor of $1.74(p<.05)$. The risk of persisting through all six years compared to stopping out is 1.81 times higher for first semester intended STEM majors in the first year compared to non-STEM majors ( $p$ $<.05)$. If a student were to increase their GPA by one point, the relative risk for persisting through all six years compared to stopping out would be expected to increase nearly twofold $(p<.001)$. In turn, if a student increased their GPA, we would expect them to be more likely to persist than to stopout.

The final set of models compared not persisting to stopping out. Model 1 consisted of background characteristics and returned two significant predictors (male and $1^{\text {st }}$ year PELL grant recipient) and a trivial pseudo $\mathrm{R}^{2}$ of 0.018 . As shown in Table 11 , for males relative to females, the relative risk of not persisting compared to stopping out would be expected to decrease by a factor of .70 $(p<.05)$. In other words, males were less likely than females to not persist compared to stopout. The risk of not persisting relative to stopping out by the end of year six is 1.55 times higher for PELL grant 
recipients than those who did not receive a PELL grant $(p<.01)$. Model 2 introduced academic preparedness controls to the background variables slightly increasing the pseudo $\mathrm{R}^{2}$ to 0.067 . Similar to the stopouts versus persisters comparison, none of the academic preparedness variables returned statistically significant relative risk ratios for stopouts versus nonpersisters. For Model 2, males continued to have a statistically significantly lower relative risk of not persisting compared to stopping out by the end of year six at a factor of $.70(p<.05)$. In addition, the risk of not persisting relative to stopping out by the end of year six continued to be higher (1.54 times higher) for PELL grant recipients than those who did not receive a PELL grant $(p<.01)$ their first year.

The final model for not persisting versus stopping out (Model 3) introduced college experience and performance variables to the background and preparedness variables strengthening the pseudo $\mathrm{R}^{2}$ to 0.276 . Males continued to have a statistically significantly lower relative risk of not persisting compared to stopping out by the end of year six at a factor of .67 $(p<.05)$. Being White increased the risk of not persisting relative to stopping out by the end of year six with a 1.56-fold increase compared to students of color $(p<.05)$. For 2010 cohort members relative to 2011 cohort members, the relative risk of not persisting to stopping out by the end of year six would be expected to decrease by a factor of $.53(p<.001)$. In other words, members of the 2010 cohort were less likely than members of the 2011 cohort to not persist compared to stopping out. Living on-campus compared to off-campus, is associated with a 1.55 -fold increase in the chance of not persisting compared to stopping out by the end of year six $(p<.05)$. In other words, students who live on-campus their first year were more likely than students who live off-campus their first year to not persist than stopout. If a student were to 
increase their GPA by one point, the relative risk for not persisting relative to stopping out by the end of year six would decrease by a factor of .68 $(p<.001)$. In turn, if a student increases their GPA, we would expect them to be more likely to stopout than to not persist. Students in the third and fourth first year financial aid quintile in comparison to students in the first quintile were more likely to not persist than stopout. The relative risk ratio of students in the third quintile in comparison to students in the first quintile not persisting relative to stopping out by the end of year six would increase by nearly twofold $(p<.05)$. The relative risk ratio of students in the fourth quintile in comparison to students in the first quintile not persisting relative to stopping out by the end of year six would increase by more than twofold given the other variables were held constant $(p<$ $.05)$. Thus, students in the middle of financial aid recipients were more likely to not persist than students in the lower two quintiles and highest quintile of financial aid received.

\section{Predicted Probabilities for Each Pathway after Year One}

To further explore the comparison of the four student pathways, I ran predicted probabilities as a postestimation of the multinomial logistic regression for the covariates that were statistically significant in at least one of the third models for each comparison. The predicted probabilities hold all other variables constant at their means. The variables that returned statistically significant results in at least one of the third models for each comparison include sex, race, cohort, first year STEM major, first semester housing, first year GPA, and first year financial aid received. Beginning with sex and as shown in Figure 4, females had a lower chance of stopping out, a lower chance of persisting, and a 
higher chance of not persisting than males. Put another way, females had a higher chance of dropping out than males.

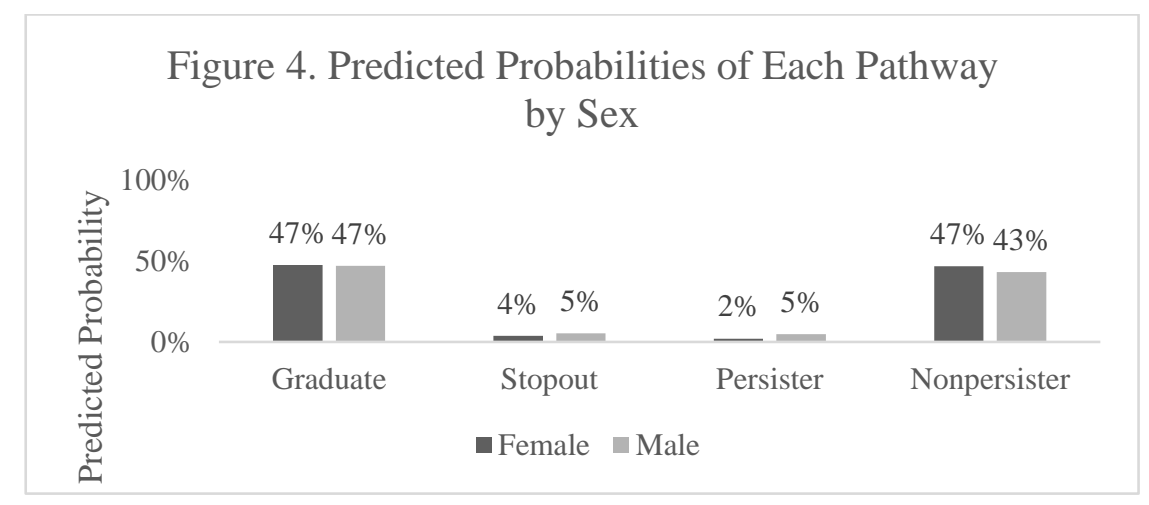

As shown in Figure 5, students of color had a higher chance of graduating, a higher chance of stopping out, and a lower chance of not persisting than white students by the end of year six.

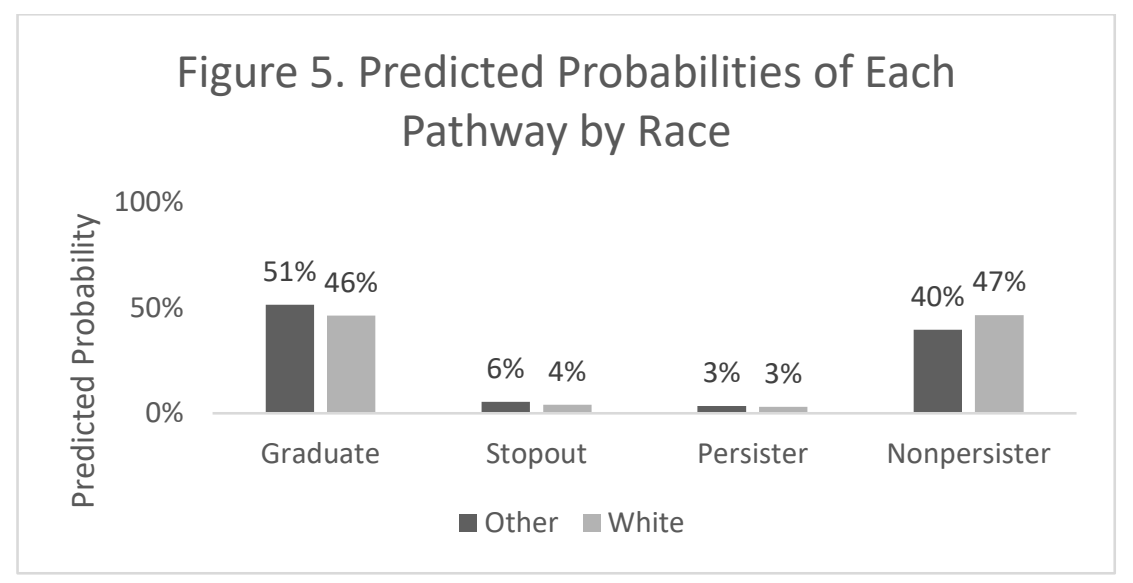

As shown in Figure 6, students who were STEM majors in their first year had a higher chance of graduating by or persisting through the end of their sixth year and a lower chance of not persisting by the end of their sixth year. 


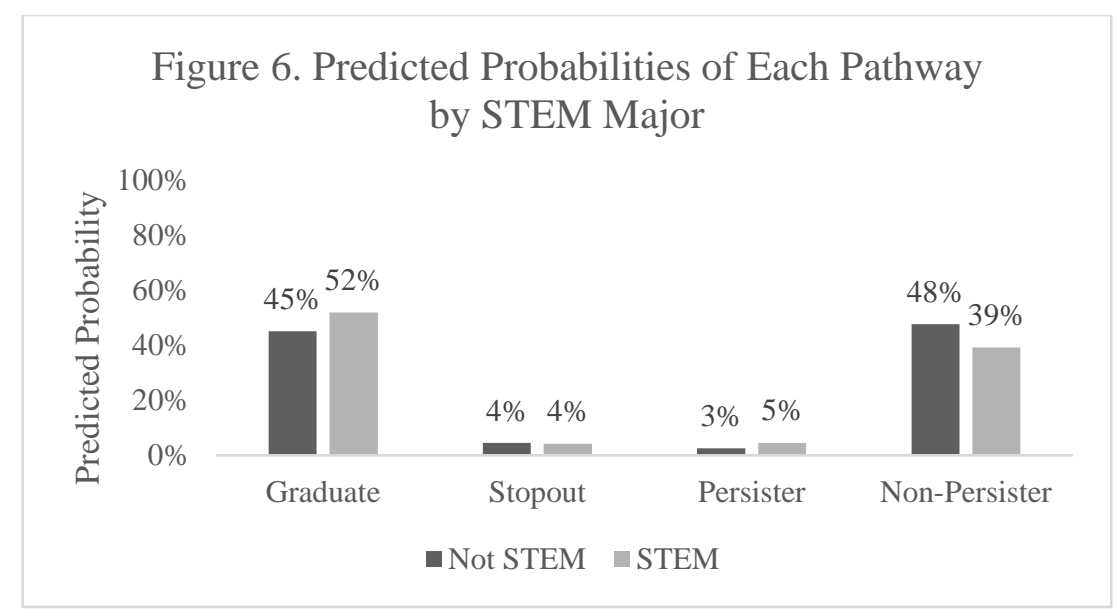

As shown in Figure 7, students in the 2010 cohort had a slightly higher chance of graduating, a higher chance of stopping out, a higher chance of persisting, and a lower chance of not persisting by the end of year six than students in the 2011 cohort.

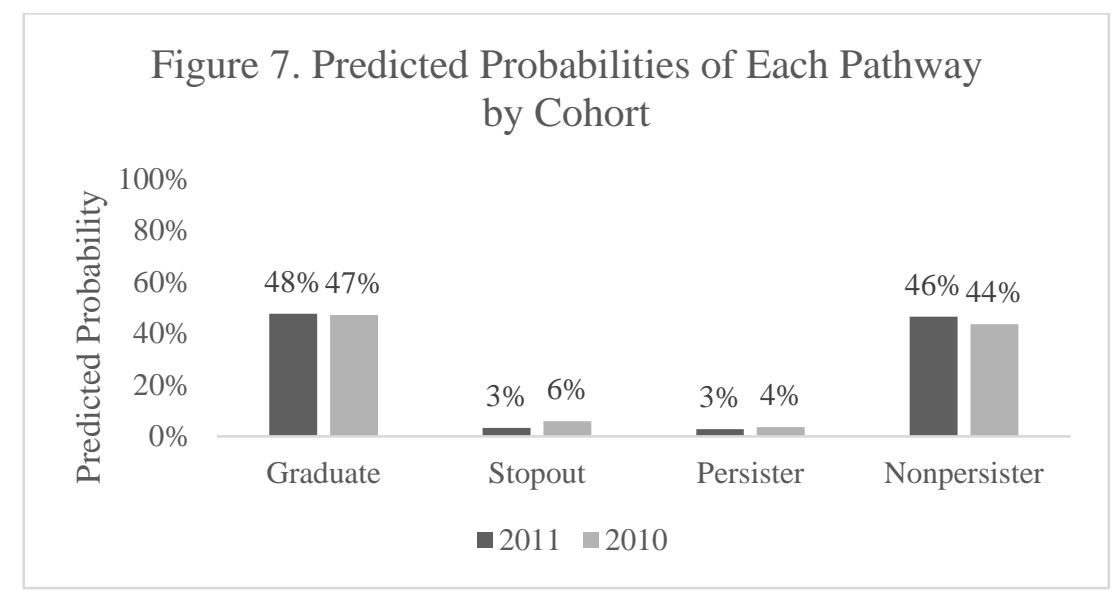

As shown in Figure 8, students who lived on-campus had a higher chance of graduating and a lower chance of stopping out by the end of Year 6 than students who lived offcampus. 


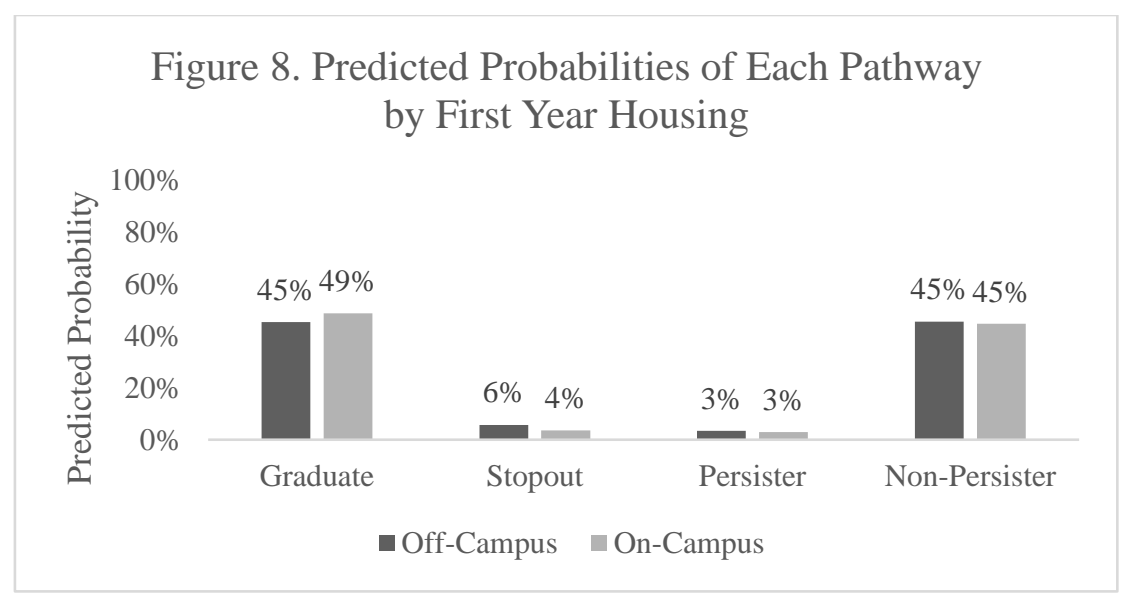

As shown in Figure 9, students who had a higher GPA had a higher probability of graduating and a lower probability of not persisting by the end of year six.

Firgure 9. Predicted Probabilities of Each Pathway by First Year GPA
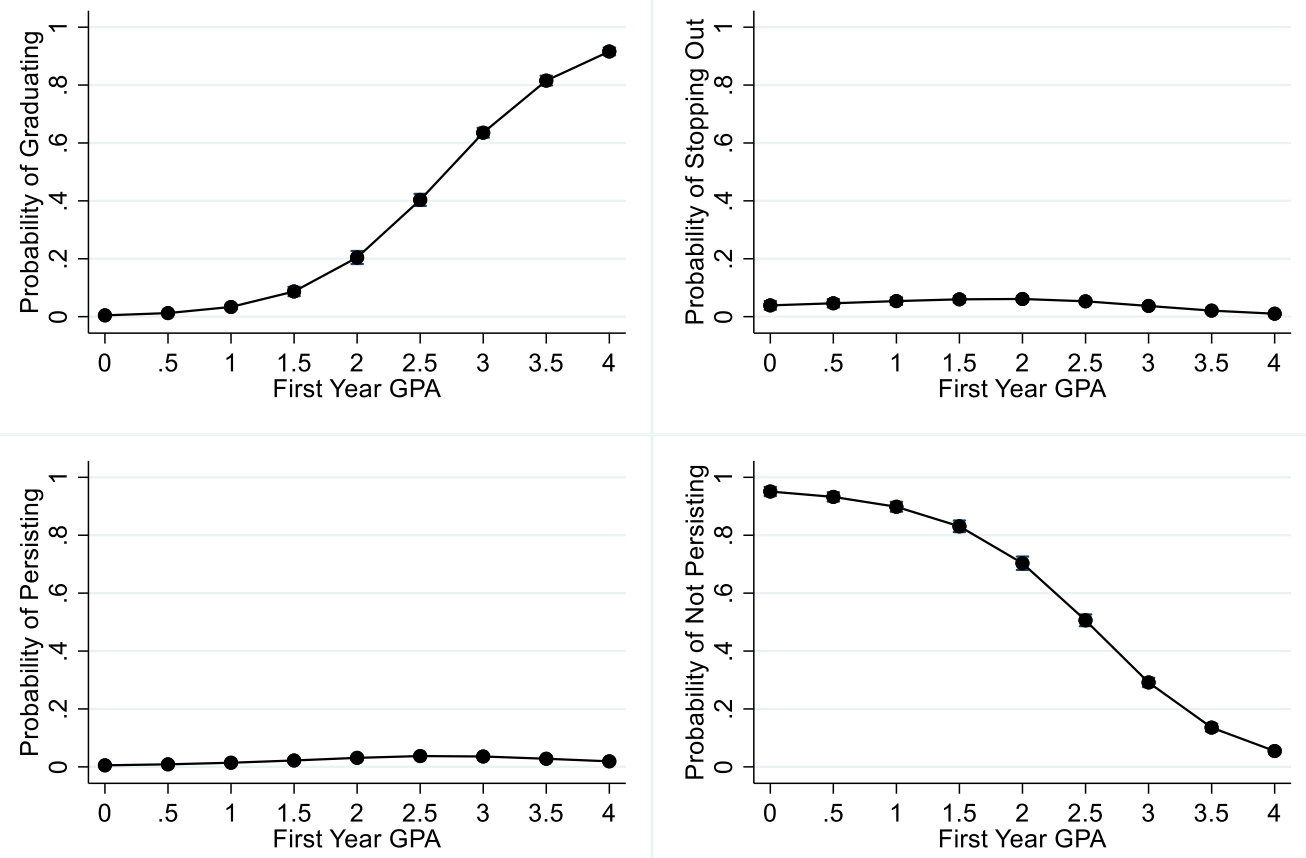
As shown in Figure 10, students who received aid in the highest one fifth of received first year financial aid had a higher probability of graduating than students in the other quintiles by the end of year six.

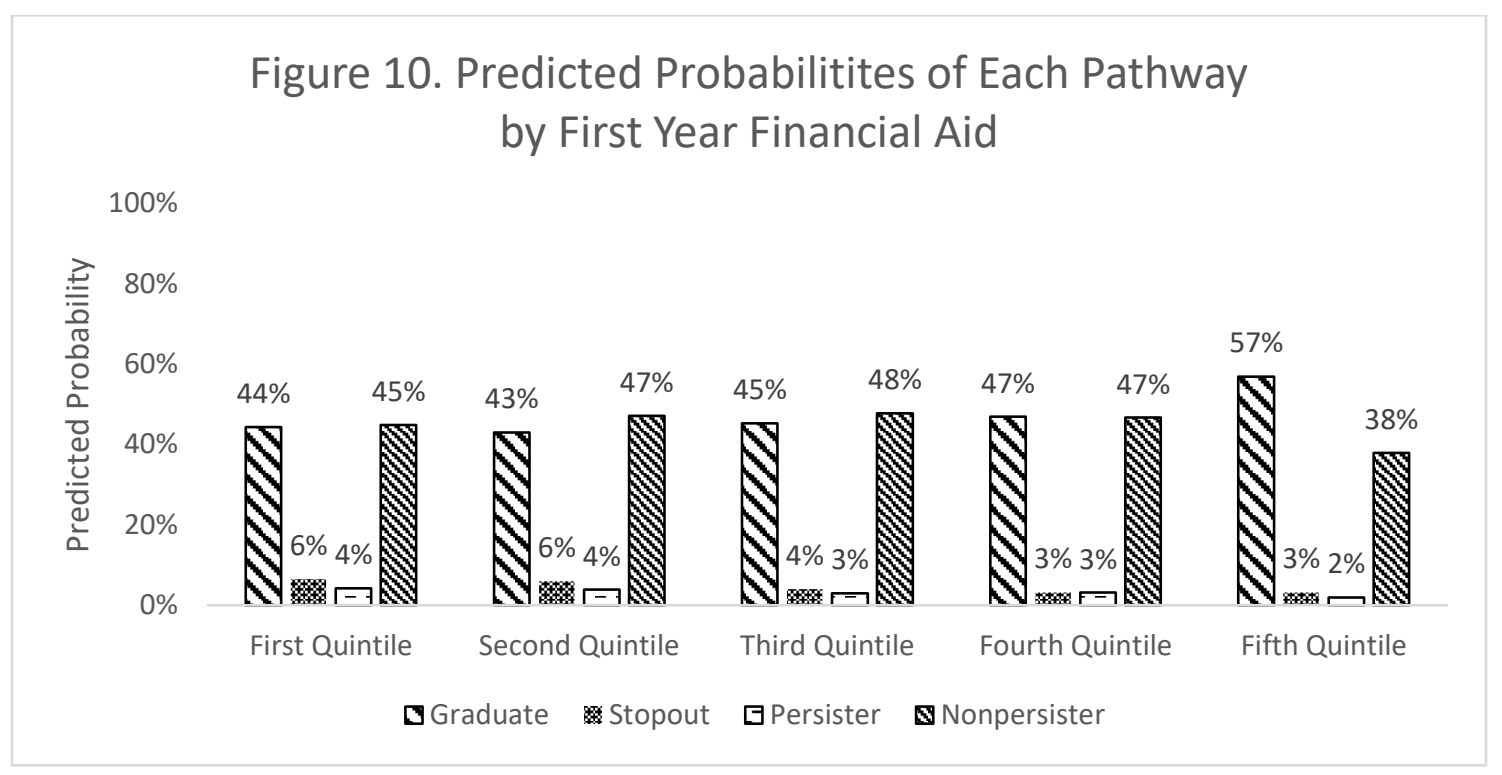

\section{Summary of MLR Findings}

Since the majority of students who stopped out did so either in the second or third years, multinomial logistic regression was conducted to investigate predictors on each pathway any time after years one and two. Year one revealed several differences between stopouts and the other enrollment pathways; year two did not return appreciably different results and are not included in detail here (see Appendix C). In the fully controlled model, relative to stopouts, graduates were less likely to be male and less likely to be in the 2010 cohort. Graduates were also more likely to live on-campus their first year, receive more financial aid, and to earn a higher first year GPA than stopouts. Stopouts appear to resemble persisters more, but there were a couple of differences including that males were more likely to be persisters than stopouts. Persisters also have higher first- 
year GPAs and were more likely to be an intended STEM major during their first semester. When comparing nonpersisters to stopouts, nonpersisters were found to more likely be White, live on-campus their first year, and receive more financial aid.

Nonpersisters were also less likely to be male, in the 2010 cohort, and had a lower firstyear GPA. While stopouts had lower GPAs than graduates and persisters after their first year, they had higher GPAs than nonpersisters. This supports the utilization of using firstyear GPA in identifying at-risk populations. The other significant findings provided mixed results between the comparisons. For example, in comparison to stopping out, living on-campus and receiving more financial aid increased the risk of not persisting and the chance of graduating. Being male returned interesting results as males were less likely to graduate or not persist but more likely to be persisters in comparison to stopping out.

Year two findings continued the emphasis on GPA as, in comparison to stopouts, graduates and persisters were more likely to have higher second-year GPAs. Being an intended STEM major during their first year also continued to return significant influence as graduates and persisters, in comparison to stopouts, were more likely to be intended STEM majors in their first year. Neither of these variables returned significant differences between nonpersisters and stopouts. Graduates, relative to stopouts, continued to see the positive influence of living on-campus their first year and continued to less likely be in the 2010 cohort. Nonpersisters, compared to stopouts, were also less likely to be in the 2010 cohort and they were less likely to be male.

\section{Conclusion}

The quantitative analyses uncovered some interesting characteristics of stopouts and factors that predict stopout as well as some significant differences between stopouts 
and other pathways. While stopouts were a small share of the cohort populations, they exhibited some notable behaviors. Over a third of students who stopped out did so for the first time in their third semester and another third did so in the next three semesters suggesting the first and second years were critical for these students. Thus, students' experiences in their first and second years should be closely evaluated by institutions in order to create interventions that may encourage students to stay instead of leave or to stay in touch while stopped out. The majority of students did not take much time off with two thirds of students who stopped out doing so for two years or less with over a third stopping out for only one semester, indicating their ability to address their challenges fairly quickly.

Similar to the stopout literature, students who stopped out received less financial aid than other pathways and were more likely to be men (Goldrick-Rab, 2006; Horn and Carroll, 1998; Kim et al., 2012; Terriquez \& Gurantz, 2015; Woosley, 2004).

Specifically, students who were males or received less financial aid have a higher chance of stopping out than those who were females or those who received financial aid in the third, fourth, or fifth quintiles. Students who lived on-campus their first year as well as students with higher first year GPAs had a lower chance of stopping out compared to those who lived off-campus and those who had lower first-year GPAs.

When comparing the quantitative findings with my qualitative findings, the analytic sample has both similarities and differences with the total stopout population. More men were interviewed and lived on-campus their first semester at the same rate as the total stopout population. Interestingly, my interview sample differed most notably from the stopout population on local residence as the large majority of interviewees was 
local while just over half of the stopout population was local. The interviewees' stories reflected a lack of academic integration, which is consistent with the significant findings of the impact of first year GPA; however, over half of the interviewees discussed starting as an intended STEM major and leaving it but first year intended STEM major was not found to be a significant predictor of stopping out.

Finally, the multinomial logistic regression found more significant differences between stopouts and graduates as well as stopouts and nonpersisters than stopouts and persisters. Students' early college experiences were found to be statistically significant differences between stopping out and the other pathways whereas academic preparedness was not found to be statistically significant for any comparison of the fully controlled models. In-college factors were also found to return statistically significant results when predicting the other student pathways in comparison to stopping out at any point after year two. These findings are in line with the general retention literature that consistently finds that within college experiences as measured by first year GPA and living oncampus during the first year are related to greater persistence rates (Allen et al., 2008; Mayhew et al., 2016; Tinto, 1993). 


\section{CHAPTER VI: \\ DISCUSSION AND CONCLUSION}

This study sought to explore four main questions: (1) who stopped out at City U, (2) why they stopped out, (3) what happens when they are out and why did they return, and (4) what was different after they returned. The mixed methodological approach allowed me to investigate the questions more comprehensively than had I chosen only one method. The quantitative analyses permitted not only an examination of the stopout population but also a comparative analysis of student enrollment outcomes that helped to explore unique aspects of this particular student group. On the other hand, the qualitative investigation provided a thick description of stopouts' experiences revealing concepts not found in the institutionally collected student records. In addition to the findings uncovering some statistically significant predictors of stopping out at City U, this study uncovered specific struggles with uncertainty, mental health, and integration faced by participants. These struggles are likely not limited to students who stopout but may also be some of the challenges faced by other students, including those who do not persist. Addressing these challenges through both development and integration lenses will allow institutions to improve student success.

\section{Discussion}

As reviewed in chapter four, two overarching themes emerged from the qualitative data: (1) Psychosocial Barriers and Development and (2) Integration and 
Isolation; however, these themes are not separate but are intertwined. The majority of participants in this study entered college without a clear direction and without their own sense of purpose. In recent decades, a college-for-all ideology has spread across the United States influencing the life course for generations of adolescents (Elder, 1998). In addition to creating broader access to higher education, this ideology has instilled a belief that everyone should attend college for the best chance at future financial stability and success.

The students in this study demonstrate one ramification of this cultural belief; they entered college following external directives that told them they were supposed to go and, in turn, lacked a personal commitment to or personalized plan for success in college. They, as individuals, did not choose to attend college, but instead attended out of obligation and external expectations leading to psychosocial barriers to their success. As institutions where one must apply and be accepted, universities and colleges operate on the assumption that students choose to be there and that students made an active decision about their college choice. Instead, the large majority of students in this study shared that City U was a default choice because it was a four-year, public institution near or in their hometown. Few interviewees considered other schools and many said that they only applied to City $\mathrm{U}$. The university has a prominent presence in its community and since the students had been told their next step after high school was college, they enrolled in City $U$ as the next logical step along their path. Similarly, upon enrolling, about half discussed choosing a STEM major because of the higher prestige of those majors in society and within their families as well as the belief that STEM majors were necessary for better employment opportunities. During their initial enrollment into college and with 
their original major selection, participants uncritically followed external formulas for their life's path since they had not yet developed an internal sense of self (Baxter Magolda, 2001). Additionally, a majority of participants lived at home during their first year, layering on college courses into their life while not fully engaging in a more comprehensive and developmental college experience. This phenomenon was supported in the quantitative data by the significant finding that living on-campus during one's first year reduced the likelihood of stopping out. Students' decisions about where to live their first year were likely influenced by both their commitment to college and other factors, such as finances and family responsibilities.

The participants, both initial STEM and non-STEM majors, shared that once they enrolled in their first-year courses, they found themselves at a crossroads as they began struggling to engage academically, leading them to question the path laid out for them by external expectations (Baxter Magolda, 2001). Some only discussed struggling with the course material and workload, which was supported in the quantitative findings by the significance of first- and second- year GPA, but most discussed struggling with motivation, interest, and in return, academics. Students' stories revealed feelings of isolation as they were not integrated into the academic components of school. For many, these struggles manifested into anxiety and depression as they faced instability realizing they were not sure why they were in college or what they wanted (Arnett, 2004). They began to question their academic efficacy and no longer wanted to just go through the motions of being in college. The students realized they were not performing up to their capabilities and experienced anxiety as they struggled to make meaning of their situation. Some only discussed their personal challenges, while others mentioned life events (e.g. 
the loss of a loved one or parents' divorce) that took their focus away from school. Few students were aware of the campus counseling office and even fewer sought assistance from campus resources or employees to address their uncertainty and challenges prior to stopping out.

This lack of reliance on institutional agents suggests isolation as well as limited integration and social capital that could have enhanced their ability to successfully navigate challenges and stay enrolled. Most students followed their internal voice by choosing to leave to figure things out and get support (Baxter Magolda, 2001, 2008). If students were more integrated into the campus community, they may be more likely to turn to the institutions' resources, staff, and faculty for support in order to explore new opportunities and work through the instability of changing plans (Arnett, 2004; Tinto, 1993). Connected students may still choose to leave the institution, but they may also stay in touch while not enrolled, which would likely increase the likelihood of and ease their reenrollment. Indeed, the few participants who shared that they talked with an advisor about taking time off returned sooner than the average of four semesters stopped out.

Interestingly, all of the students, no matter the reason they stopped out, detailed the psychosocial development they experienced while they were not enrolled; growth that they suggested allowed them to return and approach college differently. While not enrolled, participants worked for pay or volunteered, through which they explored versions of themselves and developed a sense of identity (Arnett, 2004). Many spoke of finding a new intellectual passion or committing to long held interests that were not necessarily what their families wanted them to study. Through out-of-school experiences, they gained insight into what they had to offer the world of work and how a college 
education fit into their plan. They were able to listen to their internal voice as well as cultivate it as they constructed their own foundation for their interests and experiences (Baxter Magolda, 2001, 2009). Additionally, participants discussed refining their social circles and activities, e.g. choosing people who were future-focused and supportive of their journey over causal friendships.

Upon returning to the university, over half of the participants changed majors and most discussed how they were more focused and driven to succeed having clarified their goal commitment (Tinto, 1993). Having recognized their personal growth while not enrolled, the participants now saw that their time in college was to be a period of continued development instead of just hurdles to jump through on their path to life. Through their experiences while not enrolled, participants were able to approach college with an internal commitment to their success and an optimism for the possibilities that laid ahead of them (Arnett, 2004; Baxter Magolda, 2009). Additionally, students demonstrated improved academic integration after returning through stories of engaging with their classes, their academic departments, and utilizing their relationships with faculty to help them navigate their education.

\section{Comparison of Stopout Sample, Population, and Literature}

The interview sample in this study did not fully resemble the profile of stopouts as reported by other researchers or the total stopout population in the combined cohorts. This is likely due to the cohort-specific design of the study and the institution's population as well as nonresponse bias introduced by those who were not able to take the time to participate in an interview. Other studies have found students who stopout are often older, have children, work full-time, and have financial constraints (Hoyt \& Winn, 
2004; Kim et al., 2012); however, this sample was comprised of traditionally aged students and only one had a child prior to stopping out, though two others had children while not enrolled. None of the participants discussed work conflicts as leading to stopping out and only six shared financial considerations when deciding to stopout. Of those who described financial factors influencing their stopping out, two participants discussed stopping out because of financial balances on their accounts; two shared that they did not want to waste money by doing poorly due to feeling like they needed to take time off; while another two transferred to a community college to save money on their general education requirements.

While financial considerations were not emphasized by the majority of interviewees, financial aid was an interesting variable in the quantitative analyses as the stopout population averaged a significantly lower amount of financial aid than the other pathways. Furthermore, receiving amounts in the fourth and fifth quintiles of first-year financial aid significantly lowered one's chances of stopping out. This suggests that students' access to financial aid may impact their decision to stopout as was found by Terriquez and Gurantz's (2015) study into stopping out during the Great Recession. Though the stopout students in the qualitative sample were traditional in many regards (including age and limited out-of-school responsibilities prior to stopping out), they were less likely to live on-campus than the total student population. The quantitative analyses revealed living on-campus during the first year significantly lowered a student's chances of stopping out. Students' financial aid was found to be moderately correlated (pointbiserial correlation $=0.34$ ) with living on-campus during the first year and could be 
because students who live at home would not need to take out as much financial aid as those who have room and board charges to cover.

Few of the student background variables and none of the academic preparation variables were significant predictors of stopping out, suggesting that students' in-college academic performance and financial aid received are more likely to influence their enrollment pathway (Pascarella et. al., 1981; Tinto, 1993). Research suggests that men are more likely to have interrupted patterns of enrollment (Allen et al., 2008; Clery \& Tooper, 2009; Ewert, 2012) and this was reflected in the interview sample (55.6\%) as well as the total stopout population $(60.2 \%)$ when compared with the percentage of males in the combined cohorts (49.1\%). Indeed, being male increased one's risk of stopping out consistently across the binary and multinomial quantitative analyses. It is unclear what impact the Great Recession had on men's decisions to enroll or to interrupt their enrollment; however, it is likely the Great Recession influenced men's choices about their enrollment in some way since the students under study entered university immediately following the recession when $70 \%$ of people laid off were male and when men who were working continued to experience a wage premium earning more than women (Christensen, 2015). Finally, Barefoot (2004) suggested that the majority of students who leave are not in academic failure though Allen et al. (2008) found that firstyear performance remains the strongest predictor of persistence. This study found that interview participants struggled with academic performance and motivation and that within the total stopout population, one's chances of stopping out were lowered as one's first-year and second-year GPAs went up. 


\section{Comparison of Stopout Population to Other Enrollment Pathways}

The multinomial logistic regression revealed two notable predictors from the other enrollment pathways. A lower first-year GPA and not living on-campus during the first year were risk factors of stopping out that relate to challenges with integration. Lower financial aid received, an issue of economic capital, also increased the risk of stopping out compared to the other pathways and should be noted as a risk factor. Males

were more likely to stopout or continuously persist suggesting that more attention could be given to their degree progress and planning. Finally, the significance of the cohort membership was an interesting finding with the 2010 cohort having a higher rate of stopouts. This could be related to various contextual changes such as changes in the economy or the 2011 introduction of City U's initiative that released four-year degree planning tools and encouraged students to pick a major at the end of their first year.

\section{Addressing Psychosocial Barriers and Development as well as}

\section{Isolation and Integration}

Throughout the interviewees' narratives, it is evident how intertwined their psychosocial barriers and development were with their isolation and integration within the institution. For instance, for many students during their initial enrollment, it was difficult to determine which came first, their psychosocial barriers or their isolation within the institution; instead, both of these phenomena provoked the other. When students felt isolated, they were not able to see how the institution could help them as they did not see the institution positioning itself to serve that role in their lives. As they struggled with the anxiety around their uncertainty, they did not see it as a normal part of their developmental process; instead, they felt shame and elected to leave instead of seek 
out someone within the institution to help. The recommendations that follow incorporate the experiences of the interviewees and the quantitative findings with suggestions, situated within the conceptual frameworks of this study, for institutional policy makers and higher education researchers to consider. While the stopout population may be small, their approaches to and experiences with their education are likely shared by others including students who do not persist. Thus, addressing the challenges uncovered in this study could benefit other students and the institutions they attend.

\section{Understanding Uncertainty and Obligation}

The perceptions of students by institutional agents inform both their interactions with students as well as the services they offer. If institutions assume students are apathetic and entitled, they tend to see apathetic and entitled students who they believe do not really want to engage in their education. However, students' apathy may be a defense mechanism to conceal their uncertainty (Marin, 1991; Schreiner, 2017); the uncertainty into why they were attending college and their ability to be successful as was seen in the stories of participants. As emerging adults experiencing the exploration and instability of this time in their lives, the interviewees were considering possible paths and experiencing the anxiety of the unknown (Arnett, 2004.) Additionally, students who have entered college following external formulas for their lives may rely on their past experiences in which decisions were made and things were done for them (Baxter Magolda, 2001), in turn, displaying an entitled attitude as they have rarely, if ever, had to take responsibility for the decisions in their lives. When college attendance is seen as an obligation by students, it reframes the integration role of universities. 
Higher education can work better with K-12 institutions to improve the collegegoing conversation prior to enrollment. While students benefit from schools encouraging their aspirations to attend college and assisting them with the application process, students need to understand what it takes not only to enroll in college but also to complete college (Rosenbaum, 2001). Situating the reasoning for a college education around the importance of the degree for financial and career opportunities limits students' understanding of what it takes to earn a degree and how to make the degree work for them. Expanded information about college, including the cultural capital valued by institutions of higher education, is especially important to working-class students and students of color as they turn to their high school counselors for the information and support that their families cannot provide (Gast, 2016; Holland, 2015; Rosenbaum, 2001). Students and postsecondary institutions will both benefit from a shift in the high school level conversation to a focus on how to be successful in college and the humancapital-building process of a college education (Rosenbaum, 2001). Through a broader conversation of success and growth in college, high schools lay a better foundation for students to engage in needed conversations around their paths and utilize supports once enrolled.

Institutions must be aware that their students may be enrolling because they are supposed to go to college and not because they want to go. This approach to college enrollment needs be understood by institutions if they want to improve student retention and should inform how they serve their students. The stereotypical unencumbered, confident student who is excited to figure out college and themselves was not reflected in the participants' stories and are not likely the characteristics of students who do not 
persist. If institutions want to improve their retention and graduation rates, they cannot continue to assume students will do the work, or know what the work is that needs to be done, to fit into their institutional culture and navigate their academic path. Instead, institutions can proactively assist students through services that develop their institutional social and cultural capital to help them navigate their undergraduate education and the developmental challenges they face along the way (Rosenbaum et al., 2006). This institutional support is imperative to helping students become active participants in their education (Stanton-Salazar, 1997).

As students enter college with an uncertain and obligatory mindset, institutions must intentionally design supports in the first year if they are to address retention issues and offset the national trend of $28 \%$ of four-year college students departing after the first year (Braxton et al., 2014). For many students, the first year may be the only year they give college a chance; thus, institutions must continue to improve the experiences of firstyear students. Both the participants' stories and the significant influence of the stopout population's first-year GPA highlighted the lack of academic integration experienced during the first year. Instead of assuming that students know how to academically integrate and expecting them to take responsibility for the actions needed to do so, institutions should proactively offer services designed to help students develop the skills and confidence to take the responsibility for themselves and their paths. Institutional agents can focus their first-year efforts on building students' social capital while assisting them with understanding the institutions cultural capital in order to help them successfully navigate and participate in the institution (Stanton-Salazar, 1997). Oftentimes, institutional services are built on an assumption that students miraculously 
develop into independent, responsible adults in the short months between high school graduation and college. The college environment is new to first-year students and institutions can take every opportunity to strategically integrate students into it both in the classroom and through required activities since not all students will engage in out-ofclassroom college experiences.

\section{Integrating Development into the Curriculum}

The college-for-all ideology tells students prior to entering college that there is value in a college credential, but the participants' stories suggested that they did not find value in their academic experience until after they stopped out. Arum and Roksa (2011) argued that the focus on the instrumental value of the credential has developed a consumerist orientation toward a college education leading students to expect to obtain the credential "as effortlessly and comfortably as possible" (p. 17). In turn, students, as

demonstrated in the interviewees' stories, do not expect to experience the challenges of personal and intellectual growth that can make them uncomfortable even though these processes are normal features of emerging adulthood (Arnett, 2004). Beginning with student recruitment, institutions should be explicit about what it means to become a college-educated citizen, thus educating students on the cultural capital they are gaining through their educational experiences including the personal, social, and intellectual growth that is expected of college students. To improve undergraduate education, institutions need to focus more on a culture of learning that is centered on student growth and includes high expectations for student work and engagement (Arum \& Roksa, 2011). To help acclimate students to campus, institutions can articulate to students before and after they enroll, the skills that can be developed throughout college and how those skills 
tie to their future life trajectory. By socializing students to an environment focused on growth, students will be more comfortable in the challenge and uncertainty they are experiencing as well as more willing to admit their challenge and uncertainty to faculty and staff. This normalization can encourage them to utilize their institutional social capital to work through their difficulties while they are enrolled or during a needed break, instead of leaving the institutional community altogether.

Focusing on the first year is not a new idea in the higher education literature as transition programs have become institutionalized (Mayhew et al., 2016); however, the discussion needs to shift to students' in-class and academic experiences (Arum \& Roksa, 2011; Tinto, 2012). Indeed, most students in this study were local, a majority did not live on-campus during their first year, but many discussed satisfaction with their early social experiences at City U while struggling with their academic integration. Commuter students have different needs than on-campus residents and have been found to benefit more from intentionally designed academic opportunities such as learning communities as well as improved classroom instruction and faculty engagement (Braxton et al., 2014; Jacoby \& Garland, 2004). Many of the campus initiatives that have been found to have a positive effect on student retention such as tutoring and supplemental instruction rely on students to self-select into them (Mayhew et al., 2016; Pascarella \& Terenzini, 2005), but students in the present study did not indicate participating in such initiatives. In order to improve the experiences of all students, and not just those who choose to take advantage of services, institutions should evaluate the classroom experiences of their students. Tinto (2012) argues that "student retention and graduation is shaped by the availability of clear 
and consistent expectations about what is required to be successful in college" (p. 10) and that those expectations must be communicated daily in each classroom a student enters.

Participants in this study saw general education requirements as a hurdle with little value. This brings up questions about the faculty's approach to the curriculum and instruction of general education courses and the messages that are communicated (intentionally or not). It may be that faculty members have similar feelings about general education courses and that students are interpreting the value of the curriculum from the messages they receive in those classes. If general education is approached as mass education of little value by institutional agents, and thus the institution, then it will be construed by the students as such. Since the majority of general education courses are taken in the first year of college, institutions should evaluate these in-class experiences in order to understand them from students' perspectives and develop supports for faculty and staff to improve their understanding and approaches to general education. The classroom must be at the center of students' educational life as well as at the center of institutional action relating to student success (Tinto, 2012). This includes aligning curriculum appropriately, assessing classroom and program goals, tying courses to support services, and improving faculty teaching development, but it can also include strategically incorporating students' developmental needs for exploration and selfauthorship into the curriculum.

\section{Intentionally Designing Academic Advising}

Similar to the in-class experiences, institutions can design their support services to purposefully focus on students' developmental needs, including the work they are doing as emerging adults along their path to self-authorship, instead of designing them 
transactionally as just another box to check or hurdle to get over on their path to a degree. Institutions often assume that entering students with identified majors made informed decisions about their academic path, but the participants in this study described their initial major decision-making as similar to that of their college enrollment decision. They followed external formulas to choose a major and their interactions with the institution provided limited opportunities to explore other options. Instead, institutions can alter their approach to students' major selection with the understanding that few students have had the opportunity to make informed decisions about their academic and career paths and that they would benefit from more intentional and facilitated exploration (Lewallen, 1993; Orndorff \& Herr, 1996; Stanton-Salazar, 1997). By focusing on deliberate and proactive tactics, institutional agents can encourage students' responsiveness to the services available, which can become their support networks (Stanton-Salazar, 1997). This intentionality may help obviate some of the anxiety and depression experienced by students as well as assist students in reaching out to institutional agents as challenges arise. For example, if academic advising is structured as an optional, single 30-minute appointment each semester, there is little reason for students to expect it to be anything more than a cursory conversation about degree requirements and course registration. Because academic advising can serve as a requirement to course registration, there is an opportunity to leverage it to improve students' college engagement through enhancing the role of and approach to academic advising on campus.

Instead of focusing solely on degree planning, academic advising should focus on fostering students' academic and intellectual development as it supports them through their exploration of possibilities and their ability to listen to their own internal voice 
(Arnett, 2004; Baxter Magolda, 2001; Braxton et al., 2014). In order for students to actively engage in guided conversations wherein they consider what a college education means to them, advising must be redesigned and focus on students developing their own sense of purpose while helping them articulate how the curriculum connects to that purpose. By integrating academic and career advising, advising can better address students' developmental needs around decision-making, goal-setting, and the implementation of their plans (Hughey \& Hughey, 2009). Advising conversations with first-year students should begin with who they are, how they like the institution, who they are connected to at the institution, and how their experiences in and out of classes are going in order to first establish rapport and evaluate their integration with the campus community (Campbell \& Mislevy, 2013; Rosenbaum, et al., 2006; Tinto, 1993). Having institutional agents assess students' integration and developmental needs early will normalize the challenges students face and encourage the development and implementation of strategies to address them. This approach would assist students in navigating through their crossroads as they develop their own internal voice and the ability to evaluate and coordinate external influences in order to make their own decisions about their lives (Baxter Magolda, 2009). Since entering students know little of what to expect from academic advising, institutions can define those expectations early, e.g., as centered on a personalized relationship between the student and a professional that helps the student both navigate the university, explore their options, and define their own path. 


\section{Improving Institutional Culture for Their Students}

Institutions need to better understand the needs and experiences of their student populations in order to best serve the students they currently have instead of serving the stereotypical, unencumbered student that is not the norm on most college campuses (Kuh et al., 2005; Mayhew et al., 2016; Pascarella \& Terenzini, 2005; Tinto, 2012). With an increasingly diverse student population, it is not enough to improve access to institutions of higher education. The institutional responsibility to student success does not end with the equality of opportunity to enroll in the university; instead, institutions must meet their students where they are by altering some of their approaches and cultural norms in order to help them engage with their education and reach graduation (Tinto, 1993, 2012). This includes institutional agents, including faculty, taking into consideration students' lives beyond their academic work and campus involvement when interacting with students (Luedke, 2017).

Interview participants emphasized their connections to their lives outside of school including their families and figuring out their life's path and they seemed to struggle with the integration of their personal, external worlds with their student worlds. The neglect of the outside world is often a critique of Tinto's (1993) theory of integration and, even more so, an issue when taking into consideration the experiences of students of color (Tierney, 1992). Tierney (1992) critiqued Tinto’s application of Van Gennep's rites of passage to student integration suggesting it was erroneously applied to students of color who when they enter college are not moving through stages of their own culture but instead are entering a culture distinctly different from their own. Thus, institutional agents must remember that their students come to them as whole individuals with lives 
outside of school that are just as important to them as their lives inside of school. Their lives outside of school include social and cultural capital that may not be recognized or valued by institutions but is very much a part of who they are and how they navigate their college experiences (Brooms, 2018). To more effectively serve all students, but particularly students of color, institutional agents can apply person first approaches where they recognize students' backgrounds and lives outside of college in order to develop meaningful relationships with students (Luedke, 2017). In addition to individual relationships, programs designed to bring students with shared identities together, such as Black male initiatives, can help students create a sense of belonging as they recognize their cultural wealth and create a community with which to navigate the institution and develop their personal identity and paths (Brooms, 2018; Harper, 2012). Furthermore, students will benefit from faculty taking a holistic approach to them that includes open communication about life outside of classes, integrating culturally introspective pedagogies, and being an active member in the campus community including advising student organizations (Brooms, 2018; Harper, 2012; Longerbeam \& Chavez, 2016).

Institutions should define their values and mission with their student population in mind in order to improve their collegiate experiences. Institutions do not have to be static; instead, they can evolve based on the populations they serve (Tinto, 2012; Williams, 2010). When institutions choose to remain static, following a belief that after enrollment students will choose to either be successful or not, they are perpetuating the social reproduction of societal inequalities. But as access to postsecondary education has improved and more stakeholders are holding institutions accountable for students' success, universities and colleges must design their approaches around increasing 
students' strategic utilization of cultural and social capital that can help them succeed (Rosenbaum, et al., 2006). This utilization includes the understanding of an expectation of growth, exploration, and decision-making that occurs in partnership with institutional agents.

Consistently communicating the aspects and benefits of the developmental processes of college can help students engage in the work while they are enrolled. However, no matter what institutions do, some students will choose to leave, but creating an environment where institutional agents support the consideration of and the action of leaving may help students return sooner and have a smoother process of returning, as suggested by those in this study. Moreover, Tinto (1993) suggested that "institutions that are willing to encourage students to leave are also those that are more likely to have students who will stay" (p. 206); this is the paradox of institutional commitment whereby students who feel supported in their relationships with institutional agents will turn to them to talk through their challenges in order to make better informed decisions about their paths. The interview participants in this study expressed satisfaction with their time away as it gave them an opportunity to reflect on what they wanted and exercise their agency. Institutional agents can support students' need for a break by maintaining open lines of communication and normalizing the exploration individuals experience through emerging adulthood. Not all students who are academically "lost" will stopout; some may dropout while others will continue to go through the motions until graduation without ever self-authoring their paths and leave as "lost" alumni. Engaging all students in intentional conversations and activities can help them work toward approaching their 
college education with a better-defined purpose for themselves, which will likely improve students' persistence, graduation, and life after college.

\section{Recommendations for Institutional Policy and Practice}

- Strategically disseminate the annual profile of the institutions' student population specifically for the campus community, including presenting an overview at new employee training. Beyond a cohort-specific admissions demographic and precollege academic summary, this profile should disaggregate various student groups and their academic performance and movement within the university, including academic trends such as the average number of major and academic unit changes as well as retention and graduation rates of subpopulations, participation in various campus academic and employment programs, and student experience data from campus-wide surveys.

- Instruct staff to develop programs and faculty to utilize pedagogical approaches that meet the needs of their student population with the goal of increasing the cultural and social capital needed to succeed at the institution.

Incorporate the utilization of student data in any new initiative proposal, annual report, and program assessment to help align programs with students' needs.

- Regularly track, monitor, and report on student progress in courses and academic departments to address areas of particular difficulty for students through various approaches including supplemental instruction, faculty 
professional development, and assessment of course materials, course sequencing, and course availability.

- Foster a culture of developmental support and intentional exploration.

- Incorporate an introductory overview of college student development in new employee training and ongoing professional development opportunities to assist all institutional agents with understanding the student populations they are serving.

- Normalize major exploration and change through reframing the conversation with prospective students, applicants, and first-year students.

- Expand advising services (including number of appointments available per semester and the length of time of each appointment) especially to firstyear students and those transitioning between majors.

- Require academic advising every semester for all students until graduation.

- Incorporate career advising into the academic advising conversation and establish an open referral system with the career center for information sharing and collaboration.

- Establish a team of professionals (such as advisors or academic coaches) to proactively reach out to students whose performance is not on par for success or has declined with the charge of uncovering the underlying causes for the poor performance.

- Offer experiential for-credit opportunities for first- and second-year students, in addition to offering them to juniors and seniors, to assist in 
their exploration and relating their curriculum to their world with the goal of bolstering their purpose and motivation.

- Create meaningful on-campus part-time work experiences that allow students to develop workplace skills and learn about what they have to offer the world of work.

- Form partnerships with secondary schools and teacher education programs to address the need for not only cultivating students' aspirations but also the knowledge of what it takes to be successful in college and the need for students to explore themselves and their options after high school.

○ Develop a formal reporting system so that students can signal their intention to stopout.

- Implement a communication plan to keep in touch with nonenrolled students that emphasizes to them that they remain a part of the university community. (Information to share includes campus events (e.g. speakers, campus news, and community outreach), reenrollment information (e.g. the academic calendar, registration periods, and reenrollment processes), as well as academic engagement suggestions (e.g. career and academic exploration activities, department highlights, and new majors or programs.)

- Maintain students' access to their email and student accounts in order to continue their relationship with the institution. 
- Provide neutral, non-academic unit specific, reenrollment counseling for stopouts to consider their options of academic paths, evaluate their academic progress and performance, and develop a plan to reach their newly defined goals.

- Increase the salience and normalization of the mental health counseling center including its marketing, staffing, hours of operation, and emphasis on the variety of issues its services address.

- Improve the general education and early college curriculum experience.

- Reduce general education and lower level course enrollments to help facilitate faculty-student relationships and engagement with the curriculum.

- Prioritize permanent faculty instruction in general education courses instead of part-time lecturers to further encourage long-term studentfaculty relationship building.

- Create avenues for part-time faculty to be active members of the campus community beyond teaching individual courses including establishing longer contracts for part-time lecturers that maintain their relationship to the institution, and in turn, their students.

- Develop further training for instructors and staff on the university's philosophy of general education and the value of generation education including the transferable skills gained and their applicability to the world of work. 
- Evaluate how the institution can intentionally incorporate students' cognitive development, including exploration of academic paths, into the general education curriculum.

- Tie course objectives and assignments to both content mastery as well as the development of skills that will assist students in their cognitive growth.

- Clearly articulate to students the expectation of skill development throughout their coursework in order to stress the growth that will occur throughout college.

- Incorporate reflection into coursework to provide students an opportunity to learn about themselves as they explore their challenges with the material, articulate their impactful moments, and reflect on their reactions to what they are learning.

- Create a toolbox of student success messaging that faculty can utilize to integrate supportive, developmental approaches into their courses including attendance policies and in-class daily success strategies or referrals.

\section{Contribution to the Literature}

Tinto's (1993) theory on social and academic integration to address student departure is not only seminal but remains dominant in higher education retention literature. I connect Tinto's theory with educational literature on emerging adulthood, self-authorship, and social reproduction. Understanding students' developmental needs, their pressures from societal and familial expectations, and the processes they are going 
through to navigate the intersection of their development and expectations, helps colleges to evaluate the alignment of services with the needs of students to assist with integration while identifying the difficulties students face when integrating into the institution. Additionally, students will more successfully integrate into the institution, especially academically, through an understanding and utilization of the cultural capital valued by the institution as well as by the building of their network of support with institutional agents, or social capital, to successfully navigate the institution and fully engage with their college education. Tinto $(1993,2012)$ challenged institutions to respond to and align their services to the needs of their student population in order to facilitate integration; the additional application of these three lenses helps to guide a systematic approach to understanding and addressing students' needs.

Engaging with one's life outside of college was a theme shared among the interview participants, whether it be taking time off to focus on their family and personal issues, figuring what a college education meant for their life, or focusing on their relationships and socializing while enrolled. This theme lends support to critiques of Tinto's (1993) theory, especially the individualistic focus of his theory and proposition of the necessity to separate from one's former community and roles. Scholars have argued that Tinto specifically neglected the influences of the outside world on student departure (Cabrera, Nora, \& Castaneda, 1992; Tierney, 1992). In addition to staying connected to their families and focusing on their lives, participants discussed how their social context, such as the pressure to attend college and the Great Recession, impacted their decisionmaking. 
Arnett's (2004) theory of emerging adulthood is presented as a natural, futurefocused time in one's life, but the students in this study found it stressful and anxietyprovoking as the uncertainty was unexpected. Institutions may be able to assist individuals through the challenges of this time period in their lives by acknowledging it and supporting the process through their messaging, programs, and approaches to learning and opportunity. Emerging adulthood is a time where individuals experiment with employing their agency in their decision-making as they work toward selfauthorship. Baxter Magolda (2001) found that her interviewees were still in the process of realizing their self-authorship well into their twenties and the participants in this study demonstrated taking early steps in their development as they questioned the external formulas that led them to college and debated what they wanted for themselves. Helping students identify and articulate their personal motivations and desires may empower them to listen to their internal voices as they question what they are doing in college.

The motivation behind my study was to explore stopping out, a phenomenon I frequently witnessed as an academic advisor, but found was often left out of the student success conversation both in the literature and at the institutions where I have worked. By conducting an exploratory study, I sought to understand who makes up the stopout population, what the institutional data can tell us about predicting stopout, as well as how the students who stopout describe their paths. While the stopout pathway was uncommon at City U, this population might be more or less common at other institutions. For example, students who enroll at liberal arts institutions may be less likely to stopout due to their assumed intentional selection of their institution and of going to college in general; institutional commitment that was not articulated by the participants in my study. 
However, the challenges these students faced as they attempted to balance college with their struggles with uncertainty and navigating their own identities along with family and personal issues are likely generalizable to students at all institutions including liberal arts colleges.

My mixed methods approach helps to uncover the complexities of the stopping out phenomenon as the quantitative data reveals aspects of the stopout population and predictors of the pathway while the qualitative data provides a rich story of students' experiences that cannot be uncovered in the institutionally collected data. The quantitative predictors, such as being male and having a lower first year and second year GPA, are in line with the literature into risk factors of student persistence, but they do not help explain what is going on personally with those students. The interview data uncovered the students' experiences interacting with the institution before and after stopout as well as how they spent their time while out. This multifaceted understanding can be used to develop interventions that address the needs articulated by, and likely not unique to, these students in order to improve student integration and ultimately student success.

More specifically, this study's findings revealed that students who stopped out were in college out of obligation and expectation and could not articulate what a college education meant to them personally. Generally, people who teach and work at colleges and universities do so with a deep commitment to all that higher education provides individuals and societies. This commitment and belief informs their approach to students and it is easy to assume that anyone who enters the institution would share the commitment and belief. However, the students' interviewed articulated how they did not 
share this understanding until after they stopped out, even though most of them did not need to stopout for long to develop the understanding. Thus, stopping out appears to have positive effects for some students, which is contrary to institutional beliefs about the importance of persistence and challenges how institutions define student success.

The barriers these students articulated were more complex than what is often discussed in the literature, which frequently finds that students' access to financial aid, access to mental health services, or poor performance is what leads to departure. The interviewees did not articulate just one reason behind their departure; instead, their stories demonstrated how intertwined, and overwhelming, their challenges were prior to leaving. However, what made it easy to leave in the face of challenge was that they had no idea why they were enrolled. These students experienced something that brought them back with a new approach to their education, but what if, instead of assuming students know what they are doing, institutions designed their early college academic experiences to help them uncover their intellectual interests and articulate their why? This approach will likely not only help retain students who would stopout but also those who would dropout by helping them identify how a college education is meaningful to them personally. In turn, students may be motivated to stay enrolled while working through challenges as they arise or to see faculty and staff as supports while they are not enrolled.

\section{Future Research}

Stopping out of college is a difficult outcome to analyze because it is uncommon and complex. Students stop attending as a first outcome, but then they return (second outcome) and after returning, some students persist, some graduate, and some stop attending. I would like to conduct a longitudinal, survival analysis for future research 
because it would provide a more comprehensive picture of student pathways due to the open-ended nature of the various pathways including stopping out and dropping out. Survival analysis would allow for the time-varying impact of both time-constant variables (such as demographic characteristics) and time-varying variables (such as changes to academic major, semester or annual GPA, hours earned, and financial aid received), which may better inform the development of data-driven intervention points for institutions. Specifically, a longitudinal investigation applies well to students' academic careers as it allows for an examination into how effects change over time such as which variables become increasingly or decreasingly predictive of stopping out at different points in time (DesJardins, 2003).

When I began my study, I expected to uncover differences in the reasons men and women stopped out of college; however, these differences were not found in my qualitative sample's data. Both the men and women interviewed shared their focus on financial security being a reason to both go to college and the pressure to pursue STEM, their struggles with asking for help, their desires for institutional agents to reach out to them, and their commitment to working for pay while stopped out. However, being male was a consistent predictor of stopping out, which suggests that there are underlying challenges to men's experiences in college. While both men and women face obstacles in higher education, men have been found to struggle more with academic disengagement suggesting that this is an area of further investigation as it connects to their enrollment patterns (Sax, 2008). Additionally, in what way does men's understanding and practice of masculinity affect their experiences in higher education and their engagement with others along their paths? American hegemonic masculinity informs men of the expectation that 
they be invulnerable as they are to be in control, independent, and rational (hooks, 2004; Kaufman, 1994; Morgan, 2005); all traits that make it a challenge to engage in exploration and help-seeking behaviors (Edwards \& Jones, 2009). Thus, a future study designed to investigate the connections between gender construction and understanding with men's approaches to college could help further explore men's enrollment pathways.

Additionally, as with any study, I made decisions about how to define my variables which impacts results. Specifically, the variables measuring local residency and intended STEM majors may have limited my findings as neither were found to be statistically significant. Future research should look at the definitions of these two variables to further explore the impacts of student residency and major on student pathways. Another variable that suggests further investigation is the financial aid received since the average amount received was the lowest for stopouts among all pathways. This variable was defined as total financial aid disbursed, but investigating the impact of the various types of aid could yield more nuanced results; such as Nora et al.'s (2006) finding that having a higher proportion of loans increased students' likelihood that they would not return after taking time off. Moreover, scrutinizing the financial realities of students that stopout could provide institutions with interesting findings. For example, at City U, were students who received tuition remission or tuition assistance through the logistics company partnership more likely to stopout and that is why the average amount of aid received was lower? Or does financial aid result in greater financial need, leading students to stopout so that they can work? Thus, future quantitative studies would benefit from revised predictors to understand students' situations (including financial) and performance. Finally, another variable to further consider is first year GPA since it was a 
powerful predictor of stopping out and brings up questions about whether high performing students who stopout do so for similar reasons as those did in this study. Where this study did not review the transcripts of interviewees, future studies could include transcript analyses to converge the qualitative data with students' academic performance.

Furthermore, comparative studies of various institutional types would help to expand the overall understanding of students who stopout and return. For instance, do students who enroll at residential, liberal arts colleges stopout for the same reasons as students at public institutions serving more diverse populations? Institutions that collect stopout intentions via surveys could contribute to the literature on stopout student experiences and needs through an analysis of the students' stopout timing as well as their articulated reasoning and intentions prior to stopping out. Analyses of stopout intentions as they are occurring could reveal motivations and individuals' interpretations that differ from ones that are realized through reflection allowing institutions to better meet students where they are when they are deciding to take a break. If time and resources allowed, I would like to follow a cohort of students, interviewing a large sample annually beginning with initial enrollment and staying with them as they persist, stopout, or dropout through their sixth year to understand the factors influencing their enrollment and decisionmaking throughout this time period in their lives.

\section{Conclusion}

When students enter college out of obligation, following external formulas for their lives, they have not yet defined the full value and purpose(s) of a college education for themselves. Institutional agents at colleges and universities can and should help 
students determine for themselves why they want a college education and what they want out of their education - to do this, institutions need to develop opportunities inside and outside the classroom that help students experience the meaningful development and connections a college education can provide. When colleges and universities assume students will discover on their own the potential their education can provide, institutions miss out on the opportunity to engage students who may be more likely to leave than persist when things become challenging.

Postsecondary institutions cannot take their student enrollment for granted during this tumultuous time in higher education where state appropriations continue to decrease requiring public institutions to rely more on tuition and student fees revenue. Since 2001, state and local governments have cut their funding for education with a third of states cutting funding by one third to one half (Crow \& Dabars, 2015). In less than 10 years, from 2010-2011 to 2016-2017, the average cost of tuition and fees has risen 12 percent (McFarland et al., 2018). The need for more tuition revenue has resulted in a need for enrollments to grow at a time when the number of high school graduates in the country is declining. For over a third of states, the number of high school graduates began decreasing in 2012-2013 and is expected to continue to decrease through 2026-2027, especially in the Northeast and Midwest (Hussar \& Bailey, 2018). Thus, college is becoming less affordable and the pool of high school students to recruit from is decreasing, making it more challenging for schools to meet their enrollment goals. In fall 2017, of about 350 schools who responded to a Chronicle of Higher Education survey, $44 \%$ of public institutions and 52 percent of private institutions did not meet their enrollment goals (Carlson, 2018). With the rising costs and the challenging budget 
environment, both institutions and families are feeling the financial pinch of the higher education market.

As the costs of a college education to students and their families continue to increase, the national conversation is shifting to question whether college is still worth the expense. The personal, financial benefits of a college degree have maintained through and after the Great Recession; even as earnings for all workers declined, the college wage premium continued to set college graduates apart from those with less education (Abel \& Deitz, 2015). There likely could be a point in the near future where the costs of attendance and the immediate sacrifices that have to be made to cover them will outweigh the potential for more income as individuals may not be willing to take the financial risk of enrolling in college. Institutions will have to engage more in the conversation of why a college education is worth it and why their college is worth it as they recruit new students. In addition to the economic benefits, institutions need to emphasize to prospective students their opportunities for the development of marketable skills as well as social and career networks. Prospective students need to see what their investment in an education at a particular institution will give them. To do this, schools should highlight what alums are doing, as focusing on student life and campus traditions, the fun side of college, may not be enough of a pull when students and families are looking at the long term return on their investment.

While it is unknown where the market of higher education is headed long term, it is not expected to become more affordable anytime soon to the majority of college-going Americans (Abel \& Deitz, 2015; Crow \& Debars, 2015). Nevertheless, at a minimum, the continued income gap between college graduates and those with high school diplomas or 
the equivalent will likely encourage the societal emphasis on college attendance after high school to persist for the foreseeable future. However, initial college attendance does not guarantee retention and graduation. Thus, if institutions want to improve their retention and graduation rates, it is imperative that they recognize the downside to this societal expectation along with the focus on a return-on-investment for students and work to address them early in students' collegiate careers. This includes helping students make connections between their college experiences and their lives; being explicit about what it can mean to engage in the college community; and demonstrating from day one that college is an opportunity for growth and improvement that can benefit one's career and life.

When the work of being a college student and the tough decisions that must be made along the way become reality, students are more likely to persist when they feel that they have the support of a community instead of having to go about it on their own. Institutions must recognize that it is their responsibility to normalize these experiences and develop a supportive and resource-rich community. Instead of assuming students know what they need or what to ask for, institutional agents should reach out to students when their academic behaviors and performance have changed or are not mirroring those of successful students in order to help uncover the root causes and refer students to support services. Institutions can use predictive analytics to identify barriers to student success and develop interventions around shared institutional values of student support and success to address the barriers. Proactively addressing students' psychosocial barriers and development will help to mediate isolation through actively integrating students into their college education and the institution. Recognizing the needs of today's 
college students and using that information to inform practices as well as redesign the academic experiences and how we communicate the value and opportunities of a college education, will improve both student and institutional outcomes. While institutions cannot prevent students from leaving, they can intentionally design experiences that address and normalize students' developmental and integration needs. And when students do stop attending, colleges should continue to engage with them as members of their institutional community through outreach and support that maintains connection and eases their return. 


\section{REFERENCES}

Abel, J. R., \& Deitz, R. (2014). Do the benefits of college still outweigh the costs? Current Issues in Economics \& Finance, 20(3), 1-12.

Adams, D. R., Meyers, S. A., \& Beidas, R. S. (2016). The relationship between financial strain, perceived stress, psychological symptoms, and academic and social integration in undergraduate students. Journal of American College Health, 64(5), 362-370. doi:10.1080/07448481.2016.1154559

Ahson, N. L., Gentemann, K. M., \& Phelps, L. (May, 1998). Do stop outs return? A longitudinal study of re-enrollment, attrition, and graduation. Paper presented at the $38^{\text {th }}$ Annual Forum of the Association for Institutional Research, Minneapolis, MN.

Allen, J., Robbins, S. B., Casillas, A., \& Oh, I. (2008). Third-year college retention and transfer: Effects of academic performance, motivation, and social connectedness. Research in Higher Education, 49, 647-664. doi:10.1007/s11162-008-9098-3

Armstrong, E. A., \& Hamilton, L. T. (2013). Paying for the party: How college maintains inequality. Cambridge, MA: Harvard University Press.

Arnett, J. J. (2004). Emerging adulthood: The winding road from the late teens through the twenties. New York, NY: Oxford University Press.

Arum, R., \& Roksa, J. (2011). Academically adrift: Limited learning on college campuses. Chicago, IL: The University of Chicago Press. 
Astin, A. W., \& Oseguera, L. (2012). Pre-college and institutional influences on degree attainment. In A. Seidman (Ed.), College student retention: Formula for student success (pp. 119 - 146). Westport, CT: Praeger Publishers.

Aud, S., Hussar, W., Kena, G., Bianco, K., Frohlich, L., Kemp, J., \& Tahan, K. (2011). The Condition of Education 2011 (NCES 2011-033). U.S. Department of Education, National Center for Education Statistics. Washington, DC: U.S. Government Printing Office.

Barefoot, B. O. (2004). Higher education's revolving door: Confronting the problem of student drop out in US colleges and universities. Open Learning, 19(1), 9-18.

Baxter Magolda, M. B. (2001). Making their own way: Narratives for transforming higher education to promote development. Sterling, VA: Stylus.

Baxter Magolda, M. B. (2008). Three elements of self-authorship. Journal of College Student Development, 49(4), 269-284.

Baxter Magolda, M. B. (2009). The activity of meaning making: A holistic perspective on college student development. Journal of College Student Development, 50(6), 621-639.

Baxter Magolda, M. B. (2014). Self-authorship. New Directions in Higher Education, 166, 25-33. doi:10.1002/he

Beiter, R., Nash, R., McCrady, M., Rhoades, D., Linscomb, M., Clarahan, S., \& Sammut, S. (2015). The prevalence and correlates of depression, anxiety, and stress in a sample of college students. Journal of Affective Disorders, 173, 90-96. doi: 10.1016/j.jad.2014.10.054 
Bourdieu, P. (1974). Cultural reproduction and social reproduction. In R. Brown (Ed.), Knowledge, education, and cultural change: Papers in the sociology of education (pp. 56-68). London: Tavistock.

Bourdieu, P. (1984). A social critique of the judgement of taste. Cambridge, MA: Harvard University Press.

Bourdieu, P. (1986). The forms of capital. In J. Richardson (Ed.) Handbook of theory and research for the sociology of education (pp. 241-258). New York, NY: Greenwood.

Bourdieu, P., \& Passeron, J. (1977). Reproduction in education, society and culture. London: Sage Publications.

Bozick, R. (2007). Making it through the first year of college: The role of students' economic resources, employment, and living arrangements. Sociology of Education, 80, 261-284.

Braxton, J. M., Doyle, W. R., Harley, III, H. V., Hirschy, A. S., Jones, W. S., \& McLendon, M. K. (2013). Rethinking college student retention. San Francisco, CA: Jossey-Bass.

Brooms, D. R., Clark, J. S., \& Smith, M. (2018). Empowering men of color on campus: Building student community in higher education. New Brunswick, NJ: Rutgers University Press.

Cabrera, A. F., Nora, A. L., \& Castaneda, M. B. (1992). The role of finances in the persistence process: A structural model. Research in Higher Education, 33(5), 571-593. 
Campbell, C. M., \& Mislevy, J. L. (2013). Student perceptions matter: Early signs of undergraduate student retention/attrition. Journal of College Student Retention, 14, 476-493.

Carlson, S. (2018, January 21). How enrollment challenges can spur change. The Chronicle of Higher Education. Retrieved from https://chronicle.com

Charmaz, K. (2006). Constructing grounded theory: A practical guide through qualitative analysis. Thousand Oaks, CA: Sage.

Christensen, K. (2015). He-cession? She-cession? The gendered impact of the great recession in the United States. Review of Radical Political Economics, 47(3), 368388. doi: $10.1177 / 0486613414542771$

Clark, B. R. (1960). The "cooling-out" function in higher education. American Journal of Sociology, 65, 569-576.

Clark, M. H., Middleton, S. C., Nguyen D., \& Zwick, L. K. (2014). Mediating relationships between academic motivation, academic integration, and academic performance. Learning and Individual Differences, 33, 30-38. doi:10.1016/j.lindif.2014.04.007

Clery, S., \& Topper, A. (2009). Characteristics of students who stop out. Data Notes: Keeping Informed about Achieving the Dream Data 4. Retrieved from http://www.academia.edu/1335161/Characteristics_of_students_who_stop_out.

Coleman, J. S. (1988). Social capital in the creation of human capital. American Journal of Sociology, 94, S95-S120. 
Coleman, J. S., \& Fararo, T. J. (1992). Introduction. In J. S. Coleman \& T. J. Fararo (Eds.), Rational choice theory: Advocacy and critique (pp. ix-xxii). Newbury Park, CA: Sage Publications, Inc.

Collins, R. (1979). The credential society: An historical sociology of education and stratification. New York, NY: Academic Press.

Constantine, M. G., \& Flores, L. Y. (2006). Psychological distress, perceived family conflict, and career development issues in college students of color. Journal of Career Assessment, 14(3), 354-369.

Cragg, K. M. (2009). Influencing the probability for graduation at four-year institutions: a multi-model analysis. Research in Higher Education, 50(4), 394-413.

Crow, M. M. \& Dabars, W. B. (2015). Designing the new American university. Baltimore, MD: Johns Hopkins University Press.

DesJardins, S. L. (2003). Event history methods: Conceptual issues and an application to student departure from college. In J. C. Smart (Ed.), Higher education: Handbook of theory and research (pp. 421-472). New York, NY: Springer.

DesJardins, S. L., Ahlburg, D. A., \& McCall, B. P. (1999). An event history model of student departure. Economics of Education Review, 18, 375-390.

Deutsch, N. L., \& Schmertz, B. (2011). "Starting from ground zero:” Constraints and experiences of adult women returning to college. The Review of Higher Education, 34, 477-503.

Dewey, J. (1938). Experience and education. New York, NY: Touchstone. 
Domina, T., Conley, A., \& Farkas, G. (2011). The link between educational expectations and effort in the college-for-all era. Sociology of Education, 84, 93-112. doi:10.1177/1941406411401808

Durkheim, E. (1951). Suicide. Glencoe, IL: The Free Press.

Edwards, K. E. \& Jones, S. R. "Putting my man face on": A grounded theory of college men's gender identity development. Journal of College Student Development, 50(2), 210-228. doi:10.1353/csd.0.0063

Ewert, S. (2012). Fewer diplomas for men: The influence of college experiences on the gender gap in college graduation. Journal of Higher Education, 83, 824-850.

Fan, X. (2001). Statistical significance and effect size in education research: Two sides of a coin. The Journal of Educational Research, 94(5), 275-282.

Farmer-Hinton, R. L. (2008). Social capital and college planning: Students of color using school networks for support and guidance. Education and Urban Society, 41(1), 127-157. doi:10.1177/0013124508321373

Flynn, D. (2014). Baccalaureate attainment of college students at 4-year institutions as a function of student engagement behaviors: Social and academic student engagement behaviors matter. Research in Higher Education, 55, 467-493. doi:10.1007/s11162-013-9321-8

Gast, M. J. (2016). "You're supposed to help me": The perils of mass counseling norms for working-class black students. Urban Education, 1-27. doi:10.1177/0042085916652178

Gillham, B. (2000). The research interview. London: Continuum. 
Glaser, B. G., \& Strauss, A. L. (1967). The discovery of grounded theory: Strategies for qualitative research. New York, NY: Aldine.

Goldrick-Rab, S. (2006). Following their every move: An investigation of social-class differences in college pathways. Sociology of Education, 79, 61-79.

Gonzalez, H. B., \& Kuenzi, J. J. (2012). Science, technology, engineering, and mathematics (STEM) education: A Primer. Retrieved from Federation of American Scientists website https://fas.org/sgp/crs/misc/R42642.pdf

Goyette, K. A. (2008). College for some to college for all: Social background, occupational expectations, and educational expectations over time. Social Science Research, 37, 461-484. doi:10.1016/j.ssreasearch.2008.02.002

Greene, J. C., Caracelli, V. J., \& Graham, W. F. (1989). Toward a conceptual framework for mixed-method evaluation designs. Educational Evaluation and Policy Analysis, 11, 255-274.

Grodsky, E., \& Riegle-Crumb, C. (2010). Those who choose and those who don't: Social background and college orientation. The Annals of the American Academy of Political and Social Science, 627, 14-35. doi:10.1177/0002716209348732

Habley, W. R., Bloom, J. R., \& Robbins, S. (2012). Increasing persistence: Researchbased strategies for student success. San Francisco, CA: Jossey-Bass.

Harper, S. R. (2012). Black male student success in higher education: A report from the National Black Male College Achievement Study. Philadelphia, PA: University of Pennsylvania, Center for the Study of Race and Equity in Education. 
Hausmann, L. R. M., Ye, F., Schofield, J. W., \& Woods, R. L. (2009). Sense of belonging and persistence in White and African American first-year students. Research in Higher Education, 50(7), 649-669.

Haycock, L. A., McCarthy, P., \& Skay, C. L. (1998). Procrastination in college students: The role of self-efficacy and anxiety. Journal of Counseling \& Development, 76, 317-324.

Hesse-Biber, S. (2007). Feminist approaches to in-depth interviewing. In Hesse-Biber, S. (Ed.), Feminist research practice: A primer (pp. 111 - 147). Los Angeles, CA: Sage.

Hinkelman, J. M., \& Luzzo, D. A. (2007). Mental health and career development of college students. Journal of Counseling \& Development, 85, 143-147.

Holland, M. M. (2015). Trusting each other: Student-counselor relationships in diverse high schools. Sociology of Education, 88(3), 244-262. doi: $10.1177 / 0038040715591347$

Holstein, J. A., \& Gubrium, J. F. (1995). The active interview. Thousand Oaks, CA: Sage. hooks, b. (2004). We real cool: Black men and masculinity. New York, NY; Routledge. Horn, L. J., \& Carroll, C. D. (1998). Stopouts or stayouts? Undergraduates who leave college in their first year (NCES 1990-087). Retrieved from National Center for Education Statistics website: http://nces.ed.gov/pubs99/1999087.pdf.

Hossler, D., Dundar, A., \& Shapiro, D. T. (2013). Longitudinal pathways to college persistence and completion: Student, institutional, and public policy perspectives. In L. W. Perna \& A. Jones (Eds.) The state of college access and completion: 
Improving college success for students from underrepresented groups (pp. 140165). New York, NY: Routledge.

Hoyt, J. E., \& Winn, B. A. (2004). Understanding retention and college student bodies: Differences between drop-outs, stop-outs, opt-outs, and transfer-outs. NASPA Journal, 41, 395-417.

Hughey, K. F., \& Hughey, J. K. (2009). Foundations of career advising. In K. F. Hughey, D. B. Nelson, J. K. Damminger, \& B. McCalla-Wriggins (Eds.), The handbook of career advising (pp. 1-18). San Francisco, CA: Jossey-Bass.

Hunter, A., \& Brewer, J. (2003). Multimethod research in sociology. In A. Tashakkori \& C. Teddlie (Eds.), Handbook of mixed methods in social \& behavioral research (pp. 491-512). Thousand Oaks, CA: Sage.

Hussar, W. J., \& Bailey, T. M. (2018). Projections of education statistics to 2026 (NCES 2018-019). U.S. Department of Education, Washington, DC: National Center for Education Statistics.

Ishitani, T. T. (2016). Time-varying effects of academic and social integration on student persistence for first and second years in college: National data approach. Journal of College Student Retention: Research, Theory, \& Practice, 18, 263-286. doi: $10.1177 / 1521025115622781$

Jack, A. A. (2016). (No) harm in asking: Class, acquired cultural capital, and academic engagement at an elite university. Sociology of Education, 90(1), 1-19. doi: $10.1177 / 0038040715614913$

Jacoby, B., \& Garland, J. (2004). Strategies for enhancing commuter student success. Journal of College Student Retention, 6(1), 61-79. 
Jensen, D. H., \& Jetten, J. (2016). The importance of developing students' academic and professional identities in higher education. Journal of College Student Development, 57(8), 1027-1042. doi:10.1353/csd.2016.0097

Johnson, I. Y., \& Muse, W. B. (2012). Student swirl at a single institution: The role of timing and student characteristics. Research in Higher Education, 53, 152-181. doi:10.1007/s11162-011-9253-0

Kaufman, M. (1994). Men, feminism, and men's contradictory experiences of power. In H. Brod \& M. Kaufman (Eds.), Theorizing masculinities (pp. 142-165). Thousand Oaks, CA: Sage.

Kegan, R. (1994). In over our heads: The mental demands of modern life. Cambridge, MA: Harvard University Press.

Kena, G., Hussar W., McFarland J., de Brey C., Musu-Gillette, L., Wang, X., Zhang, J., ... Dunlop Velez, E. (2016). The Condition of Education 2016 (NCES 2016-144). Retrieved from National Center for Education Statistics http://nces.ed.gov/pubsearch

Kim, D., Saatcioglu, A., \& Neufeld, A. (2012). College departure: Exploring student aid effects on multiple mobility patterns from four-year institutions. Journal of Student Financial Aid, 43(3), 3-24.

Kirk, R. E. (1996). Practical significance: A concept whose time has come. Educational and Psychological Measurement 56(5), 746-759.

Kotrlik, J. W., Williams, H. A., \& Jabor, M. K. (2011). Reporting and interpreting effect size in quantitative agricultural education research. Journal of Agricultural Education, 52(1), 132-142. 
Kuh, G., Kinzie, J., Buckley, J., Bridges, B. K., \& Hayek, J. C. (2007). Piecing together the student success puzzle: Research, propositions, and recommendations. Hoboken, N.J.: Wiley Periodicals, Inc.

Kuh, G., Kinzie, J., Schuh, J. H., Whitt, E. J., \& Associates. (2005). Student success in college: Creating conditions that matter. San Francisco, CA: Jossey-Bass.

Lareau, A., \& Weininger, E. B. (2003). Cultural capital in educational research: A critical assessment. Theory and Society, 32(5/6), 567-606.

Lehmann, W. (2013). Habitus transformation and hidden injuries: Successful workingclass university students. Sociology of Education, 87(1), 1-15. doi:10.1177/0038040713498777

Lewallen, W. (1993). The impact of being "undecided" on college-student persistence. Journal of College Student Development, 34(2), 103-112.

Liao, K. Y., \& Wei, M. (2011). Intolerance of uncertainty, depression, and anxiety: The moderating mediating roles of rumination. Journal of Clinical Psychology, 67(12), 1220-1236. doi:10.1002/jclp.20846

Long, J. S. (1997). Regression models for categorical and limited dependent variables. Thousand Oaks, CA: Sage.

Longerbeam, S. D., \& Chávez, A. F. (2016). Going inward: The role of cultural introspection in college teaching. New York, NY: Peter Lang.

Luedke, C. L., (2017). Person first, student second: Staff and administrators of color supporting students of color authentically in higher education. Journal of College Student Development, 58(1), 37-52. 
Ma, Y., \& Cragg, K. M. (2013). So close, yet so far away: Early vs. late dropouts. Journal of College Student Retention, 14(4), 533-548. doi:10.2190/CS.14.4.f

Malcolm, S., \& Feder, M. (Eds.). (2016). Barriers and opportunities for 2-year and 4year STEM degrees: Systemic change to support students' diverse pathways. Washington, DC: The National Academies Press.

Marin, R. S. (1991). Apathy: A neuropsychiatric syndrome. Journal of Neuropsychiatry, $3(3), 243-254$.

Marsh, G. (2014). Institutional characteristics and student retention in public 4-year colleges and universities. Journal of College Student Retention, 16(1), 127-151. doi:10.2190/CS.16.1.g

Mayhew, M. J., Rokenbach, A. N., Bowman, N. A., Seifert, T. A., Wolniak, G. C., Pascarella, E. T., \& Terenzini, P. T. (2016). How colleges affect students: $21^{s t}$ century evidence that higher education works. San Francisco, CA: Jossey-Bass.

McDonough, P. M. (1997). Choosing colleges: How social class and schools structure opportunity. Albany, NY: State University of New York Press.

McFarland, J., Hussar, B., Wang, X., Zhang, J., Wang, K., Rathbun, A., Barmer, A., Forrest Cataldi, E., and Bullock Man, F. (2018). The condition of education 2018 (NCES 2018-144). U.S. Department of Education. Washington, DC: National Center for Education Statistics. Retrieved October 21, 2018 from https://nces.ed.gov/pubs2018/2018144.pdf

Miles, M. B., \& Huberman, A. M. (1994). Qualitative data analysis: An expanded sourcebook. Thousand Oaks, CA: Sage. 
Morgan, D. (2005). Class and masculinity. In M. S. Kimmel, J. Hearn, \& R. W. Connell (Eds.), Handbook of studies on men and masculinities (pp. 165-177). Thousand Oaks, CA: Sage.

National College Health Assessment. (2016). Spring 2016 Reference Group Data Report. Retrieved from American College Health Association website: https://www.acha.org/documents/ncha/NCHAII\%20SPRING\%202016\%20US\%20REFERENCE\%20GROUP\%20DATA\%20R EPORT.pdf

New York State. (2018). Tuition-free degree program: The Excelsior Scholarship. Retrieved from https://www.ny.gov/programs/tuition-free-degree-programexcelsior-scholarship.

Nora, A., Barlow, L., \& Crisp, G. (2006). Examining the tangible and psychosocial benefits of financial aid with student access, engagement, and degree attainment. American Behavioral Scientist, 49, 1636-1651. doi:10.1177/0002764206289143

Nora, A., \& Crisp, G. (2009). Hispanics and higher education: An overview of research, theory, and practice. In J. C. Smart (Ed.), Higher education: Handbook of theory and research (pp. 317-353).

Nothaft, F., Boesel, M., \& Khater, S. (2018). Evaluating the housing market since the great recession (Special Report). Retrieved from CoreLogic website: https://www.corelogic.com/downloadable-docs/corelogic-peak-totrough-final030118.pdf 
Orndorff, R. M., \& Herr, E. L. (1996). A comparative study of declared and undeclared college students on career uncertainty and involvement in career development activities. Journal of Counseling \& Development, 74, 632-639.

Oseguera, L. (2005). Four and six-year baccalaureate degree completion by institutional characteristics and racial/ethnic groups. Journal of College Student Retention, 7, 19-59.

Oseguera, L., \& Rhee, B. S. (2009). The influence of institutional retention climates on student persistence to degree completion: A multilevel approach. Research in Higher Education, 50, 546-569. doi:10.1007/s11162-009-9134-y

Ostrove, J. M., \& Long, S. M. (2007). Social class and belonging: Implications for college adjustment. The Review of Higher Education, 30, 363-389. doi:10.1353/rhe.2007.0028

O’Toole, D. M., Stratton, L. S., \& Wetzel, J. N. (2003). A longitudinal analysis of the frequency of part-time enrollment and the persistence of students who enroll part time. Research in Higher Education, 44, 519-537.

Ovink, S. M. (2017). “In today’s society, it's a necessity”: Latino/a postsecondary plans in the college-for-all era. Social Currents, 4(2), 128-145. doi:10.1177/2329496516663220

Pascarella, E. T., Duby, P. B., Miller, V. A., \& Rasher, S. P. (1981). Preenrollment variables and academic performance as predictors of freshman year persistence, early withdrawal, and stopout behavior in an urban, nonresidential university. Research in Higher Education, 15, 329-329. 
Pascarella, E. T. \& Terenzini, P. T. (2005). How college affects students: A third decade of research. San Francisco, CA: Jossey-Bass.

Perna, L. P. (2006). Studying college access and choice: A proposed conceptual model. In J. C. Smart (Ed.), Higher education: Handbook of theory and research (pp. 99157). New York, NY: Springer.

Pike, G. R., Hansen, M. J., \& Childress, J. E. (2014). The influence of students' precollege characteristics, high school experiences, college expectations, and initial enrollment characteristics on degree attainment. Journal of College Student Retention, 16, 1-23. doi:10.2190/CS.16.1.a

Pisarik, C. T., Rowell, P. C., \& Thompson, L. K. (2017). A phenomenological study of career anxiety among college students. The Career Development Quarterly, 65, 339-352. doi:10.1002/cdq.12112

Porter, S. R. (2003). Understanding retention outcomes: Using multiple data sources to distinguish between dropouts, stopouts, and transfer-outs. Journal of College Student Retention, 5, 53-70.

Próspero, M. \& Vohra-Gupta, S. (2007). First generation college students: motivation, integration, and academic achievement. Community College Journal of Research and Practice, 31(12), 963-975. doi:10.1080/10668920600902051

Reay, D., Crozier, G., \& Clayton, J. (2009). 'Fitting in' or 'standing out': Working-class students in UK higher education. British Educational Research Journal, 32, 1-18. doi:10.1080/01411920902878925 
Reynolds, P. J., Gross, J. P. K., Millard, B., \& Pattengale, J. (2010). Using longitudinal mixed-methods research to look at undeclared students. New Directions for Institutional Research Assessment Supplement, 53-66. doi:10.1002/ir.372

Rios-Aguilar, C., \& Deil-Amen, R. (2012). Beyond getting in and fitting in: An examination of social networks and professionally relevant social capital among Latina/o university students. Journal of Hispanic Higher Education, 11, 179-196. doi:10.1177/1538192711435555

Rogers, W. H., \& Winkler, A. E. (2013). The relationship between the housing and labor market crises and doubling up: An MSA-level analysis, 2005-2011. Monthly Labor Review. Retrieved from U.S. Bureau of Labor Statistics website: https://doi.org/10.21916/mlr.2013.26

Rosenbaum, J. E. (2001). Beyond college for all: Career paths for the forgotten half. New York, NY: Russell Sage Foundation.

Rosenbaum, J. E., Deil-Amen, R., \& Person, A. E. (Eds.). (2006). After admission: From college access to college success. New York, NY: Russell Sage Foundation.

Rosenbaum, J. E. (2011). The complexities of college for all: Beyond fairy-tale dreams. Sociology of Education, 84, 113-117. doi:10.1177/0038040711401809

Routon, W., \& Walker, J. (2016, March). Going Greek: Academics, personal change, and life after college. Change: The Magazine of Higher Learning, 48(1), pp. 60-66. doi:10.1080/00091383.2016.1121088

Sax, L. J. (2008). The gender gap in college: Maximizing the developmental potential of women and men. San Francisco, CA: Jossey-Bass. 
Schreiner, M. (2017, May 15). Apathy. [Web log post]. Retrieved from https://evolutioncounseling.com/apathy/

Schulte, M. (2015). Stopout, swirl, double-dip, and dropout: Attempting to understand student enrollment patterns. The Journal of Continuing Higher Education, 63(2), 133-135.

Scott, M. A., \& Kennedy, B. B. (2005). Pitfalls in pathways: Some perspectives on competing risks event history analysis in education research. Journal of Educational and Behavioral Statistics, 30, 413-442.

Seifert, T. A., Goodman, K., King, P., \& Baxter Magolda, M. B. (2010). Using mixed methods to study first-year college impact on liberal arts learning outcomes. Journal of Mixed Methods Research, 4, 248-267. doi:10.1177/1558689810374960

Selingo, J. (2013). College (un)bound: The future of higher education and what it means for students. Boston, MA: Houghton Mifflin Harcourt.

Shapiro, D., \& Dundar, A. (2014). New context for retention and persistence. In D. Hossler \& B. Bontrager (Eds.), Handbook of Strategic Enrollment Management (pp. 249-267). San Francisco: Jossey Bass.

Shapiro, D., Dundar, A., Yuan, X., Harrell, A. T., Wild, J. C., \& Ziskin, M. B. (2014). Some college, no degree: A national view of students with some college enrollment, but no completion. Retrieved from National Student Clearinghouse Research Center website: http://nscresearchcenter.org/wpcontent/uploads/NSC_Signature_Report_7.pdf 
Shingala, M. C., \& Rajyaguru, A. (2015). Comparison of post hoc tests for unequal variance. International Journal of New Technologies in Science and Engineering (2)5, 22-33.

Simon, H. (1957). Administrative behavior. (2 ${ }^{\text {nd }}$ ed.) New York, NY: Macmillan.

Slonim-Nevo, V. \& Nevo, I. (2009). Conflicting findings in mixed methods research: An illustration from an Israeli study on immigration. Journal of Mixed Methods Research, 3(2), 109-128. doi:10.1177/1558689808330621

Sprague, J. (2005). Feminist methodologies for critical researchers. Walnut Creek, CA: Alta Mira Press.

Stanton-Salazar, R. D. (1997). A social capital framework for understanding the socialization of racial minority children and youths. Harvard Educational Review, 67(1), 1-40.

Steinfeldt, J. A., Steinfeldt, M. C., England, B., \& Speight, Q. L. (2009). Gender role conflict and stigma toward help-seeking among college football players. Psychology of Men \& Masculinity, 10(4), 261-272. doi:10.1037/a0017223

Stokes, J. P., \& Zusman, B. J. (1992). A study of stopouts at an urban commuter university. NASPA Journal, 29, 283-289.

Stratton, L. S., O’Toole, D. M., \& Wetzel, J. N. (2008). A multinomial logit model of college stopout and dropout behavior. Economics of Education Review, 27, 319331. doi:10.1016/j.econedurev.2007.04.003

Stuber, J. M. (2011). Inside the college gates: How class and culture matter in higher education. Lanham, MD: Lexington Books. 
Sulak, T. N., Massey, J., \& Thomson, D. (2017). Using latent profile analysis to harness the heterogeneity of nonretained college students. Journal of College Student Retention: Research, Theory, \& Practice, 18, 457-473. doi: $10.1177 / 1521025115611385$

Sumner, R., Burrow, A. L., \& Hill, P. L. (2014). Identity and purpose as predictors of subjective well-being in emerging adulthood. Emerging Adulthood, 3(1), 46-54.

Teddlie, C., \& Tashakkori, A. (2003). Major issues and controversies in the use of mixed methods in the social and behavioral sciences. In A. Tashakkori \& C. Teddlie (Eds.), Handbook of mixed methods in social \& behavioral research (pp. $3-50$ ). Thousand Oaks, CA: Sage.

Terriquez, V., \& Gurantz, O. (2015). Financial challenges in emerging adulthood and students' decisions to stop out of college. Emerging Adulthood, 3, 204-214. doi:10.1177/2167696814550684

The Carnegie Classification of Institutions of Higher Education. (2015). About Carnegie Classification. Retrieved November 19, 2018 from http://carnegieclassifications.iu.edu/

Tierney, W. G. (1992) An anthropological analysis of student participation in college. The Journal of Higher Education, 63(6), 603-618.

Tinto, V. (1993). Leaving college: Rethinking the causes and cures of student attrition ( $2^{\text {nd }}$ ed.). Chicago, IL: University of Chicago Press.

Tinto, V. (2012). Completing college: Rethinking institutional action. Chicago, IL: University of Chicago Press. 
U.S. Department of Education (2016). Undergraduate Retention and Graduation Rates. Spring 2002 through Spring 2013 and Winter 2013-14 through Winter 2015-16, Graduation Rates component; and IPEDS Fall 2009, Institutional Characteristics component. Retrieved from National Center for Education Statistics website: https://nces.ed.gov/programs/coe/indicator_ctr.asp

U.S. Department of Education. (2016b). Digest of education statistics, 2015, Table 330.10. Retrieved from National Center for Education Statistics website: https://nces.ed.gov/fastfacts/display.asp?id=76

U.S. Department of Education. (2017). Digest of education statistics, 2016, Table 331.20. Retrieved from National Center for Education Statistics website: https://nces.ed.gov/programs/digest/d17/tables/dt17_331.20.asp

Van Gennep, A. (1960). The rites of passage. Chicago, IL: University of Chicago Press. Walker, J. K., Martin, N. D., \& Hussey, A. (2015). Greek organization membership and collegiate outcomes at an elite, private university. Research in Higher Education, 56, 203-227. doi:10.1007/s11162-014-9345-8

Wells, R. (2008). Social and cultural capital, race and ethnicity, and college student retention. Journal of College Student Retention, 10, 103-128. doi:10.2190/CS.10.2.a

Williams, J. (2010). Reshaping the work-family debate: Why men and class matter. Cambridge, MA: Harvard University Press.

Williams, R. L. (1991). The origins of federal support for higher education. University Park, PA: The Pennsylvania State University Press. 
Winship, C., \& Mare, R. D. (1992). Models for sample selection bias. Annual Review of Sociology, 18, 327-350.

Woosley, S. (2004). Stop-out or drop-out? An examination of college withdrawals and re-enrollments. Journal of College Student Retention, 5(3), 293-303.

Yee, A. (2016). The unwritten rules of engagement: Social class differences in undergraduates' academic strategies. The Journal of Higher Education, 87(6), 831-858. doi:10.1353/jhe.2016.0031

Ziskin, M., Lucido, J. A., Gross, J. P. K., Hossler, D., Chung, E., \& Torres, V. (2014) The role of the institution in increasing college student persistence. In D. Hossler \& B. Bontrager (Eds.), Handbook of strategic enrollment management. San Francisco, CA: Jossey Bass. 


\section{APPENDIX A}

Interview: Demographic Questionnaire

Participant \#

Date

1. Classification (circle one):

Freshman (fewer than 30 hours earned) Sophomore (30 - 59 hours earned)

Junior (60 - 89 hours earned) Senior (90 or more hours earned)

2. Approximate Grades (circle one): Mostly As Mostly As \& Bs Mostly Bs

Mostly Bs \& Cs Mostly Cs Mostly Cs \& Ds Mostly Ds

Mostly Ds \& Fs Mostly Fs

3. Approximately how many hours do you work for pay each week (circle one)?

$\begin{array}{llllll}0 & 1-10 & 11-20 & 21-30 & 31-40 & \text { Over } 40\end{array}$

4. Did you live on campus your first year (circle one)? Yes No

5. What types of financial assistance do you currently receive (check all that apply)?

_ Scholarship from City University _ _ External Scholarship

_ Military Benefits _ _ Grants

_ Loans (Logistics Company) Assistance

Parents/Family Financial Assistance Other:

6. Will you be the first person in your immediate family to earn a bachelor's degree (circle one)? Yes No

7. What is your age?

8. What is your gender identification?

9. What is your race/ethnicity (list all that apply):

10. What is your current or intended major(s)/minor(s):

11. How many fall and/or spring semesters have you stopped out of City University?

12. Did you change your major after returning to the university (circle one)? Yes No 


\section{APPENDIX B}

Interview Guide

My name is Katie and I am a doctoral student in a Department of Sociology. For the purposes of this interview, I am interested in why you chose to stop out and subsequently return to City University. Specifically, I am interested in what led to you taking time off from City University, how you spent your time while away from City University, and your process of returning to the university. Additionally, I would like to know how you spend your time outside of school and if you talked to anyone about taking time off and returning. After your review and completion of the Informed Consent form and the demographic questionnaire, I would like to record our conversation, if you are agreeable. I have a list of questions that we will begin with, but feel free to discuss anything about your school or life experiences that have influenced your enrollment. If, at any point, I ask a question that you do not feel comfortable answering, please simply say pass. You may discontinue the interview at any time.

NOTE: Pause for participant's completion of the Informed Consent Form and the demographic questionnaire.

Do you have any questions about the informed consent before we get started?

1) Tell me about why you chose to attend City University and college in general.

2) What was your first year at City University like?

3) Tell me about your academic experiences at City University including your academic major(s)?

4) Tell me about taking time off from City University.

5) What was the experience like for you while out?

6) In what ways did you remain connected to the university?

7) What made is possible for you to come back?

8) What does success at the university look like for you?

9) Tell me about what has changed since you reenrolled?

10) What can City University do to assist students like you?

11) What would college graduation mean to you?

12) Is there anything else I have not asked about that you would like for me to know about your experiences?

Thank you for your time today. I greatly appreciate your participation and assistance. If at any point you have questions, please feel free to contact me. I wish you the best this semester. 


\begin{abstract}
APPENDIX C
Multinomial Logistic Regression for Year Two

For year two, Models 1 and 2 contained the same covariates as was tested and displayed for year one and will not be further interpreted here. After running listwise deletion, the number of observations in the year two models dropped to 3,558 or $71.2 \%$ of the full population.
\end{abstract}

Of the three comparisons, the greatest differences were found between graduates and stopouts when introducing year two variables. As shown in Table 12, none of the background variables nor the academic preparedness variables returned significant results for predicting graduating versus stopping out after year two in Model 3. For members of the 2010 cohort relative to members of the 2011 cohort, the relative risk of graduating versus stopping out any time after the second year would be expected to decrease by a factor of $.42(p<.001)$. In other words, members of the 2010 cohort were less likely than the members of the 2011 cohort to graduate than stopout. The chance of graduating compared to stopping out any time after the second year is 1.7 times higher for first year intended STEM majors compared to non-STEM majors $(p<.05)$. Living on-campus relative to off-campus during the first year was associated with a 1.7 -fold increase in the chance of graduating compared to stopping out any time after year two $(p<.05)$. If a student were to increase their $2^{\text {nd }}$ year GPA by one point, the relative chance of 
graduating compared to stopping out any time after year two would be expected to increase more than thirteen-fold given all other variables were held constant $(p<.001)$.

As shown in Table 12, only two covariates returned significant results for predicting persisting in comparison to stopping out any time after the second year in Model 3. The risk of persisting compared to stopping out any time after the second year is two times higher for first year intended STEM majors compared to non-STEM majors $(p<.05)$. If a student were to increase their $2^{\text {nd }}$ year GPA by one point, the relative risk for persisting compared to stopping out any time after year two would be expected to increase more than twofold given all other variables were held constant $(p<.001)$.

As shown in Table 12, two variables (male and 2010 cohort) returned statistically significant relative risk ratios for Model 3 for not persisting versus stopping out. For males relative to females, the relative risk for not persisting to stopping out any time after year two would be expected to decrease by factor of $.57(p<.01)$. Thus, males were less likely than females to not persist compared to stopout. For members of the 2010 cohort relative to members of the 2011 cohort, the relative risk of not persisting to stopping out would be expected to decrease by a factor of $0.39(p<.001)$. Thus, the expected risk of not persisting compared to stopping out by the end of year six is lower for students in the 2010 cohort than students in the 2011 cohort. 
Table 12

Relative Risk Ratios (and 95\% Confidence Intervals) for the Predictors on Graduating, Persisting, and Not Persisting versus Stopping Out Any Time after the Second Year $(N=3558)$

\begin{tabular}{|c|c|c|c|c|c|c|c|c|c|c|c|c|c|c|c|c|c|c|}
\hline & \multicolumn{6}{|c|}{ Graduates versus Stopouts } & \multicolumn{6}{|c|}{ Persisters versus Stopouts } & \multicolumn{6}{|c|}{ Nonpersisters versus Stopouts } \\
\hline & \multicolumn{2}{|c|}{ Model 1} & \multicolumn{2}{|c|}{ Model 2} & \multicolumn{2}{|c|}{ Model 3} & \multicolumn{2}{|c|}{ Model 1} & \multicolumn{2}{|c|}{ Model 2} & \multicolumn{2}{|c|}{ Model 3} & \multicolumn{2}{|c|}{ Model 1} & \multicolumn{2}{|c|}{ Model 2} & \multicolumn{2}{|c|}{ Model 3} \\
\hline & RRR & $\begin{array}{c}95 \% \\
\mathrm{CI} \\
\end{array}$ & RRR & $\begin{array}{l}95 \% \\
\text { CI } \\
\end{array}$ & RRR & $\begin{array}{c}95 \% \\
\text { CI }\end{array}$ & RRR & $\begin{array}{c}95 \% \\
\text { CI } \\
\end{array}$ & RRR & $\begin{array}{c}95 \% \\
\text { CI }\end{array}$ & RRR & $\begin{array}{c}95 \% \\
\text { CI } \\
\end{array}$ & RRR & $\begin{array}{c}95 \% \\
\text { CI }\end{array}$ & RRR & $\begin{array}{c}95 \% \\
\text { CI } \\
\end{array}$ & RRR & $\begin{array}{c}95 \% \\
\mathrm{CI} \\
\end{array}$ \\
\hline \multicolumn{19}{|c|}{ Background Variables } \\
\hline Local & 0.8 & $\begin{array}{c}0.6- \\
1.1\end{array}$ & 0.88 & $\begin{array}{l}0.7- \\
1.2\end{array}$ & 1.22 & $\begin{array}{l}0.9- \\
1.7\end{array}$ & 1.18 & $\begin{array}{l}0.8- \\
1.9\end{array}$ & 1.25 & $\begin{array}{l}0.0- \\
2.0\end{array}$ & 1.51 & $\begin{array}{l}0.9- \\
2.4\end{array}$ & 0.83 & $\begin{array}{c}0.6- \\
1.1\end{array}$ & 0.83 & $\begin{array}{c}0.6- \\
1.1\end{array}$ & 1 & $\begin{array}{l}0.7- \\
1.4\end{array}$ \\
\hline $\begin{array}{l}\text { First } \\
\text { Generation }\end{array}$ & 0.7 & $\begin{array}{c}0.5- \\
1.0\end{array}$ & 0.79 & $\begin{array}{c}0.5- \\
1.1\end{array}$ & 0.8 & $\begin{array}{l}0.5- \\
1.2\end{array}$ & 0.7 & $\begin{array}{l}0.4- \\
1.3\end{array}$ & 0.73 & $\begin{array}{c}0.4- \\
1.3\end{array}$ & 0.74 & $\begin{array}{c}0.4- \\
1.4\end{array}$ & 1 & $\begin{array}{l}0.7- \\
1.4\end{array}$ & 1 & $\begin{array}{l}0.7- \\
1.4\end{array}$ & 0.99 & $\begin{array}{l}0.7- \\
1.5\end{array}$ \\
\hline Male & $0.55^{* * * *}$ & $\begin{array}{c}0.4- \\
0.7\end{array}$ & $0.51^{* * *}$ & $\begin{array}{c}0.4- \\
0.7\end{array}$ & 0.66 & $\begin{array}{c}0.5- \\
1.0\end{array}$ & $1.61^{*}$ & $\begin{array}{l}1.0- \\
2.6\end{array}$ & $1.62^{*}$ & $\begin{array}{l}1.0- \\
2.6\end{array}$ & 1.55 & $\begin{array}{l}1.1- \\
2.8\end{array}$ & $0.7^{*}$ & $\begin{array}{c}0.5- \\
0.9\end{array}$ & $0.7^{*}$ & $\begin{array}{l}0.5- \\
0.9\end{array}$ & $0.57 * *$ & $\begin{array}{l}0.5- \\
0.9\end{array}$ \\
\hline White & 1.15 & $\begin{array}{c}0.8- \\
1.7\end{array}$ & 0.88 & $\begin{array}{l}0.6- \\
1.3\end{array}$ & 1.19 & $\begin{array}{l}0.8- \\
1.8\end{array}$ & 1.1 & $\begin{array}{l}0.6- \\
1.9\end{array}$ & 1.02 & $\begin{array}{c}0.6- \\
1.8\end{array}$ & 1.17 & $\begin{array}{l}0.7- \\
2.1\end{array}$ & 1.26 & $\begin{array}{l}0.9- \\
1.8\end{array}$ & 1.27 & $\begin{array}{l}0.9- \\
1.8\end{array}$ & 1.18 & $\begin{array}{l}1.1- \\
2.3\end{array}$ \\
\hline $\begin{array}{l}\text { 1st Year PELL } \\
\text { Recipient }\end{array}$ & 0.91 & $\begin{array}{l}0.7- \\
1.3\end{array}$ & 1 & $\begin{array}{l}0.8- \\
1.4\end{array}$ & 0.84 & $\begin{array}{l}0.6- \\
1.3\end{array}$ & 1.47 & $\begin{array}{l}0.9- \\
2.4\end{array}$ & 1.5 & $\begin{array}{l}0.9- \\
2.5\end{array}$ & 1.49 & $\begin{array}{l}0.9- \\
2.6\end{array}$ & $1.55^{* *}$ & $\begin{array}{l}1.1- \\
2.2\end{array}$ & $1.54 * *$ & $\begin{array}{l}1.1- \\
2.2\end{array}$ & 1.16 & $\begin{array}{c}0.8- \\
1.7\end{array}$ \\
\hline $\begin{array}{l}\text { Model } 1 \\
\text { Constant }\end{array}$ & $20.31 * * *$ & $\begin{array}{l}13.3- \\
31.0\end{array}$ & & & & & $0.40^{* *}$ & $\begin{array}{c}0.2- \\
0.8\end{array}$ & & & & & $10.26 * * *$ & $\begin{array}{l}6.7- \\
15.7\end{array}$ & & & & \\
\hline \multicolumn{19}{|c|}{$\begin{array}{c}\text { Academic Preparedness } \\
\text { Variables }\end{array}$} \\
\hline ACT Score & & & $1.12^{* * * *}$ & $\begin{array}{l}1.1- \\
1.2\end{array}$ & 1 & $\begin{array}{c}1.0- \\
1.1\end{array}$ & & & 1.02 & $\begin{array}{l}1.0- \\
1.1\end{array}$ & 0.96 & $\begin{array}{c}0.9- \\
1.0\end{array}$ & & & 1 & $\begin{array}{c}0.9- \\
1.0\end{array}$ & 1 & $\begin{array}{l}0.9- \\
1.0\end{array}$ \\
\hline $\begin{array}{l}\text { Credit Hours Ea } \\
\text { to Enrolling }\end{array}$ & ed Prior & & $1.6^{* * *}$ & $\begin{array}{l}1.2- \\
2.2\end{array}$ & 1.2 & $\begin{array}{c}0.9- \\
1.7\end{array}$ & & & 1.25 & $\begin{array}{c}0.8- \\
2.0\end{array}$ & 1.03 & $\begin{array}{c}0.6- \\
1.7\end{array}$ & & & 1 & $\begin{array}{c}0.7- \\
1.4\end{array}$ & 0.93 & $\begin{array}{l}0.7- \\
1.3\end{array}$ \\
\hline High School GF & & & $1.47 *$ & $\begin{array}{l}1.1- \\
2.0\end{array}$ & 1.05 & $\begin{array}{c}0.8- \\
1.5\end{array}$ & & & 1.39 & $\begin{array}{l}0.9- \\
2.3\end{array}$ & 1.11 & $\begin{array}{l}0.7- \\
1.8\end{array}$ & & & 0.99 & $\begin{array}{l}0.7- \\
1.3\end{array}$ & 1 & $\begin{array}{l}0.7- \\
1.4\end{array}$ \\
\hline Model 2 Consta & & & 0.3 & $\begin{array}{l}0.1- \\
1.2\end{array}$ & & & & & $0.07 *$ & $\begin{array}{c}0.01- \\
0.6\end{array}$ & & & & & $11.67^{* * *}$ & $\begin{array}{l}3.0- \\
44.8\end{array}$ & & \\
\hline \multicolumn{19}{|c|}{ Early College Variables } \\
\hline 2010 Cohort & & & & & $0.42 * * *$ & $\begin{array}{c}0.3- \\
0.7\end{array}$ & & & & & 0.62 & $\begin{array}{c}0.4- \\
1.1\end{array}$ & & & & & $0.39^{* * *}$ & $\begin{array}{l}0.2- \\
0.6\end{array}$ \\
\hline 1st Semester ST & M Major & & & & $1.73^{*}$ & $\begin{array}{l}1.1- \\
2.8\end{array}$ & & & & & $1.99^{*}$ & $\begin{array}{l}1.1- \\
3.7\end{array}$ & & & & & 0.97 & $\begin{array}{l}0.6- \\
1.6\end{array}$ \\
\hline $\begin{array}{l}\text { 1st Semester On } \\
\text { Housing }\end{array}$ & Campus & & & & $1.73^{*}$ & $\begin{array}{l}1.1- \\
2.7\end{array}$ & & & & & 1.15 & $\begin{array}{c}0.6- \\
2.1\end{array}$ & & & & & 1.55 & $\begin{array}{l}1.0- \\
2.5\end{array}$ \\
\hline
\end{tabular}


end Year GPA

2nd Year Financial Aid

$\begin{array}{rcc}\text { End Quintile } & 0.91 & 0.5- \\ & & 1.7 \\ \text { 3rd Quintile } & 1.30 & 0.6- \\ & & 2.6 \\ \text { th Quintile } & 1.11 & 0.5- \\ & & 2.4 \\ \text { Fth Quintile } & 1.74 & 0.8- \\ & & 4.0 \\ \text { Model 3 Constant } & 0.05^{* *} & 0.0- \\ \end{array}$

$\begin{array}{rr}13.11 * * * & 9.3- \\ & 18.5\end{array}$

$* p<.05, * * p<.01, * * * p<.001$

$\begin{array}{cc}2.54 * * * & 1.6- \\ & 4.0 \\ & \\ & 0.2- \\ 0.50 & 1.1 \\ & 0.3- \\ 0.67 & 1.6 \\ & 0.2- \\ 0.45 & 1.2 \\ & 0.3- \\ 0.69 & 1.6 \\ & 0.01- \\ 0.18 & 2.6\end{array}$

\begin{tabular}{cc}
0.86 & $0.6-$ \\
& 1.2 \\
& \\
& \\
0.89 & $0.5-$ \\
& 1.7 \\
1.01 & $0.5-$ \\
& 2.1 \\
0.85 & $0.4-$ \\
& 1.8 \\
0.87 & $0.4-$ \\
& 2.0 \\
$22.02 * *$ & $2.8-$ \\
& 175.4 \\
\hline
\end{tabular}

ชั 


\section{Predicted Probabilities for Each Pathway after Year Two}

As I did after year one, I ran predicted probabilities as a postestimation of the multinomial logistic regression for the covariates that were statistically significant in at least one of the $3^{\text {rd }}$ models for each of the comparisons. The predicted probabilities hold all other variables constant at their means. This includes sex, cohort, first year STEM major, first semester housing, and second year GPA. Beginning with sex and as shown in Figure 11, females had a higher chance of graduating, a lower chance of persisting, and a higher chance of not persisting than males.

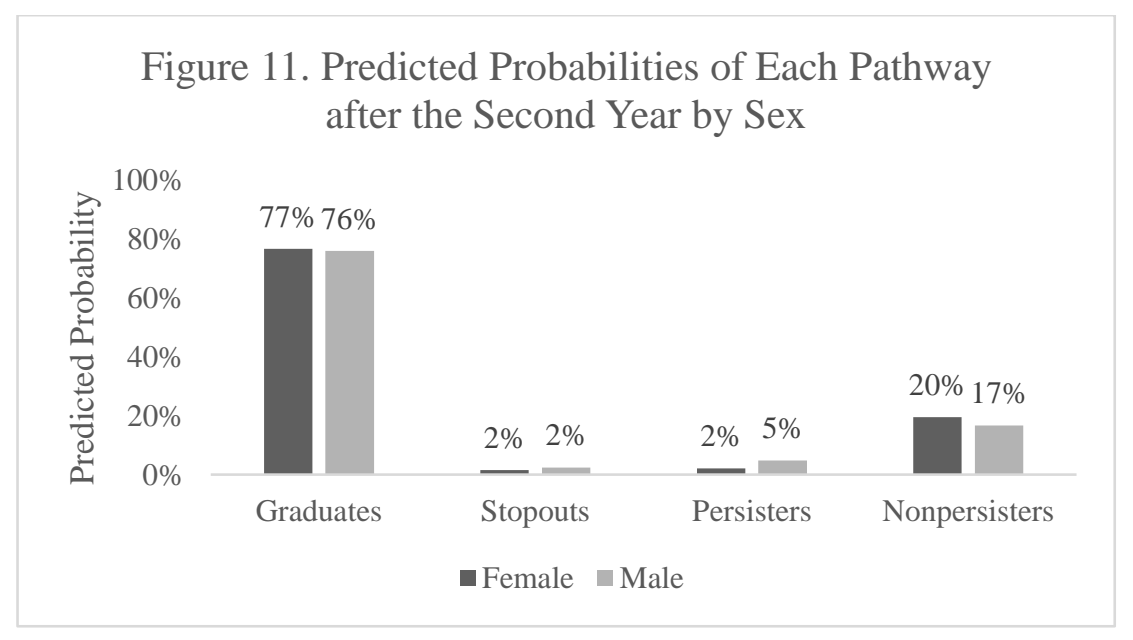

As shown in Figure 12, students in the 2011 cohort had a higher chance of graduating or not persisting any time after their second year than students in the 2010 cohort. Students in the 2011 cohort, also had a lower chance of stopping out any time after their second year or persisting through their sixth year than students in the 2010 cohort. 


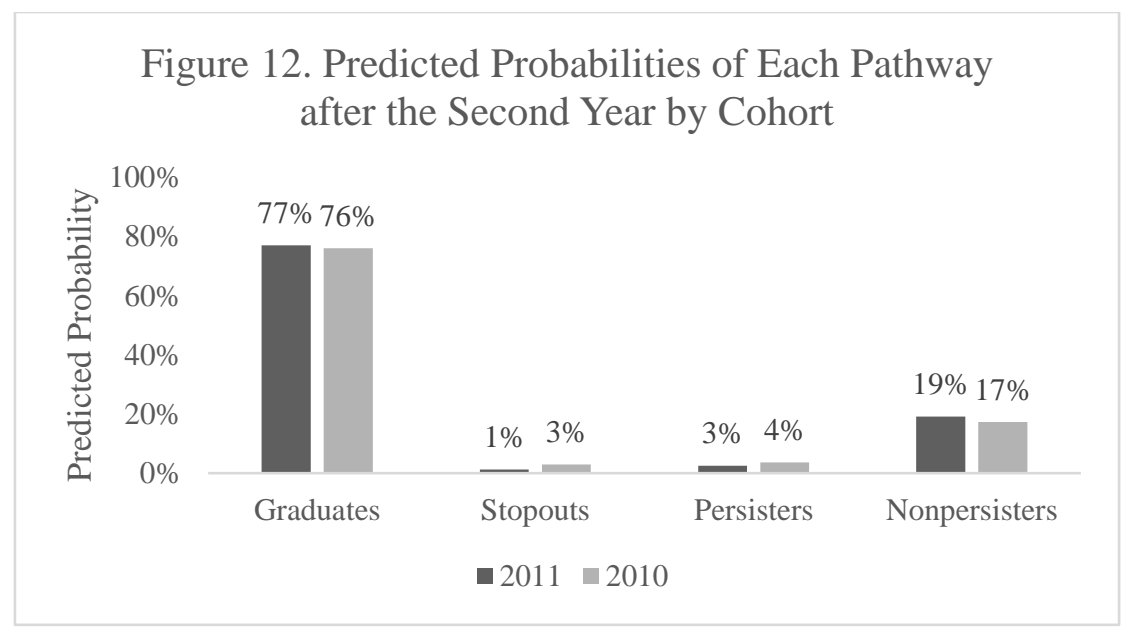

As show in Figure 13, students who were STEM majors their first year had a higher chance of graduating by or persisting through their sixth year than students who were not STEM majors. Students who were STEM majors also had a lower chance of stopping out or not persisting any time after their second year.

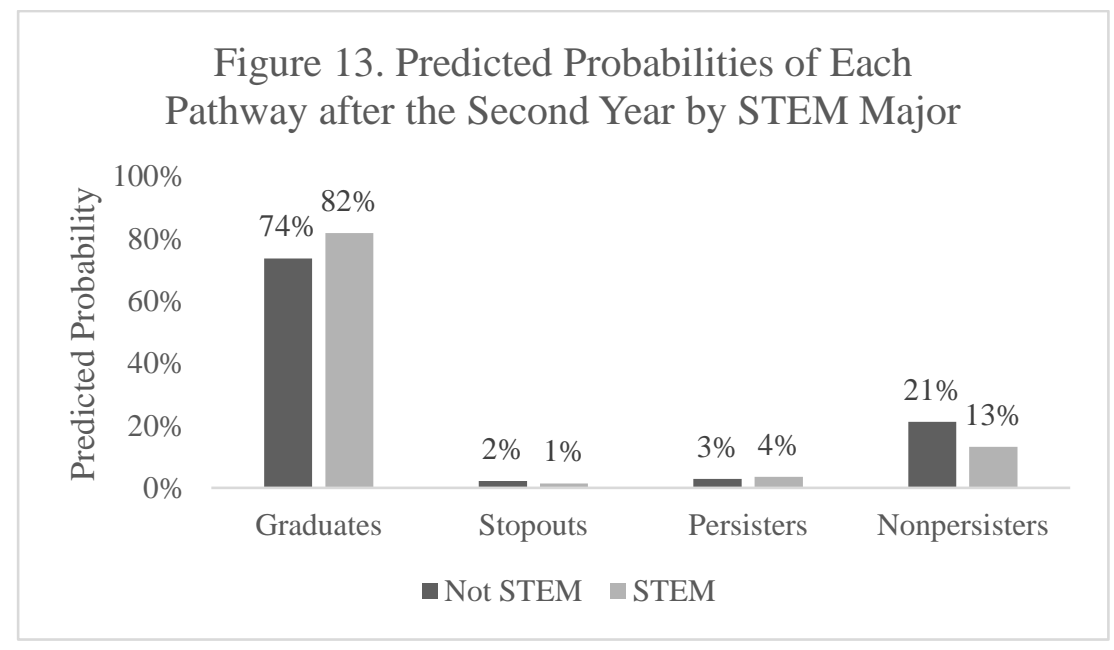

As show in Figure 14, students who lived on-campus their first semester had a higher chance of graduating any time after their second year and by the end of their sixth year than students who lived off-campus their first semester. Students who lived on-campus their first semester also had a lower chance of stopping out or not persisting any time after their second year and a lower chance of persisting through their sixth year. 


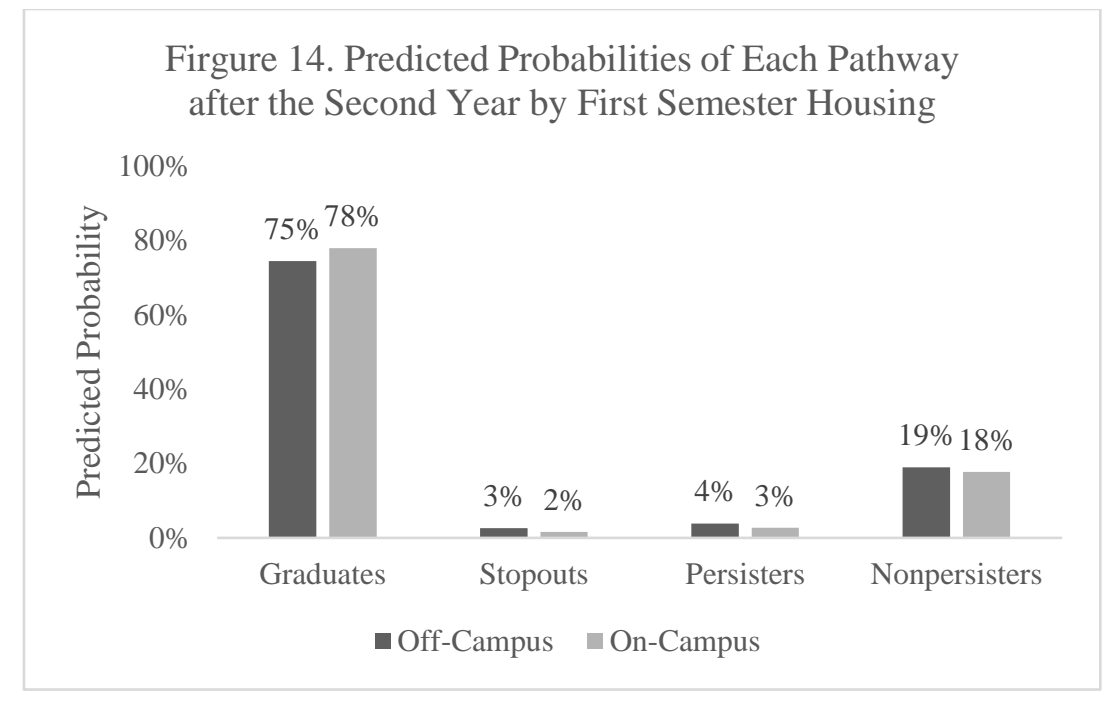

Finally, as seen in Figure 15, students who had a higher second year GPA had a higher probability of graduating and a lower probability of not persisting any time after their second year.

Figure 15. Predicted Probabilities of Each Pathway by Second Year GPA
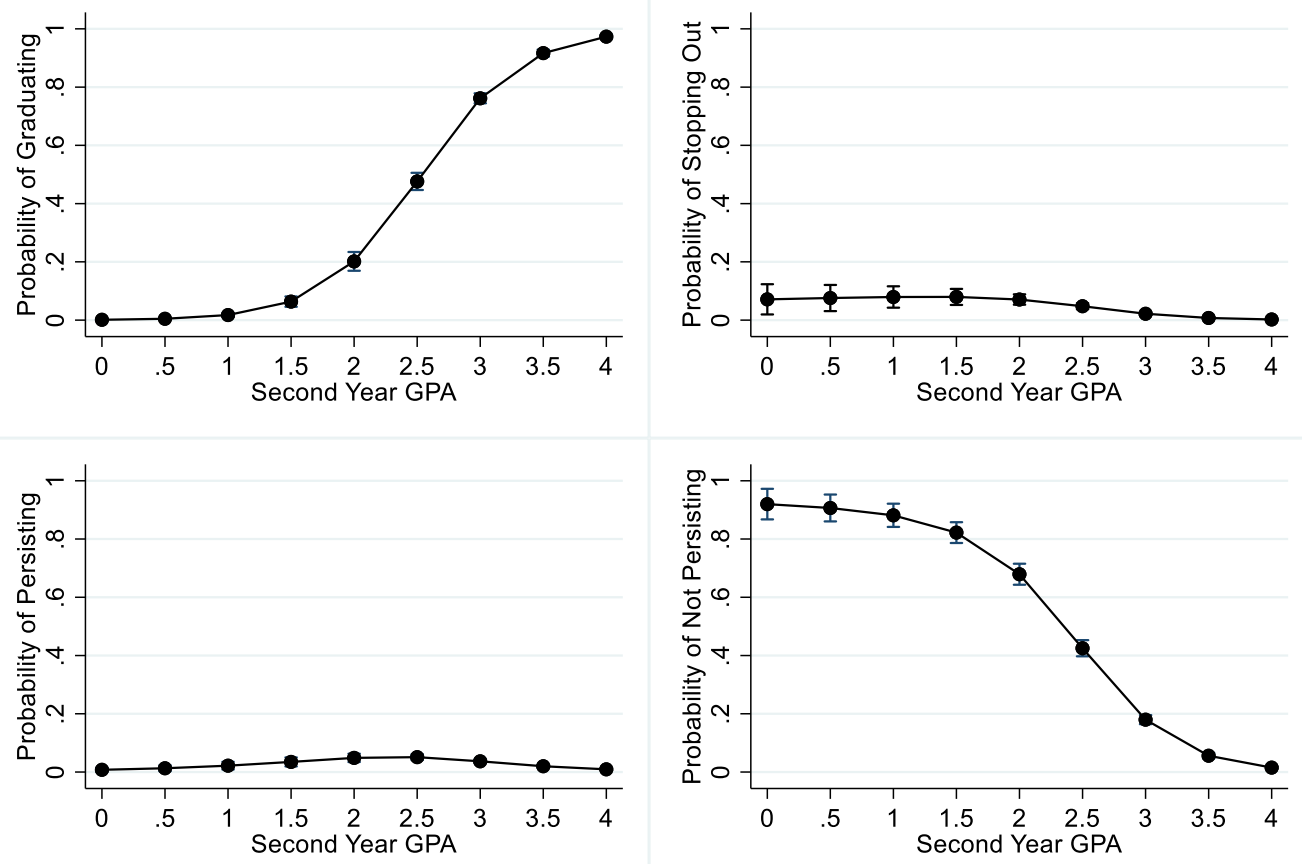


\section{CURRICULUM VITAE}

Kathryn Gardner Adamchik

502-457-0261 kgadam01@louisville.edu

\section{PROFESSIONAL PROFILE}

- Fifteen years as a higher education professional

- Ten years of academic advising experience with College of Arts and Sciences and Exploratory students

- Five years of supervision with advising professionals and eight years supervision with graduate student interns/assistants

- Five years directing exploratory advising division including program development and advising protocol

- Six years leading a mentoring program for first year Black/African American students

- Three years conducting unit assessment

- Fifteen years of active partnership with interdepartmental campus collaborations and committees

- Ten years course instruction and workshop facilitation experience

- Thirteen years hiring, supervising, and training college student employees

\section{$\underline{\text { EDUCATION }}$}

Doctorate of Philosophy in Applied Sociology, anticipated graduation: December 2018 University of Louisville - Louisville, Kentucky

Master of Education in Counseling and Personnel Services, College Student Personnel, May 2008

University of Louisville - Louisville, Kentucky

Graduate Dean's Citation Recipient

Bachelor of Arts in African and African American Studies, May 2002

Earlham College - Richmond, Indiana

Study Abroad: Kenya, fall 2000; Haiti, May 2000 


\section{EXPERIENCE}

Director of Exploratory Advising

Associate Director of Student Success Center

January 2018 - Present

University of Louisville Strategic Enrollment Management and Student Success -

Louisville, Kentucky

- Hire, train, and supervise seven professional academic counselors and graduate interns/assistants

- Coordinate GEN 100: SSE Orientation course including instructor assignments and training, curriculum development, and campus partner presentations/sections

- Serve as Lead Integrative Advisor for the Quality Enhancement Plan developing integrative advising curriculum, recruiting students and selecting and training integrative advisors

- Manage advising services to undecided and pre-unit students including advising assignments, advising campaigns, advising resource development, and collaboration with all undergraduate units

- Monitor and advocate for exploratory student persistence and academic progress

- Enhance intra-university transfer processes and advising initiatives for pre-unit students in corporation with other units

- Advise undecided and pre-unit students about academic and career decision-making, degree options and requirements, major/unit admission requirements, and university policies and procedures

- Coach students through the major and career exploration process

- Collaborate with campus constituents to update and clarify policies and procedures affecting students' persistence to degree

- Utilize EAB Student Success Collaborative, OnBase, PeopleSoft, Transfer Evaluation System, Sharepoint, SPSS, STATA and BlackBoard

Director of Exploratory Programs - Advising and Student Services

August 2013 - December 2017

University of Louisville College of Arts and Sciences - Louisville, Kentucky

- Hired, trained, and supervised five professional academic counselors and graduate interns/assistants

- Coordinated GEN 101: Arts and Sciences Orientation and GEN 201: Career Decision Making courses including instructor assignments, curriculum development, and campus partner presentations/sections

- Managed advising services to undecided and pre-unit students including advising assignments, advising campaigns, tracking program budget, and advising guide development

- Monitored exploratory student persistence and academic progress

- Enhanced intra-university transfer processes and advising initiatives for pre-unit students in corporation with other units 
- Advised undecided and pre-unit students about degree requirements, course options, major/unit admission requirements, and university policies and procedures

- Coached students through the major and career exploration process

- Active Member of Advisor Center Directors' Council, Student Aid Athletic Subcommittee, Summer Bridge Program Exploration Committee, Persistence to Graduation At-Risk Student Subcommittee, Major Change Process Committee, chaired campus search committee for Director of First Year Initiatives, co-chaired 2014 ACES Black and Latino Student Symposium conference committee

Research Coordinator/Academic Counselor - Advising and Student Services April 2008 - July 2013

University of Louisville College of Arts and Sciences - Louisville, Kentucky

- Coordinated departmental assessment and research initiatives as directed by the assistant dean

- Developed and managed internship program for graduate students

- Supervised graduate assistants and interns

- Counseled undergraduate students about academic and career development

- Accurately and efficiently processed major and minor declarations, preliminary and final degree checks

- Assisted students through campus referrals, navigating the undergraduate catalog, and understanding university policies and procedures

- Communicated with faculty and academic departments regarding students' degree requirements and concerns

- Instructed two to three orientation courses per academic year

- Assisted with the development and implementation of AIM intrusive advising framework infused with Paul-Elder's critical thinking paradigm and Socratic questioning

- Administered C.O.N.E.C.T. peer mentoring program for first year African American students including hiring, training, and supervising peer mentors, monitoring program budget, and collaborating with campus constituents

- Advised recognized student organization that is the programming and leadership development arm of C.O.N.E.C.T.

- Assisted in the recruitment of high school students through prospective student appointments, Campus Preview Day, and high school visits

- Active member of University-Wide Advising Council, Natural Sciences Advising Team, Porter Scholarship Work Group, Welcome Week Committee, PostBaccalaureate Pre-Medical Certificate Advisory Committee, and intra-departmental search committees

Graduate Intern - Career Coach-in-Training

August 2007 - April 2008

University of Louisville Career Development Center - Louisville, Kentucky

- Assisted undergraduate students with mock interviews, résumé critiques, and utilization of online job database

- Interpreted Myers-Briggs Type Indicator and Strong Interest Inventory results 
- Updated and assembled departmental policy and procedure manual

- Utilized Plone software to update departmental website

Graduate Assistant - Judicial Affairs

July 2007 - April 2008

University of Louisville Housing and Residence Life - Louisville, Kentucky

- Facilitated 14 Decision Making Workshops per semester

- Managed correspondence with students in the judicial process regarding completion of sanctions

- Utilized Judicial Officer software to input judicial reports, sanctions, and completion status; ran reports for annual departmental data including for Clery and Minger Acts

- Served on Resident Assistant selection committee

- Advised resident student organization charged with providing diversity programming to campus

Graduate Intern - First Generation Students

May 2007 - August 2007

Indiana University Southeast Office of Admission - New Albany, Indiana

- Conducted needs analyses of first generation students through existing survey data and literature review

- Coordinated an on-campus recruitment event for first generation students and their families

- Evaluated campus surveys and materials and made recommendations for improvement

- Developed an understanding of day-to-day admissions operations and recruitment processes

Teen Outreach Coordinator

February 2006 - June 2007

Louisville Free Public Library Shawnee Branch - Louisville, Kentucky

- Planned and implemented engaging library programs and outreach promotions for teen patrons

- Coordinated College Bound series for high school students

- Established and maintained partnerships with community organizations and leaders

- Assisted with day-to-day branch operations

Program Coordinator

September 2005 - February 2006

GEAR UP (Gaining Early Awareness and Readiness for Undergraduate Programs)

Partnership

Berea College Office of Special Programs - Berea, Kentucky

- Member of a three-person team that wrote successful 6-year federal grant proposal for $\$ 1.68$ million per year

- Coordinated data collection of six school district region for annual federal performance report

- Examined effectiveness of activities through program evaluations 
- Determined partner organizations' matching funds and monitored grant matching budget

Conference and Event Coordinator, Conferences, Elderhostel and Community Education February 2005 - December 2005

Berea College Office of Special Programs - Berea, Kentucky

- Assisted off-campus clients, such as Episcopal Church, KY Art Education Association, Kentucky Association of Blacks in Higher Education, and community retirees with conference planning for groups ranging in size from 20 to 1300 and insured group satisfaction

- Coordinated all campus aspects of conferences including meeting room assignments and set-up, housing assignments, scheduling, local tours, transportation, catering, media services, and staffing

Instructor/Counselor, GEAR UP Partnership

October 2002 - February 2005

Berea College Office of Special Programs - Berea, Kentucky

- Assisted Rockcastle County, KY middle and high schools to advance awareness of post-secondary educational opportunities among students and parents through newsletters, workshops, and travel opportunities

- Planned and chaperoned campus visits and educational day/overnight trips for students in grades $6-12$

- Planned and conducted summer camps and college planning workshops for middle and high school students

- Monitored program and trip budgets

- Hired, trained and supervised college student staff

Counselor, Educational Talent Search

February 2003 - August 2004

Berea College Office of Special Programs - Berea, Kentucky

- Planned and implemented educational workshops for middle and high school students focused on college preparation and career exploration

- Advised high school students on college searches, application process, and selection

- Facilitated summer camp developmental sessions and chaperoned students during camp and overnight trips

- Assisted high school seniors with transition to college

Instructor, Partners in Education

October 2002 - January 2004

Berea College Office of Special Programs - Berea, Kentucky

- Coordinated elementary English as a Second Language Tutoring Program and two gender-specific middle school mentoring programs with Madison County Schools

- Recruited, trained and supervised college student volunteers 


\section{TEACHING EXPERIENCE}

ECPY 302: Personal and Academic Inquiry

(Spring 2018 member of instructional team for two sections)

GEN 101: Arts and Sciences Orientation

(19 Sections Fall 2008 - Present)

GEN 201: Career Decision Making

(Two Sections Spring 2014 and Spring 2016 )

PAS 333: Black Student Experience

(Spring 2014 instructor for one section; Fall 2008 - Spring 2013 co-instructor for six sections)

\section{PROFESSIONAL INVOLVEMENT}

Life Design Catalyst Training - participant December 2016

OnCourse Student Success Workshop - participant May 2015

Council on Postsecondary Education Student Success Summit - conference attendee March/April 2013 - 2015

National Symposium on Student Retention - conference attendee November 2014

NACADA (National Academic Advising Association), 2008 - present member; 2009, 2011, and 2013 conference attendee

2013 National Pre-Conference Workshop: "Elevating Students of Color Success through Mentoring"

2011 Regional Presentation: "AIMing for Success"

ACPA (American College Personnel Association), 2007 - 2012 member; 2008, 2009, 2012 conference attendee Served 2009 and 2011 Summer Leadership Academy planning team Program reviewer for Commission on Career Development (2009)

Ideas to Action (i2a) Institute: Developing Critical Thinkers - attendee May 2011

CPAK (College Personnel Association of Kentucky), 2007 - 2010 member; 2007 - 2009 conference attendee 2008 Presentation: "Lessons Learned at Virginia Tech: How Might They Apply to Our Campuses?”

StrengthsQuest Educator Training - participant July 2009 
KACADA (Kentucky Academic Advising Association), 2009 - 2010 member; 2009 inaugural conference attendee

Co-Chair Publicity Committee Inaugural Conference and Inaugural Conference Planning Committee

Peace Education Program Community Institute - participant Fall 2006

National Conference on Community and Justice Facilitation Trainer Institute participant Spring 2003

\section{RECOGNITIONS}

NACADA Outstanding Advisor Award, 2013 Recipient

Provost's Award for Exemplary Advising, 2013 Recipient

Provost's Award for Exemplary Advising, 2012 Nominee

College of Arts and Sciences Rising Star Award, 2010 Nominee 